\title{
Marine Debris Survey Manual
}

\author{
Christine A. Ribic
}

Trevor R. Dixon

Ivan Vining

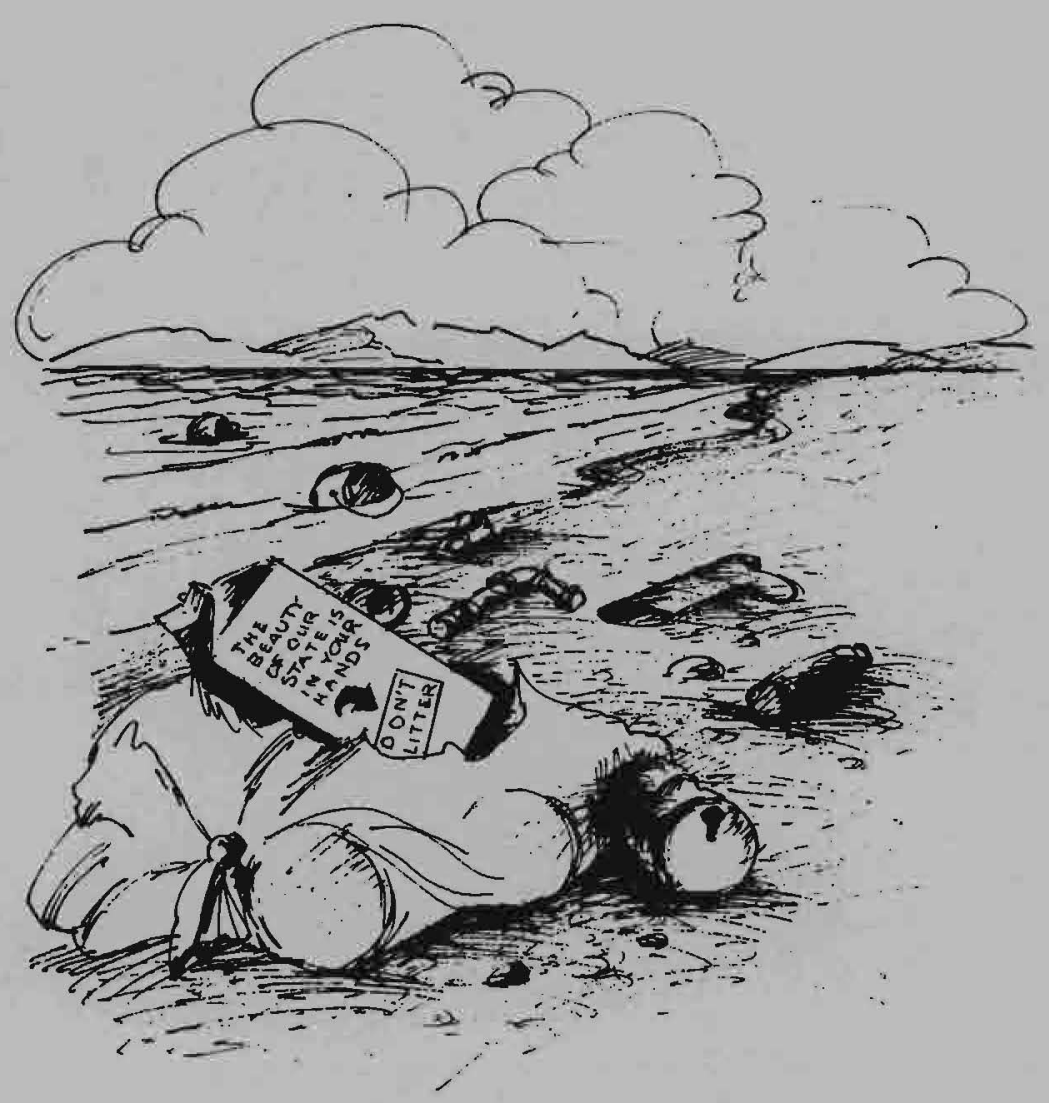

U.S. Department of Commerce 


\section{NOAA Technical Reports NMFS}

The major responsibilities of the National Marine Fisheries Service (NMFS) are to monitor and assess the abundance and geographic distribution of fishery resources, to understand and predict fluctuations in the quantity and distribution of these resources, and to establish levels for their optimum use. NMFS is also charged with the development and implementation of policies for managing national fishing grounds, with the development and enforcement of domestic fisheries regulations, with the surveillance of foreign fishing off U.S. coastal waters, and with the development and enforcement of international fishery agreements and policies. NMFS also assists the fishing industry through marketing service and economic analysis programs and through mortage insurance and vessel construction subsidies. It collects, analyzes, and publishes statistics on various phases of the industry.

The NOAA Technical Report NMFS series was established in 1983 to replace two subcategories of the Technical Report series: "Special Scientific Report - Fisheries" and "Circular." The series contains the following types of reports: scientific investigations that document long-term continuing programs of NMFS; intensive scientific reports on studies of restricted scope; papers on applied fishery problems; technical reports of general interest intended to aid conservation and management; reports that review, in considerable detail and at a high technical level, certain broad areas of research; and technical papers originating in economics studies and in management investigations. Since this is a formal series, all submitted papers, except those of the U.S.-Japan series on aquaculture, receive peer review and all papers, once accepted, receive professional editing before publication.

Copies of NOAA Technical Reports NMFS are available free in limited numbers to government agencies, both federal and state. They are also available in exchange for other scientific and technical publications in the marine sciences. Individual copies may be obtained from the U.S. Department of Commerce, National Technical Information Service, 5285 Port Royal Road, Springfield, VA 22161. Although the contents of these reports have not been copyrighted and may be reprinted entirely, reference to source is appreciated.

\section{Recently Published NOAA Technical Reports NMFS}

96. Marine flora and fauna of the eastern United States-Copepoda, Cyclopoida: Archinotodelphyidae, Notodelphyidae, and Ascidicolidae, by Patricia L. Dudley and Paul L. Illg. January 1991, 40 p.

97. Catalog of osteological collections of aquatic mammals from Mexico, by Omar Vidal. January 1991, $36 \mathrm{p}$.

98. Marine mammal strandings in the United States: proceedings of the second maxine mammal stranding workshop; Miami, Florida, 3-5 December, 1987, edited by John E. Reynolds III and Daniel K. Odell. January 1991, 157 p.

99. Marine flora and fauna of the northeastern United States: erect Bryozoa, by John S. Ryland and Peter J. Hayward. February 1991, 48 p.

100. Marine flora and fauna of the eastern United States: Dicyemida, by Robert B. Short. February 1991, 16 p.

101. Larvae of nearshore fishes in oceanic waters near Oahu, Hawaii, by Thomas A. Glarke. March 1991, 19 p.
102. Marine ranching: proceedings of the seventeenth U.S.-Japan meeting on aquaculture; Ise, Mie Prefecture, Japan, 16-18 October 1988, edited by Ralph S. Svrjcek. May 1991, 180 p.

103. Benthic macrofauna of the New York Bight, 1979-89, by Robert N. Reid, David J. Radosh, Ann B. Frame, and Steven A. Fromm. December 1991, 50 p.

104. Incidental catch of marine mammals by foreign and joint venture trawl vessels in the U.S. EEZ of the North Pacific, 1973-88, by Michael A. Perez and Thomas R. Loughlin. December 1991, 57 p.

105. Biology, oceanography, and fisheries of the North Pacific transition zone and subarctic frontal zone, edited by Jerry A. Wetherall. December 1991, 92 p.

106. Marine ranching: proceedings of the eighteenth U.S.-Japan meeting on aquaculture; Port Ludlow, Washington, 18-19 September 1989, edited by Ralph S. Svrjeck. February 1992, 136 p.

107. Field guide to the searobins (Prionotus and Bellator) in the western North Atlantic, by Mike Russell, Mark Grace, and Elmer J. Gutherz. March 1992, 26 p. 
NOAA Technical Report NMFS 108

\section{Marine Debris Survey Manual}

Christine A. Ribic

U.S. EPA Environmental Research Laboratory

Corvallis, $O R$

Trevor R. Dixon

The Tidy Britain Group

United Kingdom

Ivan Vining

Center for Quantitative Science

University of Washington

Seatlle, WA

April 1992

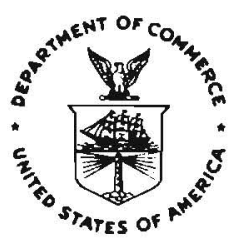

U.S. DEPARTMENT OF COMMERCE

Barbara Hackman Franklin, Secretary

National Oceanic and Atmospheric Administration John A. Knauss, Under Secretary for Oceans and Atmosphere National Marine Fisheries Service

William W. Fox Jr., Assistant Administrator for Fisheries 
The National Marine Fisheries Service (NMFS) does not approve, recommend or endorse any proprietary product or proprietary material mentioned in this publication. No reference shall be made to NMFS, or to this publication furnished by NMFS, in any advertising or sales promotion which would indicate or imply that NMFS approves, recommends or endorses any proprietary product or proprietary material mentioned herein, or which has as its purpose an intent to cause directly or indirectly the advertised product to be used or purchased because of this NMFS publication. 


\section{Contents}

Introduction $\quad$ v

How to Use This Manual vi

Chapter 1: Methodology 1

Definition and Categories of Marine Debris $\quad 4$

$\begin{array}{lr}\text { General Monitoring Guidelines } & 8\end{array}$

Chapter 2: Shipboard Sighting Surveys for Large Debris Items 13

General Description $\quad 13$

Objectives and Purpose $\quad 13$

Population of Interest $\quad 13$

Field Measurement $\quad 13$

$\begin{array}{ll}\text { Quality Assurance Program } & 17\end{array}$

$\begin{array}{lr}\text { Field Sampling Designs } & 18\end{array}$

Analytical Procedures $\quad 18$

$\begin{array}{lr}\text { Summary } & 19\end{array}$

$\begin{array}{lr}\text { Appendix } & 20\end{array}$

Chapter 3: Shipboard Trawling Surveys for Small Debris Items 25

General Description $\quad 25$

Objectives and Purpose $\quad 25$

Population of Interest $\quad 25$

Field Measurement $\quad 25$

Quality Assurance Program $\quad 30$

Field Sampling Designs

Analytical Procedures

$\begin{array}{lr}\text { Summary } & 32\end{array}$

$\begin{array}{ll}\text { Appendix } & 33\end{array}$

Chapter 4: Beach Surveys for Small to Large Debris Items 37

General Description $\quad 37$

$\begin{array}{ll}\text { Objectives and Purpose } & 37\end{array}$

$\begin{array}{lr}\text { Population of Interest } & 37\end{array}$

$\begin{array}{lr}\text { Historical Information } & 38\end{array}$

$\begin{array}{lr}\text { Field Measurement } & 39\end{array}$

$\begin{array}{lr}\text { Pilot Studies } & 40\end{array}$

Quality Assurance Program $\quad 42$

Field Sampling Designs $\quad 42$

$\begin{array}{ll}\text { Analytical Procedures } & 47\end{array}$

$\begin{array}{lr}\text { Case Studies } & 47\end{array}$

$\begin{array}{ll}\text { Alaska Beach Surveys } & 48\end{array}$

$\begin{array}{ll}\text { The Tidy Britain Group } & 49\end{array}$

Summary

53

Appendix 
Chapter 5: Benthic Surveys for Large Submerged Debris Items 61

General Description $\quad 61$

$\begin{array}{ll}\text { Objectives and Purpose } & 61\end{array}$

Population of Interest $\quad 61$

Historical Information $\quad 61$

$\begin{array}{ll}\text { Trawl Surveys } & 62\end{array}$

Field Measurement 62

Quality Assurance Program 63

Field Sampling Designs $\quad 65$

Analytical Procedures $\quad 66$

$\begin{array}{ll}\text { Submersible Surveys } & 67\end{array}$

$\begin{array}{ll}\text { Field Measurement } & 67\end{array}$

Quality Assurance Program 68

$\begin{array}{ll}\text { Field Sampling Designs } & 69\end{array}$

Analytical Procedures $\quad 69$

$\begin{array}{lr}\text { Diving Surveys } & 69\end{array}$

$\begin{array}{ll}\text { Field Measurement } & 69\end{array}$

Quality Assurance Program $\quad 71$

Analytical Procedures 73

Summary $\quad 73$

Appendix $\quad 74$

Chapter 6: Aerial Surveys

General Considerations $\quad 77$

$\begin{array}{ll}\text { Aerial Photography } & 77\end{array}$

$\begin{array}{ll}\text { Conclusion } & 78\end{array}$

$\begin{array}{ll}\text { Glossary } & 79\end{array}$

List of Acronyms

$\begin{array}{lc}\text { Citations } & 83\end{array}$ 


\section{Introduction}

Over the last several years, concern has increased about the amount of man-made materials lost or discarded at sea and the potential impacts to the environment. The scope of the problem depends on the amounts and types of debris. One problem in making a regional comparison of debris is the lack of a standard methodology. The objective of this manual is to discuss designs and methodologies for assessment studies of marine debris.

This manual has been written for managers, researchers, and others who are just entering this area of study and who seek guidance in designing marine debris surveys. Active researchers will be able to use this manual along with applicable references herein as a source for design improvement. To this end, the authors have synthesized their work and reviewed survey techniques that have been used in the past for assessing marine debris, such as sighting surveys, beach surveys, and trawl surveys, and have considered new methods (e.g., aerial photography). All techniques have been put into a general survey planning framework to assist in developing different marine debris surveys.

We thank the following people who discussed the different survey methodologies with us: Jay Brueggeman, Ray Highsmith, Scott Johnson, Barry Troutman, and Heather Trulli. We thank David Redford for allowing us to use EPA SOP No. 4-35. We thank the Center for Marine Conservation, the Environmental Protection.Agency, the Tidy Britain Group, Scott Johnson, Linda Jones, Jeffrey June and Heather Trulli for the use of their data forms.

We thank the following people for reviewing various drafts and parts of this manual: James Coe, E. David Ford, Donald Gunderson, James Herkelrath, Scott Johnson, Linda Jones, Jeffrey June, Theodore Merrell, Thomas W. Miller, David Redford, David Rugg, and Heather Trulli.

We thank the following people for reviewing the entire manual: Marcia Bollman (editorial review), Deborah Coffey (quality assurance review), David Laist, Tony Olsen, and four anonymous reviewers. Any remaining errors or omissions are ours. For the technical editing of this manual, we wish to thank Marcus Duke of the School of Fisheries, University of Washington.

For the Tidy Britain Group case study, the survey data and other information were compiled as part of the Tidy Britain Group's Marine Litter Research Programme and from joint studies with the Advisory Committee on Pollution of the Sea. Tim Dixon was a co-researcher, with additional support from the Keep Wales Tidy Campaign and the University of Keele. Technical assistance was provided by the British Plastics Federation.

We thank Cindy Helfrich for typing the many drafts of this manual and illustrator Sandra Johnson for the cover drawing. We thank the National Marine Fisheries Service Marine Entanglement Research Program for the use of their slides of marine debris, which served as inspiration for the drawing.

The senior author's salary was provided by the U.S. Environmental Protection Agency. The manual has been subjected to the Agency's peer and administrative review, and has been approved for publication.

This manual was the result of discussions held at the Sixth Session of the Intergovernmental Oceanographic Commission's Working Group on the Global Investigation of Pollution in the Marine Environment (25 September-1 October 1986). The Marine Mammal Commission recommended that the National Marine Fisheries Service Marine Entanglement Research Program take on the effort of producing a procedures manual and drafted the original scope of work for this project.

Major funding was provided by the National Marine Fisheries Service Marine Entanglement Research Program to the University of Washington (Contract No. 52ABNF$0-00071)$.

Christine A. Ribic, Research Ecologist Corvallis, August 31, 1991 


\section{How to Use This Manual}

We do not expect the user to read this manual from cover to cover. We expect specific chapters will be of more interest to the user than others. Thus, we have made the chapters self-contained. However, the general scope of this manual and discussion of the general arrangement of this manual are explained in Chapter 1. Therefore, we recommend that the user read Chapter 1 before reading any other chapters. 


\section{Chapter 1}

\section{Methodology}

In the late 1960s and 1970s, trash and other debris of human origin in the ocean began to be recognized as a widespread problem (Risebrough 1969; Heyerdahl 1971; Colton 1974; NAS 1975). Various solid materials of human origin were becoming increasingly apparent both on beaches and floating at sea. The debris then, as now, typically included derelict fishing gear, plastic bags or sheeting, paper products, strapping bands, rope, line, cans, bottles, balloons, plastic pellets, wood planks, clothing, light bulbs, rubber tubes, and gloves. These items were either discarded or lost at sea or carried to the ocean from land by rivers, domestic and industrial outfalls, shoreline runoff, offshore winds, or other means of transport. Although scattered records of seals and other marine life entangled in such debris have been reported for at least several decades before 1970 (see for example Scheffer 1950), such occurrences were considered isolated events and the growing amount of debris was characterized as a litter problem (NAS 1975).

Since the mid-1980s, however, many articles, papers, and reports documenting marine debris and its effects have appeared in the popular, scientific, and technical literature (Duerr 1980; Horsman 1982, 1985; Bourne 1983; Wehle and Coleman 1983; Coleman and Wehle 1984; Dean 1985; Gosliner 1985; Shomura and Yoshida 1985; Wallace 1985; Carr 1986, 1987; CEE 1986, 1987a; 1988, Clark 1986; Coe 1986; Fowler and Merrell 1986; Azzarello and Van Vleet 1987; Bean 1987; FAO 1989; Laist 1987; Lentz 1987; Pruter 1987, a and b; Wilber 1987; Wolfe 1987; Augerot 1988; Gramentz 1988; Heneman and the CEE 1988; MPDTF 1988; O'Hara et al. 1988; Cawthorn 1989; Croxall 1990; Klemm and Wendt 1990; Parker 1990). This new information describes problems that are far more widespread and significant than previously recognized, and it established marine debris as another major form of ocean pollution.

The increase in amounts of marine debris over the past several decades can be attributed to at least three factors (MMC 1991). First, synthetic materials replaced natural fibers in the manufacture of more and more everyday items. Because these materials tend to degrade more slowly in seawater, the total amount of debris in the ocean at any given time re- flects the total amount of debris entering over a longer time period. Second, synthetic materials often are less expensive than the natural fibers they replace, thereby decreasing incentives to reuse or recycle items. Third, and most obvious, there are simply more ships and coastal residents that can lose or discard materials.

The impacts from marine debris include

- aesthetic degradation (Heyerdahl 1971; NAS 1975);

- hazards to wildlife (Laist 1987; Bourne 1990; Ryan 1990a; Sileo 1990);

- economic losses (e.g., damage to boats and fishing gear and decreased tourism; Heneman and the CEE 1988); and

- human health hazards (e.g., physical injury to bathers, exposure to chemical packaging and possible spread of contagious disease [Dixon and Dixon 1981a, 1986; High 1985; Wallace 1985; Pruter 1987a]).

Because of the visual aspect of beach litter, beach cleanups by volunteers have been organized to both educate the public about the extent of the problem and to help mitigate aesthetic effects (Neilson 1985, Dixon 1987, HMEPA 1991). In the United States, state-wide cleanups are now coordinated by the Center for Marine Conservation (O'Hara 1989, CMC 1991). Hazards to wildlife have been detailed in many studies. Entanglement in discarded net fragments has been of primary concern for impacts to marine mammals (Table 1). Ingestion of debris has been reported most frequently for sea birds although ingestion by sea turtles, economically important fish, and cetaceans (Walker and Coe 1990) is of growing concern (Table 1). Impacts on the population level have been difficult to document (Laist 1987; Pruter 1987a; Ryan 1987a; 1988a; Ryan and Jackson 1987; Ryan et al. 1988). The most frequently cited and controversial (e.g., Scordino 1985) case is the decline of the northern fur seal (Callorhinus ursinus) population because of entanglement in discarded fishing nets (e.g., Fowler 1987; Fowler et al. 1990). Economic losses (Meade et al. 1990; Takehama 1990) and public health problems (Dixon 1981, 1987; Dixon and Dixon 1981b, 1986; Wagner 1990) have been less publicized. 
Table 1

Impacts of marine debris on marine animals.

\begin{tabular}{|c|c|c|}
\hline Impact & Animal/Taxon & Reference \\
\hline \multirow[t]{5}{*}{ Entanglement } & $\begin{array}{l}\text { Monk seal } \\
\text { (Momachus schauinslandi) }\end{array}$ & $\begin{array}{l}\text { Andre and Ittner }(1980) \\
\text { Balazs }(1979) \\
\text { Henderson }(1984 ; 1985 ; 1990)\end{array}$ \\
\hline & $\begin{array}{l}\text { Northern fur seal } \\
\text { (Callorhinus ursinus) }\end{array}$ & $\begin{array}{l}\text { Bigg (1979) } \\
\text { Fowler }(1982 ; 1984 ; 1985 ; 1987 ; 1988) \\
\text { Fowler and Ragen (1990) } \\
\text { Fowler et al. (1989) } \\
\text { Sanger (1974) } \\
\text { Scheffer (1950) } \\
\text { Scordino (1985) } \\
\text { Scordino and Fisher (1983) } \\
\text { Scordino et al. (1984; 1988) }\end{array}$ \\
\hline & Other marine mammals & $\begin{array}{l}\text { Bonner and McCann (1982) } \\
\text { Calkins (1985) } \\
\text { Cawthorn (1985) } \\
\text { Croxall et al. (1990) } \\
\text { Jones and Ferrero (1985) } \\
\text { Ryan (1990b) } \\
\text { Shaughnessy (1980) } \\
\text { Stewart and Yochem (1985; 1987; 1990) }\end{array}$ \\
\hline & Seabirds & $\begin{array}{l}\text { Conant (1984) } \\
\text { Dean (1985) } \\
\text { DeGrange and Newby (1980) } \\
\text { Ryan (1990b) } \\
\text { Schrey and Vauk (1987) }\end{array}$ \\
\hline & Turtles & Balazs (1985) \\
\hline Ingestion & Seabirds & $\begin{array}{l}\text { Ainley et al. (1990, a and b) } \\
\text { Baltz and Morejohn (1976) } \\
\text { Bayer and Olson (1988) } \\
\text { Bond (1971) } \\
\text { Bourne and Imber (1982) } \\
\text { Connors and Smith (1982) } \\
\text { Day (1980) } \\
\text { Day et al. (1985) } \\
\text { Dickerman and Goelet (1987) } \\
\text { Fry et al. (1987) } \\
\text { Furness (1983; 1985, a and b) } \\
\text { Harper and Fowler (1987) } \\
\text { Hays and Cormons (1974) } \\
\text { Kenyon and Kridler (1969) } \\
\text { Ogi (1990) } \\
\text { Parslow and Jefferies (1972) } \\
\text { Pettit et al. (1981) } \\
\text { Randall et al. (1983) } \\
\text { Rothstein (1973) } \\
\text { Ryan (1985; 1986; 1987, a and b; 1988c; 1990b) } \\
\text { Sileo et al. (1990) } \\
\text { Slip et al. (1990) } \\
\text { van Franeker (1983; 1985) } \\
\text { van Franeker and Bell (1988) } \\
\text { Zonfrillo (1985) }\end{array}$ \\
\hline
\end{tabular}




\begin{tabular}{|c|c|c|}
\hline \multirow[t]{20}{*}{ Impact } & Animal/Taxon & Reference \\
\hline & Fishes & Anonymous (1981) \\
\hline & & Carpenter et al. (1972) \\
\hline & & Hjelmeland et al. (1988) \\
\hline & & Hoss and Settle (1990) \\
\hline & & Kartar et al. $(1973,1976)$ \\
\hline & & Kubota (1990) \\
\hline & & Ryan (1990b) \\
\hline & Turtles & Balazs (1985) \\
\hline & & Bourne (1985) \\
\hline & & Carr (1987) \\
\hline & & Cawthorn (1985) \\
\hline & & Duronslet et al. (1991) \\
\hline & & Lutz $(1990)$ \\
\hline & & Plotkin and Amos (1990) \\
\hline & & Ryan $(1990 b)$ \\
\hline & & Sadove and Morreale (1990) \\
\hline & Marine mammals & Ryan $(1990 b)$ \\
\hline & & Sadove and Morreale (1990) \\
\hline & & Walker and Coe $(1990)$ \\
\hline
\end{tabular}

In response to growing concern over marine debris, actions have been taken by governments nationally as well as internationally to reduce discharges at their source (Bean 1984). For example, intentional at-sea dumping of garbage generated on land became subject to international control as of 1972 through the Convention on the Prevention of Marine Pollution by Dumping of Wastes and Other Matter (commonly called the London Dumping Convention). Similarly, at-sea disposal of garbage generated during the routine operation of ships (e.g., garbage not deliberately carried to sea for the purpose of disposal) was addressed through a 1978 Protocol to the 1973 International Convention for the Prevention of Pollution by Ships (commonly called the MARPOL Convention). Specifically, the 1978 Protocol to the MARPOL Convention added five Annexes, each dealing with a different form of pollution from ships. Of these, Annex $V$ established regulations on discharging ship-generated garbage, including a prohibition of discharging all plastics at sea.

National efforts to implement programs consistent with these conventions may go beyond the specific measures required by the international regimes. For example, in the United States, substantial education efforts have been mounted through the Marine Entanglement Research Program of the National Marine Fisheries Service (NMFS). These programs are directed toward mariners, beach users, and other groups as well as the public at large. The programs advise the groups about debris-related problems, new regulatory requirements, and proper garbage handling and disposal practices.

As these efforts were implemented, it became apparent that monitoring studies would be needed to assess the effectiveness of actions in reducing the overall amount of marine debris as well as certain types of debris of particular concern, such as plastics generally, medical wastes, and fishing gear (MMC 1987). To address marine pollution monitoring needs generally, the Intergovernmental Oceanographic Commission (IOC), part of UNESCO, initiated a program for the Global Investigation of Pollution in the Marine Environment (GIPME) in 1976 (Andersen et al. 1986). The GIPME program is guided by a comprehensive plan consisting of four stages (Kullenberg 1986): a mass balance determination (including baseline measurements); a contamination assessment (including an evaluation of the distribution, movement, and trends in levels of pollutants in the marine environment); a pollution assessment (involving an evaluation of a pollutant's effect on marine life); and regulatory action.

To provide direction for its GIPME program, the IOC established a Working Group to oversee international efforts. Among other things, the GIPME Working Group 1) develops manuals on procedures for collecting, recording, and archiving data on specific marine pollutants; 2) supports training exercises 
in the use of those procedures; and 3) conducts inter-calibration exercises to ensure that data collected by one country or group can be statistically comparable with those collected by others. As an example of its efforts, the Working Group adopted a manual describing a standard methodology for monitoring tar balls and dissolved oil in seawater and on beaches (IOC 1984) and subsequently assisted efforts to test procedures in the manual in the Caribbean Sea area (Corredor et al. 1987). The success of this approach is evident from publications that have successfully documented and described the extent of tar pollution in the Caribbean (Atwood et al. 1987, a through c).

Prior to 1986, the GIPME Working Group had not addressed monitoring needs for marine debris. Therefore, at its Sixth Session in Paris, France, on 25 September-1 October 1986, it reviewed debris-related information and agreed that a procedures manual for monitoring debris on beaches and at sea warranted consideration. To assist in developing the manual and to help in encouraging and guiding marine debris monitoring efforts in the U.S., the Marine Mammal Commission recommended to the NMFS that a manual be developed as part of the Marine Entanglement Research Program to encourage opportunistic monitoring efforts in the U.S. and that this manual be provided to the GIPME Working Group for consideration in its series of pollution manuals (MMC 1987).

Following some preliminary work on the manual, the matter was examined further at the Second International Conference on Marine Debris held in Honolulu, Hawaii, on 2-7 April 1989, at which time a Conference Working Group to Assess the Amount and Types of Marine Debris (hereafter referred to as the Assessment Working Group) was formed (Ribic 1990). Its participants agreed that work on a procedures manual should proceed as a matter of high priority and that the work should focus on describing study methodologies to meet the first two stages of the above-mentioned GIPME program plan for pollution monitoring (i.e., baseline studies and contaminant assessment) (Ribic 1990).

In this regard, the Assessment Working Group noted that two basic approaches have been used to assess marine debris: open-water surveys (including both visual sighting surveys, surface trawls, and benthic trawls); and beach surveys. Initially, studies most often involved beach surveys (e.g., Gregory 1977; 1978, a and b, 1987; Dixon and Dixon 1980, 1981b, 1983; Merrell 1984, 1985; Henderson and Pillos 1985), which Dixon and Dixon (1981a) suggested were the most cost-effective monitoring strategy for debris. However, recent attempts to di- rectly assess debris in the open ocean, usually on vessels of opportunity, have increased (e.g., Gregory et al. 1984; Dahlberg and Day 1985; Jones and Ferrero 1985; Yoshida and Baba 1985, $\mathrm{a}$ and b; Ignell and Dahlberg 1986; Mio and Takebama 1988; Yagi and Nomura 1988; Nasu and Hiramatsu 1990). In most cases, the individual monitoring studies have had different objectives and different sampling designs, thus making comparisons and broad assessments questionable (Ribic and Bledsoe 1986). A case illustrating problems with non-standardized methodology is that of assessing roadside litter in the U.S.; areas were not comparable because different survey techniques were used (Marquez and Zandi 1985).

Therefore, the purpose of this manual is to review the sampling designs used to measure marine debris and to put them into a framework useful to others in planning and executing surveys to assess the types, amount, distribution, and movement of marine debris in open water and on beaches. By doing so, we hope that scientists, resource managers, and others who can collect useful data will be encouraged to do so in a manner that will be useful and help contribute to a broader understanding of the status and trends of marine debris pollution.

This manual is divided into chapters according to type and location of debris survey. Chapter 2 deals with shipboard sighting surveys for larger debris in open water, Chapter 3 addresses shipboard surface sampling for smaller debris in open water, Chapter 4 reviews beach surveys, Chapter 5 addresses benthic surveys for larger debris in open water, and Chapter 6 deals with the experimental approach of aerial surveys. Even though the manual is divided into separate chapters, investigators may use two or more survey methodologies from the separate chapters to estimate the magnitude of the marine debris problem in a particular area. The rest of Chapter 1 discusses terminology and categories of marine debris, the importance of defining objectives prior to starting a survey, and general monitoring guidelines. A glossary is provided at the end of the manual.

\section{Definition and Categories of Marine Debris}

As note previously, the marine debris problem was initially characterized as a marine litter problem. The National Academy of Sciences (1975) defined marine litter as solid materials of human origin that are discarded at sea or reach the sea through waterways or domestic and industrial outfalls. While the definition is broad and remains useful, we prefer the term "marine debris" because it does not suggest impacts are 
primarily aesthetic. The Academy's definition properly distinguished between sources of debris that originated at sea and those that originated on land. In this manual, the term "vessel-source" debris will refer to material of human origin discarded in open water. MARPOL Annex V established regulations governing the discharge of garbage during the normal operations of ships, including a prohibition of at-sea disposal of any plastics (Augerot 1988). An example of vessel-source debris is fishing-related debris such as trawl net fragments. "Landbased" debris, in this manual, will refer to material of human origin that reaches the sea through waterways or domestic and industrial outfalls. Included in "landbased" debris is litter left by beach users, material lost from coastal landfill sites, and items such as tampon applicators discharged through sewage outfalls. This discinction is important because MARPOL Annex $\mathrm{V}$ addresses the problem of vessel-source debris only, whereas the Clean Water Act addresses landbased debris (e.g., ocean dumping of landbased garbage and combined sewer overflow systems) (U.S. EPA 1990b). Any marine debris sampling scheme, especially surveys done on land, must recognize that sampled material may originate from both sources.

Marine debris may be classified based on size. This type of distinction is important because size will influence the way debris is dispersed and deposited, the wildlife impacts that may occur, and what type of survey approaches may be practical. The Assessment Working Group (Ribic 1990) proposed the following debris categorization by size:

$$
\begin{aligned}
& \text { mega-debris-debris }>2-3 \mathrm{~cm} \\
& \text { macro-debris- } 5 \mathrm{~mm} \text { to } 2-3 \mathrm{~cm} \\
& \text { meso-debris-<5 } \mathrm{mm} \\
& \text { micro-debris-powdered }
\end{aligned}
$$

"Macro-debris," "megalitter" (McCoy 1988; Gregory 1990), and "large plastic" (Day and Shaw 1987) are terms used to describe marine debris visible to the eye or with binoculars during the course of vessel sighting surveys and beach surveys. The lower size limit of this type of debris varied, ranging from $<0.5$ $\mathrm{cm}$ (McCoy 1988) to $1.5 \mathrm{~cm}$ (Morris 1980a), and up to $2.5 \mathrm{~cm}$ in length (Dahlberg and Day 1985; Day and Shaw 1987). McCoy (1988) used $7 \times 50$ binoculars to make observations on a stationary ship in calm seas. Alternately, Day and Shaw (1987) used 10X binoculars on a moving ship in variable seas. In this manual, the following size categories for debris are used.

small debris $<2.5 \mathrm{~cm}$ (not visible by eye in water), e.g., polystyrene pellets, fragmented plastic medium

debris $\geq 2.5 \mathrm{~cm}$ and $\leq 10 \mathrm{~cm}$, e.g., styrofoam cups, tampon applicators

large debris $>10 \mathrm{~cm}$ and $\leq 1 \mathrm{~m}$, e.g., bleach bottles, gillnet floats

very large debris $>1 \mathrm{~m}$, e.g., derelict fishing net

The boundary of $2.5 \mathrm{~cm}$ can be justified because MARPOL Annex $V$ regulations state that material released from ships will be ground to $<2.5 \mathrm{~cm}$. The distinction among the other categories, while more arbitrary, is based on sizes of the major debris items often found on beaches.

There are many categories used for medium to very large debris by studies done in open water (Table 2). Researchers usually identified individual items to produce an exhaustive list and then grouped the debris into major categories. The general groupings used have been similar. The debris items are usually organized according to what the items are made from (e.g., paper, rubber, plastic, wood, glass, metal), the manufacturer's intended use (e.g., fishing gear, ropes, bottles), or a combination of the two. The major categories have typically been fishing gear, plastic, styrofoam, glass, wood, metal, paper, and miscellaneous. Fishing gear was usually subdivided into nets and other gear (including plastic floats). Sometimes plastic and styrofoam were put into one category. Wood was mostly divided into natural (e.g., logs) and man-made (e.g., boxes). In some studies, cloth, cardboard, and rubber were separated into major categories. Most of the open-water studies did not state that particular debris items were of interest, though some of the categories used tended to reflect that interest (e.g., the emphasis on fishing gear in the studies of Mio and Takehama 1988 and Nasu and Hiramatsu 1990; [Table 2]). Beach debris surveys tended to use categories that reflected specific study objectives (Table 3). For example, because Merrell (1985) emphasized entangling debris, his list reflects that interest (Table 3). Willoughby (1986) emphasized man-made materials with long degradation times; thus, his list did not include paper or cardboard (Table 3 ). One of the most general lists is that used by the Center for Marine Conservation (CMC) (formerly the Center for Environmental Education), with 59 individual items (CEE 1988 [Table 3]; form can be found in Appendix 4). The CMC's list parallels the major categories used in the open-water studies with one exception: fishing gear is put into the plastic category. Classifying fishing gear can be problematical because the category is one of function rather than material from which the object is made. The U.S. Environmental Protection Agency (1990b) categorized fishing gear by material, so net- 
Table 2

Debris categories used by open-water sighting surveys for medium to very large debris (pieces $>2.5 \mathrm{~cm}$ ).

\begin{tabular}{|c|c|c|}
\hline Reference & Categories & Comments \\
\hline Venrick et al. (1973) & $\begin{array}{l}\text { plastic bottles } \\
\text { plastic fragments } \\
\text { glass fishing floats } \\
\text { glass bottles } \\
\text { rope } \\
\text { balloon } \\
\text { finished wood } \\
\text { shoebrush } \\
\text { rubber sandal } \\
\text { paper items } \\
\text { coffee can }\end{array}$ & $\begin{array}{l}\text { List of items found; categories not } \\
\text { set up in advance }\end{array}$ \\
\hline Morris (1980a) & $\begin{array}{l}\text { plastic bags } \\
\text { cups } \\
\text { sheets } \\
\text { packing material } \\
\text { bottles } \\
\text { fragments } \\
\text { timber } \\
\text { rubber } \\
\text { nylon rope } \\
\text { feathers } \\
\text { glass bottles } \\
\text { paper items }\end{array}$ & $\begin{array}{l}\text { List of items found; categories set up in } \\
\text { advance }\end{array}$ \\
\hline Dixon (T.J.) and Dixon (1983) & $\begin{array}{l}\text { man-made wood items } \\
\text { paper } \\
\text { cardboard } \\
\text { nylon rope } \\
\text { netting } \\
\text { plastics and styrofoam } \\
\text { metal } \\
\text { glass }\end{array}$ & \\
\hline Dahlberg and Day (1985) & $\begin{array}{l}\text { plastic } \\
\text { styrofoam } \\
\text { metal } \\
\text { glass } \\
\text { paper } \\
\text { cloth } \\
\text { wood }\end{array}$ & 48 individual items listed \\
\hline Mio and Takehama (1988) & $\begin{array}{l}\text { net gear } \\
\text { plastic bands } \\
\text { other fishing gear } \\
\text { styrofoam } \\
\text { other plastic articles } \\
\text { pieces of wood/drifting logs } \\
\text { seaweed } \\
\text { other }\end{array}$ & \\
\hline Yagi and Nomura (1988) & $\begin{array}{l}\text { styrofoam } \\
\text { buoys } \\
\text { plastic sheets/bags } \\
\text { fishing net fragments } \\
\text { rope } \\
\text { wood } \\
\text { glass } \\
\text { metal } \\
\text { other }\end{array}$ & \\
\hline
\end{tabular}


Table 2 (continued)

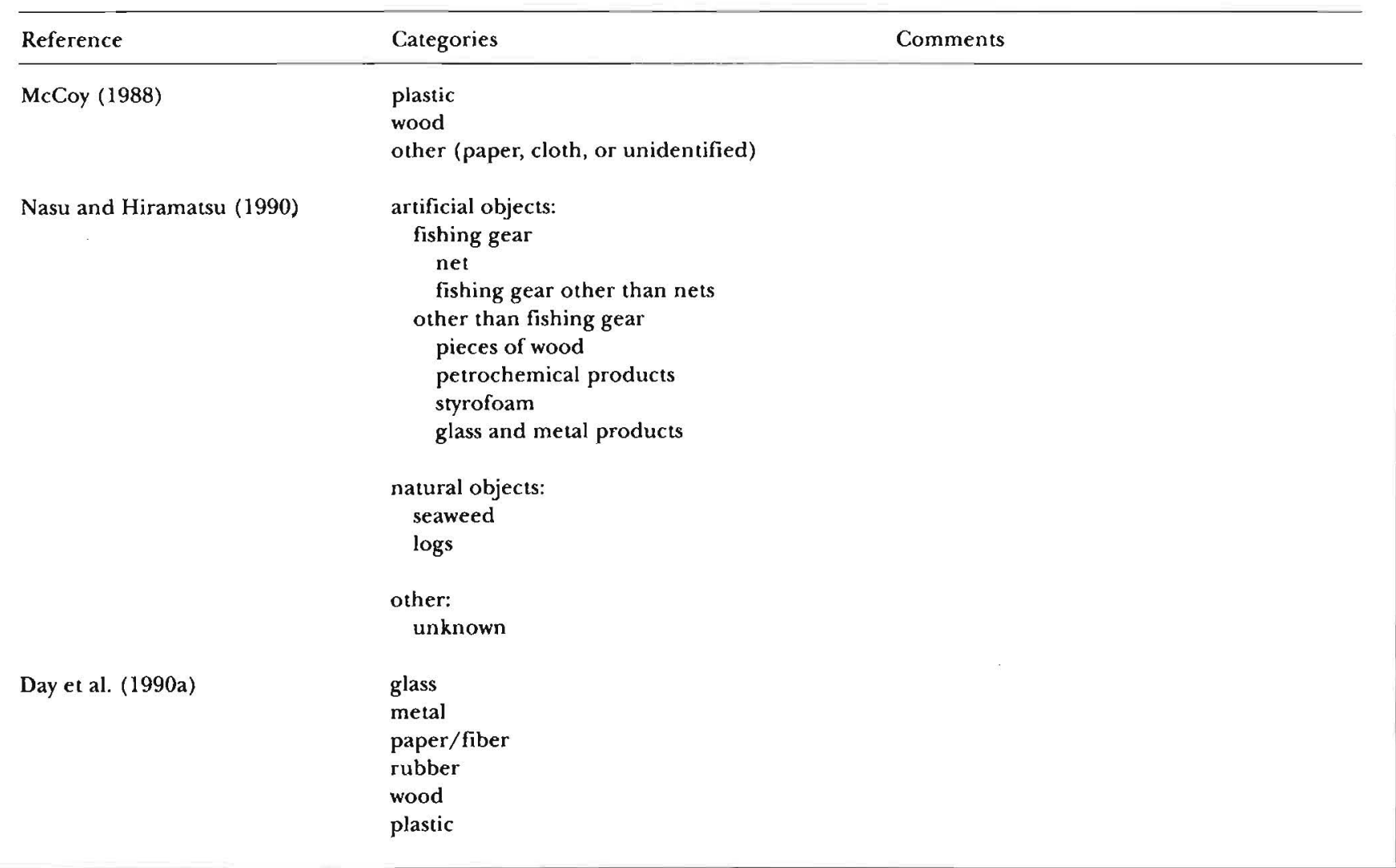

ting is found under plastic while buoys are found under the polystyrene category. The National Park Service (Cole et al. 1990) used the category "Plastic Fishing Gear," which is a combined material and function category.

Most categories are self-explanatory and require no specific knowledge for use (e.g., rope, styrofoam food containers); however, some others such as buoy bags (Merrell 1985) and crustacean pot floats (Cole et al. 1990) may require more definition. Few studies conclusively define each debris category. The most detailed list of definitions was found in Appendix B of Cole et al. (1990), where over 50 debris categories were listed; this appendix was used to define debris categories in the glossary of this manual.

For medium and large debris categories, we recommend that researchers organize lists of items first by material type (i.e., plastic including foamed plastics [styrofoam], glass, metal, rubber, fiber [cloth], wood, paper) and then, under these primary categories, develop secondary categories according to function or manufactured product (e.g., fishing gear, bottles, medical use). All individual items would be listed under one of these primary or secondary categories, or both. We recognize that complete standardization of categories is not possible owing to specific study objectives and debris unique to the particular area. An example of this was the expansion of the CMC form from 59 to 200 items by the harbor studies program (U.S. EPA 1990a).

For small debris, all the studies in Table 4 occurred in open water and used similar categories. The items identified by the Assessment Working Group (Ribic 1990) as being most important to record are reflected in the studies in Table 4.

Primary categories by material can be developed similar to medium-size and larger debris categories. For small debris, color and size may become important in determining the likelihood that different species may detect and ingest debris. Additional subcategories based on size and color would be useful for small debris. Size categories could be based on the most common size for pellets. Because most pellet sizes fall between $1 \mathrm{~mm}$ and $6 \mathrm{~mm}$ (Carpenter and Smith 1972; Carpenter et al. 1972; Gregory 1977, 1978a, 1983, 1990), three categories -<1 mm, 1-6 $\mathrm{mm}$, and $>6 \mathrm{~mm}-\mathrm{can}$ be used. Color categories could be based on Day et al. $(1985,1990 \mathrm{~b})$, who used 11 colors (transparent, red/pink, blue, yellow, white, tan, green, brown, black/gray, orange, miscellaneous). 
Table 3

Debris categories used by beach surveys for medium to very large debris (pieces $>2.5 \mathrm{~cm}$ ).

\begin{tabular}{|c|c|c|}
\hline Reference & Categories & Comments \\
\hline Dixon and Cooke (1977) & $\begin{array}{l}\text { plastic } \\
\text { glass } \\
\text { metal } \\
\text { paper }\end{array}$ & $\begin{array}{l}\text { Counting containers; } 21 \text { individual items } \\
\text { listed }\end{array}$ \\
\hline Merrell (1985) & $\begin{array}{l}\text { trawl web } \\
\text { straps-open } \\
\text { straps-closed } \\
\text { trawl floats } \\
\text { synthetic line } \\
\text { bait containers } \\
\text { gillnet floats } \\
\text { bottles } \\
\text { caps and lids } \\
\text { fragments - hard } \\
\text { fragments-soft } \\
\text { buoy bags } \\
\text { six-pack yokes } \\
\text { other }\end{array}$ & \\
\hline Willoughby (1986) & $\begin{array}{l}\text { plastic bags } \\
\text { footwear } \\
\text { styrofoam } \\
\text { bottles } \\
\text { tins } \\
\text { ropes and netting } \\
\text { lamp bulbs }\end{array}$ & $\begin{array}{l}\text { Only man-made materials with long } \\
\text { degradation times counted }\end{array}$ \\
\hline Vauk and Schrey (1987) & $\begin{array}{l}\text { plastic } \\
\text { paper } \\
\text { metal } \\
\text { glass } \\
\text { fishing gear } \\
\text { clothing } \\
\text { foodstuff } \\
\text { wood }\end{array}$ & $\begin{array}{l}\text { Individual items enumerated; then put into } \\
\text { categories }\end{array}$ \\
\hline $\begin{array}{l}\text { Center for Environmental } \\
\text { Education (1988) }\end{array}$ & $\begin{array}{l}\text { plastic } \\
\text { glass } \\
\text { styrofoam } \\
\text { metal } \\
\text { paper } \\
\text { man-made wood } \\
\text { rubber }\end{array}$ & 59 subcategories \\
\hline Cole et al. (1990) & $\begin{array}{l}\text { plastic fishing gear } \\
\text { plastic packaging material } \\
\text { personal effects } \\
\text { miscellaneous plastics }\end{array}$ & 51 items listed \\
\hline
\end{tabular}

\section{General Monitoring Guidelines}

The Assessment Working Group (Ribic 1990) divided marine debris studies into baseline and assessment categories. By definition, baseline studies were designed to determine the characteristics of the debris problem (e.g., what type of material is found). Base- line studies for marine debris are generally carried out over large geographical areas with low sampling frequency. Assessment studies, however, were considered to be more focused in their objectives. Two examples of assessment studies are measuring density of debris in certain areas and measuring changes over time (i.e., trend monitoring). Assess- 
Table 4

Debris categories used by open-water sampling studies for small debris (pieces $<2.5 \mathrm{~cm}$ ).

\begin{tabular}{|c|c|c|}
\hline Reference & Categories & Comments \\
\hline $\begin{array}{l}\text { Colton et al. } \\
\text { (1974) }\end{array}$ & $\begin{array}{l}\text { white opaque polystyrene spherules } \\
\text { translucent to clear polystyrene spherules containing } \\
\text { gaseous voids } \\
\text { opaque to translucent polyethylene cylinders or discs } \\
\text { styrofoam } \\
\text { sheets of thin, flexible, wrapping material } \\
\text { pieces of plastic }\end{array}$ & \\
\hline Day et al. (1985) & $\begin{array}{l}\text { fragments } \\
\text { monofilament line fragments } \\
\text { pellets } \\
\text { polypropylene line fragments } \\
\text { styrofoam } \\
\text { miscellaneous/unidentified }\end{array}$ & 10 color categories used \\
\hline Ryan (1988b) & $\begin{array}{l}\text { industrial pellets } \\
\text { pieces of manufactured items } \\
\text { fibers } \\
\text { styrofoam/other foamed plastics }\end{array}$ & $\begin{array}{l}9 \text { color categories used (color when } \\
\text { wet); } 3 \text { categories of wear used }\end{array}$ \\
\hline Day et al. (1990b) & $\begin{array}{l}\text { pellets } \\
\text { fragments } \\
\text { styrofoam } \\
\text { polypropylene line fragments } \\
\text { miscellaneous line/threads }\end{array}$ & 11 color categories used \\
\hline
\end{tabular}

ment studies tend to be more limited in geographical area and have more intense sampling efforts. This split in the types of studies reflects the ideas of Barnard et al. (1985), who divided monitoring studies into two types: descriptive monitoring and location-specific monitoring. Other researchers (Gilbert 1987) do not distinguish between the two types of studies and refer to the baseline and assessment studies collectively as monitoring studies in contrast to research studies (e.g., research studies to determine the transport of pollutants through the environment). In this manual, we use the framework in Table 5, which presents the survey types relevant to marine debris surveys. In terms of the baseline and assessment study definitions made by the Assessment Working Group (Ribic 1990), surveys with objectives 1-4 (Table 5) are assessment studies, whereas studies with objective 5 (Table 5) are baseline.

Whether or not the studies are baseline or assessment, good planning is essential to collect useful information. Advice in this manual is organized by the planning guidelines of Gilbert (1987):

1 State the objectives clearly.

2 Define the population of interest.
3 Collect information on the geographic areas of interest to develop the sampling plan (e.g., physical features, weather patterns, historical information).

4 Define the field measurement to be made.

5 Examine data from previous studies or conduct pilot studies to approximate the likely variability in the field measurements.

6 Develop a quality assurance program plan to ensure that the data collected will be of high quality, verifiable, and defensible.

7 Develop field sampling designs and measurement procedures that will yield representative data from the defined population, along with a specified variance or confidence limit. If necessary, make decisions on identifying the source of debris (vessel-source versus landbased).

8 Determine the statistical analyses to be used.

9 Conduct the study according to the written protocol.

10 Analyze the data.

11 Evaluate the study (e.g., were the objectives met? Were the collected data adequate to meet the stated objectives? Should the design be modified?). 
Table 5

Marine debris study objectives adapted from Lettenmaier et al. (1982).

Objective Description

(1) Surveillance

(2) Model parameterization

(3) Cause-effect

(4) Trend detection

(5) Baseline

\author{
Detect impact of known poliution source or detection of point source pollution (e.g., spills). \\ Need frequent sampling, possibly continuous monitoring. \\ Example: \\ Cargo spill (Dixon and Dixon 1981b) \\ Polystyrene spherules (Kartar et al. 1973, 1976)
}

Provide data on time and space scales to allow identification of input decay rates; linked to prediction. Sampling is frequent and intense in a small area for a short time period.

Example:

Population dynamics of marine debris (Gerrodette 1985)

Identify functions relating input and output; assess present conditions. Sampling is frequent and intense in a small area for a short time period.

Example:

Turnover rates for debris on beaches (Dixon and Cooke 1977; Johnson 1988, 1990a)

Analyze time series for evidence of changes in a statistical sense. Long sequences of observations at frequencies on the order of weekly or monthly at stations scattered throughout a large area.

Example:

Assessment of changes of trawl web over time (Ribic and Johnson 1990)

Assessment of changes in total debris over time (Ribic 1991)

Assessment of changes in total plastic over time (Johnson 1990a)

For little or no pre-existing data; establish the level of the problem. Low sampling frequencies. Spatial density depends on problem (local problem will result in more concentrated stations; problems covering a large area can result in dispersed stations).

Example:

Nationwide beach surveys (O'Hara 1989, 1990)
Clearly defining and stating the objectives cannot be overemphasized. The objectives can be as simple as determining the kinds of debris occurring on a particular beach to as complex as determining a decrease in the amount of entangling debris seen on Alaska beaches as a consequence of MARPOL Annex V. Explicitly stated objectives guide the development of the sampling design from defining the population of interest to what data are collected and how they are analyzed. Stating objectives also sets the scope of the study and data analyses, which is important given that no single sampling design can answer all questions of interest, as is evident from Table 5 .

The population of interest in marine debris studies is often associated with a geographical area. Examples of populations of interest include net fragments in the North Pacific Ocean, domestic waste in the North Sea and tar in the Caribbean. Mediumor larger-sized debris on Texas beaches can also be a population of interest. Populations of interest can have a temporal component, such as large debris on
Texas beaches in the fall or net fragments in the North Pacific during the fishing season. It may be that only certain areas are available for study. For example, only beaches with good public access or ocean areas visited regularly by vessels of opportunity may be available for study. Then the population of interest (e.g., debris on all beaches) is not available, and only a subset (e.g., debris on public beaches) is available. Given such restrictions, the target population (population of interest minus the restricted areas) may not be truly representative of the larger population of interest, unless certain assumptions can be made and tested (e.g., debris composition on private beaches is not different from that on public beaches). Deciding on the target population is important because that population will be used to define the sampling frame from which representative units for measurement are chosen. A "representative unit" is a unit selected from the sampling frame in such a way that it, in combination with the other representative units, will give an accurate picture of the 
phenomenon being studied (Gilbert 1987). Another word for representative unit is "sampling unit" (the term used in this manual). Typical sampling units for marine debris studies are beaches or transects on beaches, areas of ocean scanned, area swept by surface sampler, and area swept by demersal trawl.

Information on the physical environment, weather patterns, and site history may be useful in planning the sampling design. For example, wind direction plays a large part in the deposition of debris on beaches in the United Kingdom (Dixon and Dixon 1981a). Therefore, in this situation, information regarding offshore and onshore winds is important for determining sampling times. For open-water studies, information on currents or areas where debris are concentrated can be used to decide where the sampling should be concentrated (i.e., stratification variables). In addition, surface drift experiments may be used to identify sampling conditions in relation to oceanographic conditions (e.g., onshore currents). This aspect is considered further in the individual chapters.

Defining the field measurements is important and is discussed in more detail in the individual chapters. Issues that must be resolved are defining what will be measured, what the sampling unit is, how the measurements will be taken on the sampling unit, and what field methodology will be used. These are critical elements of geographically-based surveys such as those for marine debris. The sampling unit may be a fixed area of ocean with the measurement being counts of all items $>2.5 \mathrm{~cm}$. The field methodology may be a strip transect. All of these issues should be resolved before the start of the field work and noted in the quality assurance program plan discussed below.

Pilot studies play a critical role in survey design, particularly for large-scale or long-term surveys (or both). Pilot studies play a key role in training for field measurement techniques, preliminary assessment of debris sources (which may change the design), and assessment of debris variability in the sampling units over the geographical area of interest. Pilot studies also are invaluable for determining cost and effort to complete the survey. Then, study objectives can be modified or new objectives stated because of sampling constraints found during the pilot study (e.g., available resources, type of equipment on hand).

Quality assurance program plans have not been described for many published surveys, and we are uncertain whether many studies have had one. Quality assurance activities help to make studies repeatable. Detailed descriptions of what was done (e.g., standardized procedures) can be used by other researchers to help design their surveys. In addition, if many people are involved in a study that is conducted over a long time period, the quality assurance program plan provides a unified set of directions to follow. Quality assurance program plans address measures that will describe data quality. They should contain a training element such that the accuracy of data collected by volunteers can be assured. On

a more personal level, the plan should incorporate procedures that maintain a safe working environment.

Developing field sampling designs and measurement procedures that give representative data requires a statistical assessment. Sample size requirements are determined, a procedure for choosing sampling units is developed, and precision and statistical power are discussed. Developing a sampling design is the most problematical task for a study. There may be many sampling designs to choose from, but each design is likely to have different effects on results and require different effort for the survey. Field sampling designs will be addressed in the individual chapters.

Certain statistical analyses are appropriate for most studies of marine debris. These are called descriptive statistics (e.g., means, variances, plots of data) and exploratory data analyses (e.g., box plots). All are available in a wide variety of computer packages. The more difficult decisions are made when there are statistical hypotheses to be tested. How to test for changes in trend over time or changes in mean level over time are questions that can be addressed in a variety of ways. In general, there are parametric and nonparametric statistical methods. Both approaches have strengths and weaknesses. The scope of this manual precludes discussion of these in detail. Standard statistical texts (e.g., Conover 1980; Sokal and Rohlf 1981) should be consulted; Gilbert (1987) presents a discussion on detecting changes in trend.

Evaluating the study design is critical. Sometimes changes in design are made owing to problems in the field as they arise. In addition, as more is learned about the problem of interest, objectives and study designs change. For example, the beach surveys in Alaska started by Merrell (1985) have changed from a general survey of trawl webbing on beaches to focus on detectable changes that may be due to MARPOL Annex V. The effect of this particular change is discussed in more detail in Chapter 4.

Individual chapters follow the 11 guidelines of Gilbert (1987) with an emphasis on guidelines 1, 2, 4, and 7 . The other guidelines are discussed when appropriate. In all cases, investigators are encouraged to discuss design and data analysis procedures with a statistician. 



\section{Chapter 2}

\section{Shipboard Sighting Surveys for Large Debris Items}

\section{General Description}

This chapter discusses open-water sighting surveys whereby all floating debris are identified and counted from an elevated platform on a moving ship. Transect width may vary from $100 \mathrm{~m}$ to the visual horizon depending on the type of debris being studied. Surveys are usually conducted from the glare-free side of the ship, and objects are sighted visually either unaided or with binoculars.

Sighting surveys collect information on the distribution and amounts of floating, medium to very large debris in areas of the open water during specific time periods. Baseline surveys have been done in the North Pacific Ocean using vessels of opportunity (Dahlberg and Day 1985; Ignell 1985; Jones and Ferrero 1985; Ignell and Dahlberg 1986; Mio and Takehama 1988; Day et al. 1990a; Mio et al. 1990; Nasu and Hiramatsu 1990; Shaw 1990). Vessels of opportunity also have been used to survey areas of the North Sea (Dixon (T.J.) and Dixon 1983) and the Mediterranean Sea (Morris 1980a). Dedicated vessels have been used in assessment studies to detect temporal trends in the North Pacific along $137^{\circ} \mathrm{E}$ longitude between $0^{\circ}$ and $34^{\circ} \mathrm{N}$ latitude (Yagi and Nomura 1988). Other studies have resurveyed areas to look for temporal changes; for example, Day and Shaw (1987) surveyed the Gulf of Alaska along $155^{\circ}$ longitude in 1984 and 1985.

\section{Objectives and Purpose}

Typical objectives for open-water sighting surveys are as follows:

- to identify types of floating marine debris;

- to estimate densities of floating marine debris;

- to identify areas of low or high concentrations of floating marine debris relative to either oceanographic features (e.g., currents, convergence zones) or man-made structures (e.g., offshore oil platforms);

- to relate floating debris to entanglement or other effects on animals; and

- to detect temporal and spatial changes in the occurrence of marine debris.

\section{Population of Interest}

In planned studies, debris in specific oceanic areas comprises the population of interest, which must be defined by the researcher. For example, fur seal researchers were interested in the amount of floating net debris around the Pribilof Islands, the breeding rookeries for northern fur seals. Therefore, floating net debris in a specific area around the islands during the fur seal breeding season was defined as the population of interest, and surveys were conducted in that area (Yoshida and Baba 1985b; Baba et al. $1988 ; 1990)$. Alternatively, the population of interest can be as large as all the debris in the North Pacific Ocean (Mio and Takehama 1988; Mio et al. 1990; Nasu and Hiramatsu 1990). Defining the population of interest is determined by the objectives of the study.

Restrictions to the population of interest are likely when surveys rely on vessels of opportunity. In such cases, areas of the ocean are surveyed not because of any particular sampling plan but because that is the ship's destination. This restriction often is not stated by authors, who may generalize the debris in the sampled area to an entire oceanic area without any justification for doing so. We basically consider it inappropriate to generalize results from vessels of opportunity studies.

\section{Field Measurement}

The most common variables of interest for openwater sighting surveys are density (number $/ \mathrm{km}^{2}$ ) and types of medium to very large debris.

\section{Description}

Observer(s) on a moving ship stand on the flying bridge or other elevated section. Observer heights above the water line and speed of ship will vary according to the type of ship. Using the glare-free side of the ship for observation, observer(s) visually scan for objects floating on the ocean as the ship moves through the area. Binoculars are generally not used 
to sight objects; instead, they are used only to confirm the identity or to help estimate sizes of objects. The number of observers on a survey varies (1-10). The Assessment Working Group (Ribic 1990) recommended that a minimum of two observers be emplyed in any survey. Survey transects must be defined in terms of width and length: the survey width (i.e., the maximum distance from the ship's side in which debris will be censused) may vary, in part, depending on the number of observers; length of transect is defined as the straight-line distance covered by the ship during an observation period. Observation periods may be defined in terms of time periods of constant sighting conditions, vessel speed, and direction. Length is then calculated by recording beginning and ending location (latitude/longitude) or by calculating the distance traveled using the ship's speed at the start of the transect, or both (the latter method assumes the ship is moving at a constant speed). If vessel's speed or course changes, then new coordinates, speed, and time must be recorded.

\section{Options}

Strip Transect-In a strip transect, only objects within a specified distance from the side of the ship are counted (Fig. 1). All objects are assumed to be

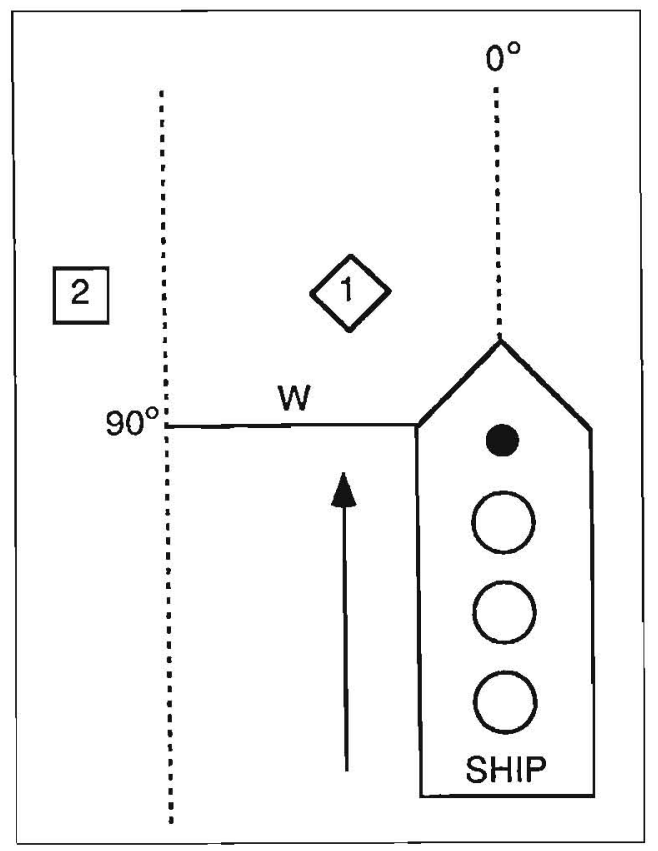

Figure 1

Schematic diagram of a strip transect. $W=$ specified strip width. The dark circle indicates the observer, and the strip is between 0 and $90^{\circ}$. Object 1 is inside the strip and is recorded while Object 2 is outside the strip and is not recorded (even if observed). seen within that strip and any objects seen outside the specified distance are not counted (e.g., object 1 in Figure 1 is counted; object 2 is not). Common strip widths are $50 \mathrm{~m}$ (Day and Shaw 1987; Day et al. 1990a) and $100 \mathrm{~m}$ (Dixon (T. R.) and Dixon 1983). The actual strip width used will depend on the study objectives. Other researchers have counted all debris seen without regard to a specified strip width and then have truncated the data at certain distances for analysis (e.g., $50 \mathrm{~m}$, Dahlberg and Day 1985; $10 \mathrm{~m}$, Mio and Takehama 1988). Appendix 2A contains a protocol by the Tidy Britain Group for using strip transects to estimate debris density.

Line Transect-All objects are counted regardless of the distance from ship, and the perpendicular distance from the object to the ship is measured (Fig. 2). Two other variables-the distance of the object to the ship at the time of first sighting and the angle of observation (Fig. 2)-can be measured and converted to a perpendicular distance. While these latter two variables have been recorded most frequently (Dahlberg and Day 1985; Mio and Takehama 1988; Nasu and Hiramatsu 1990), perpendicular distance (Mio et al. 1990) is preferred (Burnham et al. 1980). When the latter two variables are measured, the measurement errors inherent in both variables

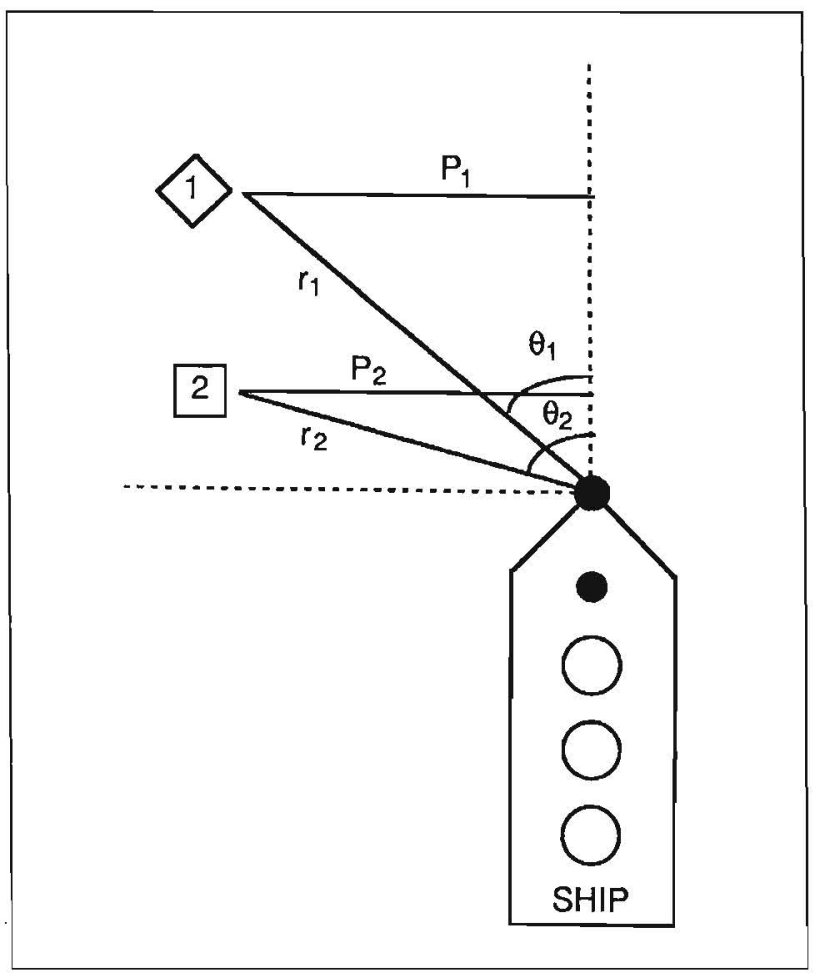

Figure 2

Schematic diagram of a line transect. $P_{i}=$ perpendicular distance of object $i$ to ship, $r_{i}=$ distance from object i to observer at time of sighting, and $\theta_{i}=$ angle between object $i$ and observer at sighting. 
result in errors in perpendicular distances that are difficult to correct. When perpendicular distance is measured, errors can be dealt with by using distance classes (Burnham and Anderson 1984). For example, instead of using all distances as recorded, distances can be grouped into distance classes (e.g., 0-5 m, $5-10 \mathrm{~m}$ ). Errors made in estimating an object $6 \mathrm{~m}$ from the ship, versus $7 \mathrm{~m}$, are then unimportant because the data are analyzed in terms of distance classes rather than individual distances.

It is beyond the scope of this manual to present a detailed discussion of the advantages and disadvantages of the line- versus strip-transect method. Both have strengths and weaknesses (Burnham and Anderson 1984). The strip transect method requires that all objects be seen in the strip of width $w$, but distance or angle measurements are unnecessary. Bias in the density estimate results from objects being missed within the strip, from objects along the strip perimeter mistakenly being included or excluded from the ship, from observer differences (e.g., experience differences, fatigue), from the physical setting (e.g., weather, speed of travel), and from variability in the objects (e.g., color, size, shape).

The line transect method requires four assumptions: 1) objects on the line are detected with certainty; 2) objects do not move in response to the observer before detection; 3) perpendicular distance data are accurate; and 4) detections are independent. For sighting marine debris, the first and third assumptions are the two most likely to be violated. The first assumption can be handled by having one observer watch the center line. The third assumption will be difficult to fulfill given the problems of estimating distances at sea; however, training observers to estimate distances at sea would be an important part of the quality assurance program plan. Biases due to observer differences, the physical setting, and object variability are incorporated into the analysis of the perpendicular distances.

Of the two methods, theoretical studies by Burnham et al. (1985) suggest that, in terms of increased efficiency and lower bias, the line transect method gives better density estimates than the strip transect method. If an observer at sea can accurately measure angles and distances or accurately use distance classes, the line transect method is preferred (Ribic 1990).

\section{Variables to Consider}

Weather-Avoid making observations when conditions restrict visibility. For example, Yoshida and Baba (1985b) made no observations when visibility fell below $200 \mathrm{~m}$. Sea state has also been used to determine when observations should take place. For example, Dixon (T.J.) and Dixon (1983) restricted observations to sea states (based on a combination of wind, waves, and swell height) of 3 or less, whereas Shaw (1990) used sea states of 4 or less, and Day et al. (1990a) did not sample when high waves could have affected "sightability."

Characteristics of Marine Debris-Various authors (Dahlberg and Day 1985; Jones and Ferrero 1985; Mio and Takehama 1988) have noted that color, size, shape, and buoyancy of objects affect their sightability. Currently, no data are available with which the problem can be evaluated. When using a strip transect approach, trials could be undertaken with materials of known characteristics deliberately placed at different distances from a vessel or in varying weather conditions to determine sighting probabilities.

Vessel Variability-Ship's speed and observer's height above the water will affect marine debris sightings (Mio and Takehama 1988). While the importance of these variables has been noted, no data are available to determine optimal height of ship speed for marine debris surveys. If all data are combined into one set, the sighting differences due to vessel variability add to the variability in the data.

Measurement Variability-Exact measurements are critical for the data analysis stage (Burnham et al. 1980). Most studies have estimated angle and distance from the ship to the object at first sighting with no indication that the accuracy of the data has been checked. If the perpendicular distances are discovered to be inaccurate, the analysis can still proceed by putting the distances into distance classes (Burnham and Anderson 1984). Distances can be measured with a range finder or binoculars with reticles. Distance classes (e.g., 0-10 m, 10-20 m, etc.) can be set up prior to the study and used instead of measured distances. Accuracy of distance classes will still be important because the boundaries between classes must be identified.

\section{Data Collection}

Researchers should collect the following data.

- date

- time at start of transect

- duration of transect (time elapsed)

- location (latitude/longitude) at start of transect

- distance traveled during transect: ship's speed at start of transect (the transect should be stopped if the vessel changes speed) location at end of transect (latitude/longitude) 
- sighting condition-visibility, wind speed and direction, cloud cover, sea state, direction of sun relative to ship's course

- a list of all items sighted by classification (see Chapter 1), location at sighting, and distance/angle measurements (if line transect)

- comments

Note that the first five items in the above list are necessary whether or not debris is sighted on a transect. This information is used to calculate the total number of transects made, effort, and area surveyed. A transect is defined as the straight-line distance between the starting and ending locations of the ship or the straight-line distance traveled for the duration of the transect based on the ship's speed at the start of the transect. In both cases, the ship's course must not change during the observation period.

Forms for collecting debris sighting data have not been standardized, and few researchers have published their data forms. Figure 3 is a suggested data

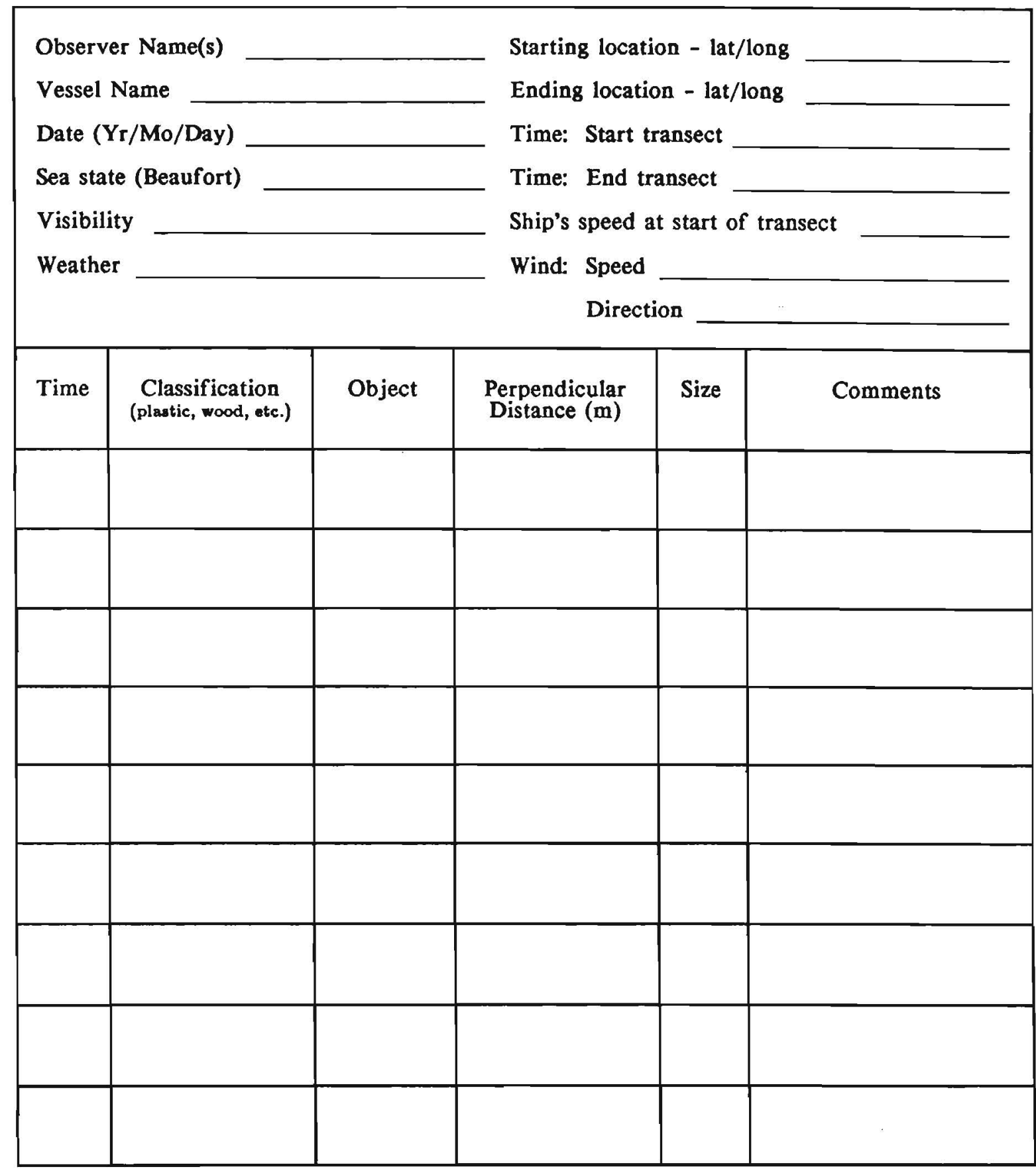

Figure 3

Suggested data form for open-water mega-debris sightings. 
form, and Appendix Figure B (this chapter) is an example of a data form used by the Marine Mammal Observer Program to collect marine debris information. Debris information is substituted for species information (L.L. Jones, NOAA, National Marine Mammal Laboratory, Seattle, WA, pers. commun. February 1991).

\section{Material and Personnel}

The basic equipment needed for sighting debris is a pair of binoculars (e.g., $8 \times 40,10 \times 50$ ) to identify sighted objects. Typical costs for high quality binoculars are $\$ 300-1,000$ (1991 U.S. dollars). Perpendicular distances can be measured with a range finder or binoculars with reticles and compass (\$500-1,000). Clipboards, pencils, and data forms will be necessary to record the data (approximately $\$ 200$ ). A tape recorder may be useful for documenting and verifying observations.

The major cost of a dedicated debris survey at sea is the ship. Ship costs are related to vessel size, equipment, and trip duration. For example, a vessel about $38 \mathrm{~m}$ (125 ft) long for high seas travel and that fulfills the NOAA requirements for doing small cetacean sighting work will probably cost in excess of $\$ 6,600$ / day, not including fuel cost. Therefore, for a 1-month cruise, the ship alone would cost approximately $\$ 198,000$ (excluding fuel costs). An observer's travel expenses and salary are additional. The salary of the observer needs to be a minimum of $\$ 3,000 /$ mo to compete with other observer programs (L.L. Jones, NOAA, National Marine Mammal Laboratory, Seattle, WA, pers. commun. February 1991). Other expenses might be necessary, such as extra equipment (e.g., a wrench and hook to retrieve nets). Thus, for two observers, the $338 \mathrm{~m}$ (125 ft) ship, and travel expenses (e.g., $\$ 1,000$ per observer), a 1 -month cruise could cost over $\$ 216,500$. Larger vessels (e.g., NOAA research vessels like the Oceanographer and the Miller Freeman), are much more expensive (for estimates, write Director, Pacific Marine Center, NOAA, 1801 Fairview, Seattle, WA 98102). Surveys near the coast will be able to use smaller ships, which may rent for as low as $\$ 1,000$ / day (L.L. Jones, NOAA, National Marine Mammal Laboratory, Seattle, WA, pers. commun. February 1991).

Given the high cost of a dedicated research cruise, researchers usually use research vessels scheduled for other purposes. This "vessel of opportunity" research considerably lowers the cost (to $\$ 8,000$ in the preceding example) because the researcher will only have to pay for travel, room, and board. Assuming $\$ 10 /$ day for room and board, the cost for a 1-month cruise will be less than $\$ 1,000$ for two people for the use of a ship compared to $\$ 30,000$ to $\$ 200,000$ + when chartering a vessel. The trade-offs are in the great restriction of the population of interest and the availability of such cruises. Additional expense can be saved if biologists or oceanographers (volunteers) make debris sightings between their primary research tasks. For volunteer-collected data, quality assurance of the collected data will be an important issue that needs to be resolved before such a program is implemented.

Required personnel includes at least two observers experienced or trained in sighting objects floating at sea and who also have training or experience in the use of equipment to measure distances and angles. Because experienced observers see more than inexperienced observers, an inexperienced observer should be paired with an experienced observer. Whenever possible, for different cruises during the study, the same observers should be involved in the field work to help control observer variability (Day and Shaw 1987; Dixon (T.R.) and Dixon 1983).

\section{Quality Assurance Program}

Unfortunately, publications describing results of open-water sighting surveys have not described or acknowledged a quality assurance plan. Some details of importance for ensuring quality data from open-water sighting surveys are as follows:

- What is the population of interest, and what is the population actually available for sampling (i.e., restrictions to the sampling frame; Guideline 7, Chapter 1)?

- What is the justification for concluding that the target population represents the broader population of interest?

- How is a transect defined (e.g., strip or line transect, how wide, how long)? How is the transect selected for sampling?

- How is the sighting survey to be carried out (e.g., how many people, how is debris sighted and verified [with or without binoculars], what side of the ship will be used [one or both], how high above the water will the observer be, what are the restrictions on sighting conditions, how fast will the vessel travel)?

- How experienced are the observers in sighting objects at sea?

- Were the observers trained to estimate angles and distances at sea? How were they trained? 
- Were devices or procedures used to aid in making and verifying these measurements?

Of critical importance to the sighting survey is estimating the distances (and angles, if necessary) from the ship to the debris object. Most ships have a compass on the flying bridge that can be used to measure angles. Distance or distance classes can be measured by visual estimation, or with either a range-finder (which can be as simple as a set of calipers or a cardboard triangle) or binoculars with reticles. A range-finder or binoculars with reticles can only be used when the horizon is clear. Poor visibility due to fog or low clouds and sea state (i.e., the horizon is obscured by the swells and the ship's pitch is extreme) will affect the use of these items. Appendix Figure A (this chapter) contains an example of a range-finder to estimate the outer boundary of the strip and contains a figure explaining the use of the range-finder. Practical advice and further references concerning the estimation of distances and the use of range-finders at sea can be found in Gould and Forsell (1989). Along with consultation with experienced observers, this information should be used to prepare a detailed training session for observers to ensure the quality of the collected distance measurements.

In addition to carrying out the survey, the approach for data entry and analysis is outlined. For example, who will check the data to ensure correct entry? What analysis techniques will be used and why? Obviously, all such details need not be put into a published paper; however, the quality assurance program plan should be referenced with key features noted in publications to the extent possible, and details should be available to interested parties on request. Appendix Figure A (this chapter) contains detailed instructions used by the Tidy Britain Group to carry out strip transects.

As a practical matter, funding agencies should require and review the quality assurance program plan. If a government agency is funding the study, they may wish to codify the study protocols as Standard Operating Procedures (SOP), (e.g., see EPA SOP in Appendix Figure B, chap. 3).

\section{Field Sampling Designs}

The actual sampling design depends on the objectives of the project. Is the survey a baseline study or an assessment study? If it is an assessment study, is it to develop model parameters or to detect changes in space or time (see Table 5 in Chapter 1)? Given the large areas of ocean to be considered, some general guidelines can be stated. More published information is available regarding open-water distribution of marine debris in the North Pacific than in any other ocean body (Mio and Takehama 1988; Mio et al. 1990; Nasu and Hiramatsu 1990). There is probably enough information available to establish survey lines for regular monitoring (as suggested by Nasu and Hiramatsu 1990). How one picks the areas or survey lines depends on the objectives of the survey. If a survey of general debris trends over time is the goal, transect lines in areas known to concentrate debris may be desirable (e.g., northeast to northwest of the Hawaiian Islands [Nasu and Hiramatsu 1990]). If the goal is to monitor conditions in an area of special interest (e.g., near the Pribilof Islands [Yoshida and Baba 1985b; Baba et al. 1988]), then transect lines obviously should be located in that area regardless of possible surrounding concentration points.

The number of surveys needed also depends on the objectives. Ribic and Bledsoe $(1986,1990)$ produced some sample size estimates based on a specific definition of a transect for estimating density of floating debris. The study did not consider stratification because of insufficient information. Because previous information indicated that debris was sparse in the open ocean, estimates of sample sizes needed were large (and probably impractical on a large scale) based on the nonparametric approach of Burnham et al. (1980).

Given the constraints of open-water surveys done on vessels of opportunity, the typical sampling design is a series of systematic transects made along the vessel track with the number of transects determined by the number of observers and sighting conditions. Even with a dedicated cruise, logistical constraints will usually preclude a completely randomized design. For large oceanic areas, a systematic survey design would be the alternative in most cases, as seen in the design of many NOAA National Marine Fisheries Service surveys (Rice and Wolman 1982; Bakkala and Wakabayashi 1985).

\section{Analytical Procedures}

Burnham et al. (1980) give detailed procedures for analyzing line transect data, including an available computer program named TRANSECT. Most researchers used strip transect estimates even when line transect information was collected (Dahlberg and Day 1985; Mio and Takehama 1988). For the sighting function model used in line transect estimation, both Nasu and Hiramatsu (1990) and Mio et al. (1990) used a hazard rate model that was developed for whale sighting surveys. 
For a strip transect, density $(\hat{D})$ (number $/ \mathrm{km}^{2}$ ) is estimated by

$$
\hat{D}=\frac{n}{2 L w}
$$

where

$$
\begin{aligned}
n= & \text { number of objects counted, } \\
L= & \text { total length of all the transects } \\
& (\mathrm{km}), \text { and } \\
w= & 1 / 2 \text { the width of the strip transect } \\
& (\mathrm{km}) .
\end{aligned}
$$

For a line transect, density $\hat{D}$ (number $\left./ \mathrm{km}^{2}\right)$ is estimated by

$$
\hat{D}=\frac{n \hat{f}(0, \theta)}{2 L}
$$

where $\hat{f}(0, \theta)=$ the estimated probability distribution function at zero distance (based on the function $\hat{f}(x, 0)$ fit to the perpendicular sighting distances) (units are $1 / \mathrm{km}$ ), $n=$ number of objects counted, $L=$ total length of all the transects $(\mathrm{km})$.

Each individual transect can be used to estimate the variance of $\hat{D}$ :

$$
\hat{\operatorname{Var}}(\hat{D})=\frac{\sum_{i=1}^{R} 1_{i}\left(\hat{D}_{i}-\hat{D}\right)^{2}}{L(R-1)}
$$

where $\hat{D}_{i}=$ density estimate for transect $i$ (number/ $\mathrm{km}^{2}$ ),

$l_{i}=$ length of transect $i(\mathrm{~km})$,

$R=$ total number of transects, and

$L=$ total length of all the transects $(\mathrm{km})$.

See Burnham et al. (1980) for further details.

Exploratory data analysis can be done to compare densities between areas or latitude/longitude bins.
Confidence intervals can be calculated (Burnham et al. 1980). Testing hypotheses regarding density estimates between areas and between years can be done with a variety of parametric and nonparametric statistical methods. Avoid combining data sets from different areas when observations from each area were made in different years because area differences will not be distinguishable from yearly differences. Analysis of the data set depends on the objectives of the study, and a statistician should be consulted.

\section{Summary}

- Density of marine debris is the preferred field measurement.

- Strip and line transect methodologies are available for density estimation. More discussion is necessary before the preferred methodology can be chosen for marine debris surveys.

- At least two observers should be used.

- Debris should be sighted by visual observation; binoculars should be used to identify or verify item classification and to estimate distances.

- Cost considerations make dedicated surveys for baseline studies unlikely. Vessels of opportunity (see Glossary) are the usual method. Inherent restrictions on the population of interest should be recognized and considered.

- If the same cruise track is resampled over time, temporal trends can be assessed using vessels of opportunity.

- Because of the relative sparseness of debris in the open ocean, large numbers of transects are needed.

- A quality assurance program plan should be developed describing sampling design, field methods, and data analysis.

- A statistician should be consulted at the survey planning stage and should be involved throughout the study. 


\section{Appendix}

The litter at sea survey is designed to produce information on the distribution of all floating, man-made material which can be seen floating on the water from a ship.

The system depends on several factors which will affect its accuracy.

1. How rough is the surface of the sea? Is it too rough to see everything floating? A wind of force 3 or more usually causes too many waves to allow the observer to see everything within a band $100 \mathrm{~m}$ from the side of the ship.

2. The density of floating litter, or how much litter there is in an area can only be measured accurately by 'sampling.' This means that everything seen within a known area should represent the amount of litter floating in an area much larger all around. By 'sampling,' this amount can be estimated from the small area being measured.

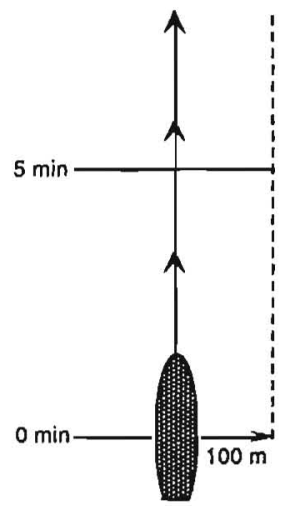

The litter at sea survey works on the following idea:

Record the time every 5 minutes. All items of litter recorded in each 5minute period have been seen in the area shaded. This area is $100 \mathrm{~m}$ wide and 5 minutes long. If the ship's speed is recorded, then this area can be easily worked out. From this the number of litter items $/ \mathrm{km}^{2}$ can be estimated. This figure can then be compared with any other measured anywhere else, if the same method has been used.

\section{WHAT DO I RECORD?}

1. The position of the ship at the start of recording (lat. and long.).

2. The ship's speed in knots.

3. Your height above the water in meters.

4. The approximate wind speed and direction.

5 . The time ever 5 minutes.

6. The ship's position at the end of your recording (lat. and long.).

7. Number of litter items seen within each 5-minute period of time.

8. Identify as closely as you can every item of litter you see. What it is made out of is especially important. If you cannot tell, do not guess!!

9. Can I clearly see the whole of the width of the sampling area. from the side of the ship out to 100 meters?

Note: It is important that only the items of litter seen within the 100 meter band are recorded. Others will make all the results wrong.
Method for Measuring 100 Meters Out from the Side of the Ship Depending on the Height of the Observer Above Water LEVEL

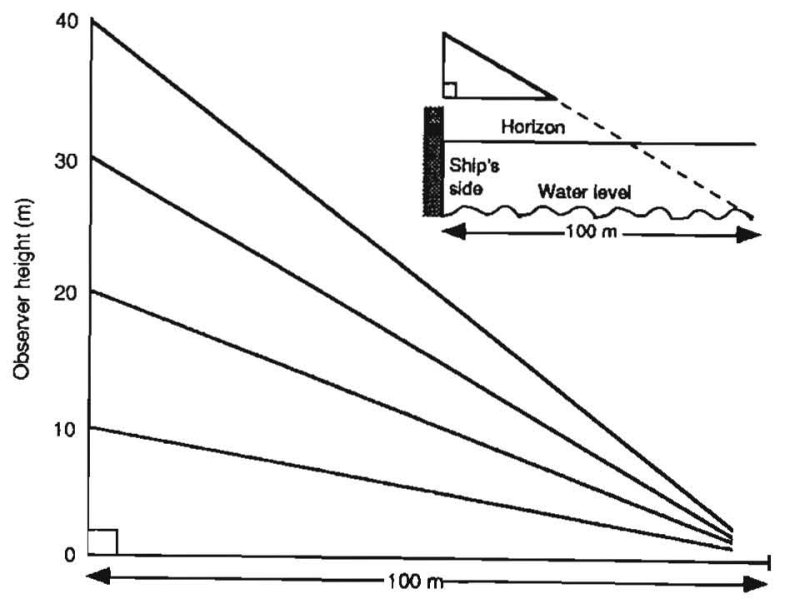

Using the guide above, cut out a paper or cardboard triangle that is at the required angle given for your height above the water. This angle is given by a line drawn between point $\mathrm{A}$ and your height above the water. Keeping the right angle of the triangle towards you, look along the remaining edge of the triangle out from the side of the ship. Where this meets the water, that point will be 100 meters out from the side of the ship.

\section{What Do I Record About the Floatng Litter Seen?}

Any item of floating litter seen within the 100 -meter band can be described, if it cannot be fully identified, e.g.:

1 egg box, polystyrene, undamaged

1 paper cup

1 plastic sheet about 6 feet long and 2 feet wide

2 wooden planks about 3 feet by 2 feet

8 cardboard sections all about 2 feet square and corrugated cardboard

1 plastic container, washing up liquid

If a particular item cannot be identified, then simply record it as one item made of one of the following:

1. wood 6. plastic

2. fishbox 7. polystyrene

3. all paper and 8. metal drums of all sizes cardboard items 9. glass bottles, containers, fishing

4. fishing net floats, etc.

5. rope

As a general rule, items which cannot be described at all should be listed as unidentified. The purpose of the survey is to collect information on the materials making up the litter as well as the number of items seen.

T.J. Dixon 


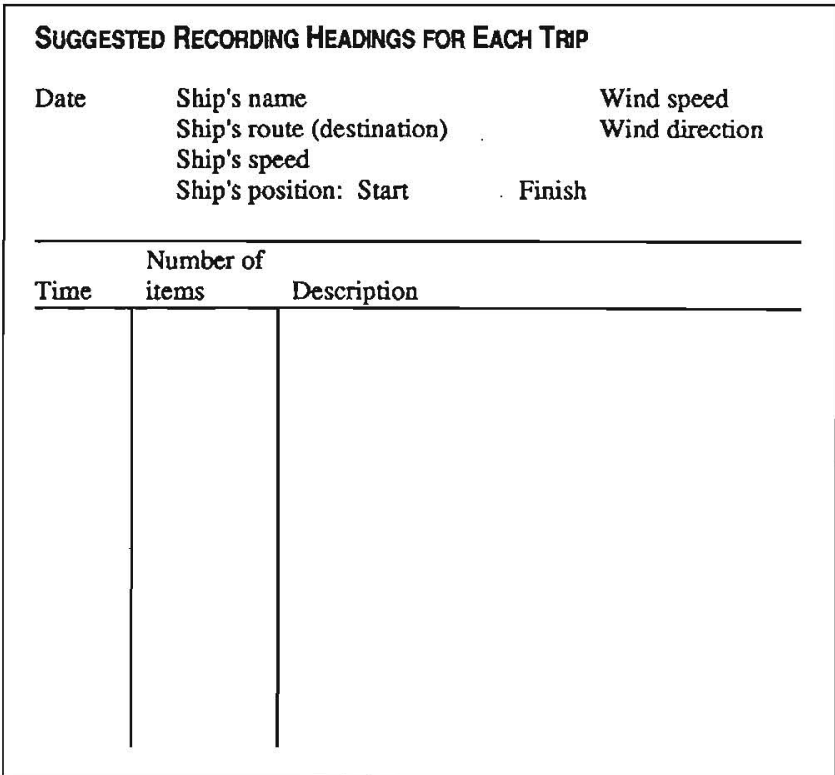

Appendix Figure $\mathbf{A}$ (Continued) 


\section{RECORD OF SHIPBOARD OBSERVATIONS OF DERELICT FISH NETS AND DISABLEMENT OF VESSELS BY MARINE LITTER}

This form should be included in your ship's Marine Mammal Report which is forwarded to: Platforms of Opportunity Proaram, KIML, 7600 Sand Pt. Hay M.E.. Bldg. Seattle. HA 98115 (F/NHC3)

\section{DERELICT NET OBSERVATION:}

NAHE OF VESSEL

LOCATION OF NET (LORAN Or COOrdinates)

DATE

REPORTER (name, adoress, phone)

OESCRIPTION OF NET:

Stretch-mesh size

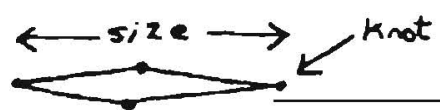

Material (monofil nylon, polyprop, etc.)

Color

Twine diameter

Attached floats (number, description)

Estimated size (length, volume, etc.)

Number and tyne of marine mammals, birds, fish in net

If possible, take photographs and forward small representative.sample of net and floats to above address.

\section{VESSEL DISABLEMENT:}

NAME OF VESSEL

LOCATION OF DISABLEMENT (LORAN Or cOOrdinates)

DATE

CONTACT FOR FURTHER INFCP'LATICN

CAUSE OF OISABLEMENT:

Net Rope

OESCRIPTIOH OF OEBRIS:

Material (monofil nylon, polyprop, etc.)

Color

Size (length, volume, wt., etc.)

Twine dianeter

Floats attached (number, description)

stretch-mesh size

Corrective Action (tow to port, cleared without assistance, divers)

ADD ANY ADDITIOHAL REMARKS ON REVERSE OF THIS FORM.

(MMHL will forward this form to MMFS' Auke Bay Laboratory) 
MARINE MAMMAL SIGHTING FORM

* DO NOT FILL IN BOXES PRECEDED BY AN ASTERISK

1. NAME

VESSEL

RECORD ID *

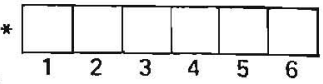

2. DATE (Yr./Mo./Day) \& TIME (local) OF SIGHTING
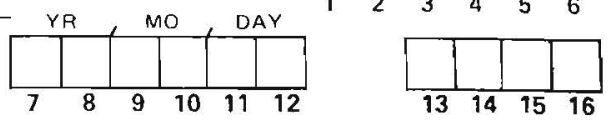

3. LATITUDE (degrees/minutes/10ths)-N/S

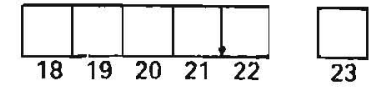

4. LONGITUDE (degrees/minutes/10ths)-E/W

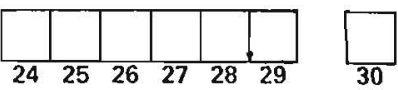

5. SPECIES Common name

Scientific name

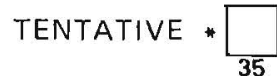

6. NUMBER SIGHTED

$\pm$

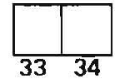

C.I. *
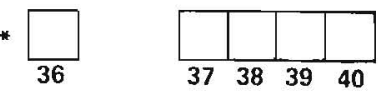

7. BEHAVIOR

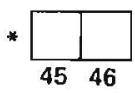

8. ANGLE FROM BOW (10's of degrees)

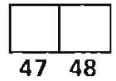

9. INITIAL SIGHTING DISTANCE

10 's of meters

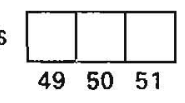

10. VISIBILITY

11. SEA STATE (Beaufort)

12. VIS CODE

13. WEATHER

14. SEA SURFACE TEMP $\left({ }^{\circ} \mathrm{C}\right)$
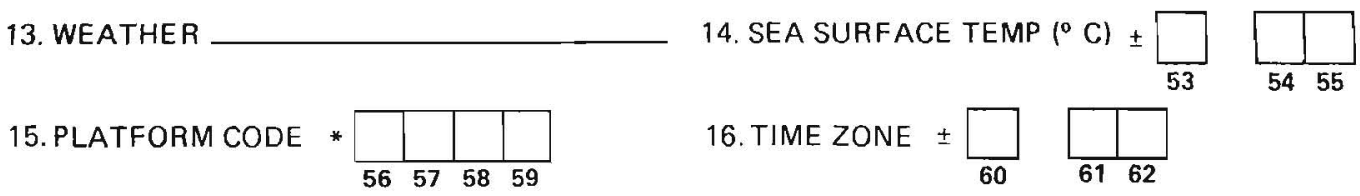

16. TIME ZONE
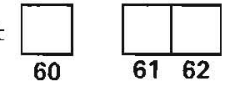

17. How did you identify animal(s)? Sketch and describe animal; associated organisms; behavior (include closest approach); comments.

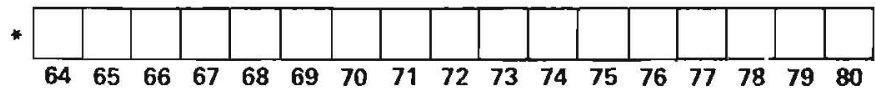





\section{Chapter 3}

\section{Shipboard Trawling Surveys For Small Debris Items}

\section{General Description}

To sample floating small (and some medium) debris from a moving vessel, a surface sampler (e.g., neuston net) is pulled along the sea surface to collect debris. The lowest size of the small debris sampled depends on mesh of the net used. The upper limits of medium debris sampled depend on the size of the opening (mouth). The density of debris is calculated, and the distribution of the debris is mapped.

Most studies of small floating debris have been conducted in conjunction with large surveys of fish larvae or plankton; such surveys typically cover large oceanic areas (e.g., North Atlantic-Colton et al. 1974; southeastern continental shelf and slope water of the United States-van Dolah et al. 1980; sea surface off the southwestern Cape Province of South Africa-Ryan 1988b). Some surveys have been made in harbors and bays (Trulli et al. 1990; U.S. EPA 1990b; Yukinawa and Mio 1990). Most, if not all, of the studies to date concerning floating small debris would be considered to be baseline studies (see Table 6 for sources).

\section{Objectives and Purpose}

Typical objectives are as follows:

1. Estimate types and quantities of small debris,

2. determine distribution of small debris, and

3. assess changes in the types and amounts of small debris in given areas over time.

\section{Population of Interest}

As with sighting surveys, various types of debris in a large oceanic area are usually the populations of interest. The population of interest can be as small as the floating debris in harbors (Trulli et al. 1990; U.S. EPA 1990b; Yukinawa and Mio 1990) and as large as floating debris in coastal and oceanic waters between Cape Cod and the Caribbean Sea (Colton et al. 1974). While smaller areas can usually be surveyed easily, surveys of large oceanic areas are more prob- lematical. In this case, small debris surveys are typically conducted in conjunction with other oceanographic surveys (i.e., vessels of opportunity). Restrictions to the population of interest can arise. For example, in studies done in conjunction with large surveys of fish larvae, the areas chosen and the survey design used are appropriate for the objectives of the fish larvae survey, and not necessarily for the debris survey. Whether or not a restriction of the population of interest exists and whether or not it is significant in relation to the objectives of the debris survey have to be evaluated on a case-by-case basis.

\section{Field Measurement}

The number, type, density, and weight of small debris in a strip transect are common variables of interest.

\section{Description}

A surface sampler (e.g., a neuston net) is deployed by 1 or 2 people to sample the surface water while the ship is moving at speeds usually $<5$ knots. The net is placed on a boom so that it can sample water surfaces outside the ship's wake, either to the side of the ship or forward of the bow. The vessels used by a harbor studies program are shown in Figure 4. The amount of time the net is sampling (or alternately, not sampling) is calculated by one person watching the net during the tow. The net may be equipped with a flowmeter to measure the volume of water sampled directly (Carpenter 1976), although debris may foul the flowmeter, causing it to fail. The width of the strip is determined by the width of the opening (mouth) of the net used (Table 6). Length of the transect is the straight-line distance traveled, determined by the ship's speed during the transect and duration of tow. Lengths of transects from previous studies varied from $0.065 \mathrm{nmi}$ to $13 \mathrm{nmi}$ (Table 6). In areas of high debris density, lengths will be shorter because the net can be towed only until it is full. Longer tows are typically made in areas of low debris density; short tows (e.g., 2 min in length) may miss 


\section{A OSV Peter W. Anderson}

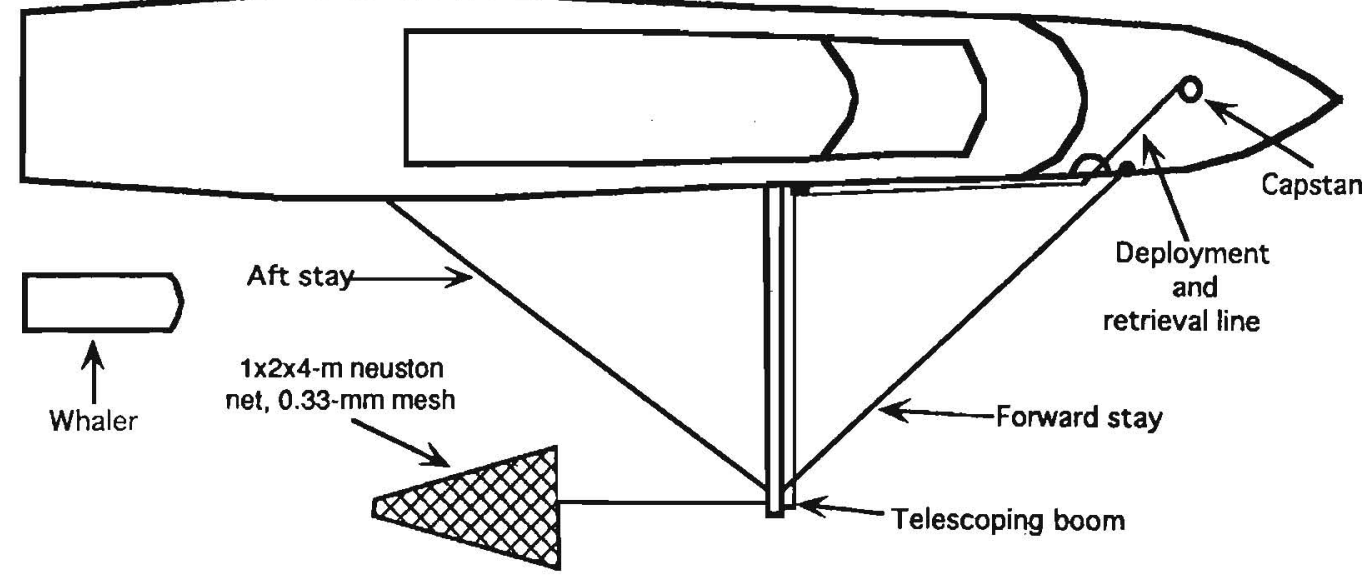

B

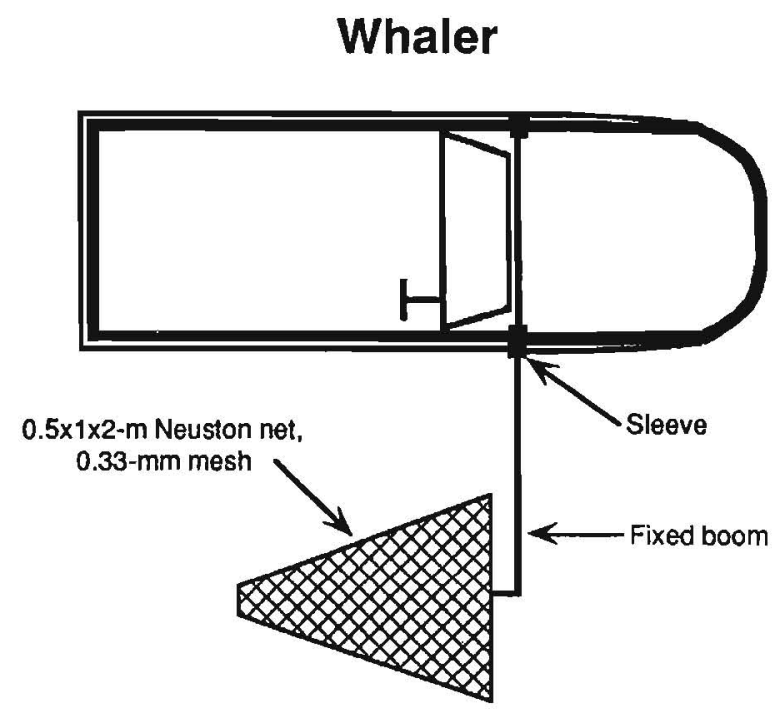

Figure 4

Example of sampling vessel equipped with telescoping boom (from the U.S. Environmental Protection Agency [1990b]). the small debris entirely. The size of debris sampled is determined by the mesh size of the net (Table 6). Larger mesh sizes do not collect all of the smallestsized debris.

\section{Variables to Consider}

Weather-If the sea is too choppy, tows should not be made because the net will be submerged or be completely out of the water, and it will not sample the surface waters. In addition, debris may become resuspended in the water column below the level of the net. Tows should not be made in strong winds because the net will sail out of the water.

Net mesh-The size of debris collected by the surface sampler depends on the size of the net mesh. Ultimately, the particular debris of interest will influence the net mesh size. Carpenter (1976) and the U.S. EPA (1990b) recommend using a net mesh of 0.333 $\mathrm{mm}$ to sample polystyrene spherules. We therefore recommend that $0.333-\mathrm{mm}$ mesh net be used in most cases because it will catch most sizes of small debris.

Ship's Speed-Most tows are made at speeds of 5 knots or less (Table 6), although some larger mesh nets may be used at speeds up to 7 knots. The ship 
Table 6

Examples of nets used to sample floating small debris.

\begin{tabular}{|c|c|c|c|c|}
\hline Reference & Net & $\begin{array}{l}\text { Net } \\
\text { mesh }\end{array}$ & $\begin{array}{l}\text { Description } \\
\text { of tow }\end{array}$ & $\begin{array}{l}\text { Length of } \\
\text { tow (nmi) }\end{array}$ \\
\hline $\begin{array}{l}\text { Austin and Stoop- } \\
\text { Glas (1977) }\end{array}$ & $3 / 4$ opening plankton net & $\begin{array}{l}\text { Not } \\
\text { stated }\end{array}$ & $\begin{array}{l}\text { 5-min surface } \\
\text { tow }\end{array}$ & Not stated \\
\hline $\begin{array}{l}\text { Environmental } \\
\text { Protection Agency } \\
\text { (1990b); Trulli et al. } \\
(1990)\end{array}$ & $\begin{array}{l}\text { Neuston-type net with dimensions: } \\
1 \times 2 \times 4 \mathrm{~m}, 0.5 \times 1 \times 4 \mathrm{~m}, 0.5 \times 1 \times \\
2 \mathrm{~m}\end{array}$ & $0.33 \mathrm{~m}$ & $\begin{array}{l}30 \text {-min tow at } \\
2 \text { knots }\end{array}$ & $\begin{array}{l}\text { Variable } \\
\text { depending } \\
\text { on slick } \\
\text { size and } \\
\text { debris } \\
\text { density }\end{array}$ \\
\hline Carpenter et al. & $\begin{array}{l}\text { Oblique plantkton tows with } 0.5-\mathrm{m} \\
\text { diameter at mouth }\end{array}$ & $0.333 \mathrm{~mm}$ & Not stated & Not stated \\
\hline $\begin{array}{l}\text { Carpenter and } \\
\text { Smith (1972) }\end{array}$ & l-m diameter neuston net & $0.33 \mathrm{~mm}$ & $\begin{array}{l}30-\mathrm{min} . \text { to } \\
6-1 / 2-\mathrm{hr} \text { tows } \\
\text { at } 2 \text { knots }\end{array}$ & $1-3$ \\
\hline Colton et al. (1974) & $2 \times 1 \mathrm{~m}$ rectangular neuston net & $0.947 \mathrm{~mm}$ & $\begin{array}{l}10 \text {-min, tow at } \\
5 \text { knots }\end{array}$ & 0.83 \\
\hline $\begin{array}{l}\text { Day and Shaw } \\
(1987)\end{array}$ & $\begin{array}{l}\text { Ring net ( } 1.3-\mathrm{m} \text { mouth diameter, } \\
4.5-\mathrm{m} \text { length) }\end{array}$ & $0.333 \mathrm{~mm}$ & $\begin{array}{l}10-\mathrm{min} \text { tow at } \\
5.6 \mathrm{~km} / \mathrm{h}\end{array}$ & Q.50 \\
\hline Day et al. (1990b) & $\begin{array}{l}\text { Sameoto neuston sampler: } 0.5 \mathrm{~m} \\
\text { wide } \times 0.3 \mathrm{~m} \text { high } \times 0.6 \mathrm{~m} \text { long }\end{array}$ & $0.500 \mathrm{~mm}$ & $\begin{array}{l}10 \text {-min tow at } \\
2 \text { knots }\end{array}$ & 0.33 \\
\hline FAO (1989) & No details given & $1.4 \mathrm{~cm}$ & $\begin{array}{l}20 \text {-min tow at } \\
2.5-3 \text { knots }\end{array}$ & $0.83-1$ \\
\hline $\begin{array}{l}\text { Gregory et al. } \\
\text { (1984) }\end{array}$ & $\begin{array}{l}\text { Sameoto and Jarozynski aluminum- } \\
\text { framed otter-style neuston net }(60-\mathrm{cm} \\
\text { wide mouth), } 0.860 \mathrm{~mm} \text { or } \\
0.475 \mathrm{~mm} \text { net mesh }(40 \mathrm{~cm} \times \\
40 \mathrm{~cm} \text { or } 60 \mathrm{~cm} \times 40 \mathrm{~cm})\end{array}$ & $\begin{array}{l}0.475 \\
0.860 \mathrm{~mm}\end{array}$ & $\begin{array}{l}\sim 1-\text { hr tow at } \\
4-6-1 / 2 \text { knots }\end{array}$ & $4-6.5$ \\
\hline Morris (1980a) & Neuston sledge & $0.32 \mathrm{~mm}$ & $\begin{array}{l}20 \text { to } 45-\mathrm{min} \\
\text { tows at } 2-4 \\
\text { knots }\end{array}$ & $0.67-3$ \\
\hline $\begin{array}{l}\text { Morris and Hamilton } \\
(1974)\end{array}$ & Lowestoft plankton sampler & $0.270 \mathrm{~mm}$ & Not stated & Not stated \\
\hline Ryan (1988a) & $\begin{array}{l}1.57 \mathrm{~m} \times 0.42 \mathrm{~m} \text { rectangular } \\
\text { neuston net }\end{array}$ & $0.90 \mathrm{~mm}$ & $\begin{array}{l}2-\min \text { tow } \\
\text { at } 1 \mathrm{~m} / \mathrm{sec}\end{array}$ & 0.65 \\
\hline Shaw (1977) & $\begin{array}{l}\text { Sameoto and Jarozynski seston } \\
\text { tow: } 0.4 \mathrm{~m} \text { wide mouth }\end{array}$ & $0.363 \mathrm{~mm}$ & $\begin{array}{l}15 \text {-min tow } \\
\text { at } 4 \text { knots }\end{array}$ & 1 \\
\hline $\begin{array}{l}\text { Shaw and Mapes } \\
\text { (1979) }\end{array}$ & $\begin{array}{l}\text { Sameoto and Jarozynski seston } \\
\text { tow }\end{array}$ & $0.363 \mathrm{~mm}$ & $1 \mathrm{nmi}$ & 1 \\
\hline $\begin{array}{l}\text { van Dolah et al. } \\
(1980)\end{array}$ & $1 \mathrm{~m} \times 2 \mathrm{~m}$ Boothbay neuston net & $0.947 \mathrm{~mm}$ & $\begin{array}{l}10-\mathrm{min} \text { tow at } \\
2.5 \mathrm{~m} / \mathrm{sec} \text { or } \\
15-\mathrm{min} \text { tow at } \\
1.8 \mathrm{~m} / \mathrm{sec}\end{array}$ & $0.84-0.87$ \\
\hline
\end{tabular}




\begin{tabular}{|c|c|c|c|c|}
\hline \multicolumn{5}{|c|}{ Table 6 (continued) } \\
\hline Reference & Net & $\begin{array}{l}\text { Net } \\
\text { mesh }\end{array}$ & $\begin{array}{l}\text { Description } \\
\text { of tow }\end{array}$ & $\begin{array}{l}\text { Length of } \\
\text { tow (nmi) }\end{array}$ \\
\hline $\begin{array}{l}\text { Yukinawa and Mio } \\
\text { (1990) }\end{array}$ & $\begin{array}{l}\text { Ring net with } 1.4 \mathrm{~m} \text { diameter } \\
\text { mouth }\end{array}$ & $\begin{array}{l}1.7 \mathrm{~mm} \text { at } \\
\text { mouth, } \\
0.5 \mathrm{~mm} \\
\text { at cod end }\end{array}$ & $\begin{array}{l}10 \text { min at } \\
3 \text { knots }\end{array}$ & 0.5 \\
\hline Wilber (1987) & $1 \times 0.5 \mathrm{~m}$ neuston net & $\begin{array}{l}0.333 \\
0.500 \mathrm{~mm}\end{array}$ & $1 \mathrm{nmi}$ & 1 \\
\hline Wong et al. (1974) & $\begin{array}{l}80 \mathrm{~cm} \times 30.5 \mathrm{~cm} \text { Kohl scientific } \\
\text { model neuston net }\end{array}$ & $0.150 \mathrm{~mm}$ & $\begin{array}{l}10 \text { to } 15-\mathrm{min} \\
\text { tows at } 4-5 \\
\text { knots }\end{array}$ & $0.67-1.25$ \\
\hline
\end{tabular}

must be going faster than the tide in bays and sounds. For nets with a $0.333-\mathrm{mm}$ mesh, we recommend a towing speed of approximately 2 knots. The duration of the tow depends on the amount of debris in the water; however, a tow should be made for at least $10 \mathrm{~min}$. The duration of the tow also will be influenced by other ship operations and will have to be determined on a case-by-case basis. The speed of the ship should be such that there is no backwash.

\section{Data Collection}

The following information should be recorded each time a sampler is deployed.

- time of day

- location

- date

- volume of water sampled (if the net has a flowmeter) or time the net is not sampling rounded to the nearest $0.25 \mathrm{~min}$ (if net does not have a flowmeter); without a flowmeter, duration of sampling equals duration of tow minus duration of net not sampling

- distance traveled: starting and ending position (latitude/longitude) or duration of transect and ship's speed

- width of sampler (fixed by choice of net)

- sea state and tidal conditions

- presence/size of debris concentrations (if sampled)/current features

Few forms have been published for recording sample collection. Appendix Figure A (this chapter) contains the sample collection form used by the U.S. Environmental Protection Agency (1990b). Figure 5 contains a suggested data form for use with surface sampling, and Figure 6 contains a suggested data form for sorting samples.

\section{Material and Personnel}

Basic equipment needed for sampling small debris is as follows:

- To collect the samples: neuston net (surface sampler) and all equipment needed to deploy the net log forms (sample collection) (see Figure 5)

- To analyze the samples: pre-weighed vials bottles to store samples/labels for the vials trays for sorting and drying samples forceps (to sort samples) magnifying glass (to identify samples) data sheets (for sample analysis) (see Figure 6) gloves 30-L bags for medium debris

No standard surface sampling net is available; Carpenter (1976) describes a variety of nets, although no prices are given. The Sameoto and Jarozynski (1969) net will cost about $\$ 75$ (1991 U.S. dollars), while other neuston nets may cost $\$ 100-\$ 300$ (1991 U.S. dollars) depending on mesh size and type of frame used (Ja Halstead, Research Nets, Inc., Bothell, WA, pers. commun. August 1991). Square-mouthed nets will give a less variable area sampled than ring nets (H. Trulli, Battelle Memorial Institute, Duxbury, MA, pers. commun. January 1991); therefore, squaremouthed nets are preferred over ring nets. Budgeting $\$ 1,500$ for supplies should cover the incidental items. 
Observers:

Ship:

Tow/Sample No.

Starting Location:

Time: Start

Time Not Sampling

Ship's Speed at Start of Tow:

Width of Sampler:

Comments: e.g., (a) unusual weather conditions, (b) problems encountered while sampling.
Date (Yr/Month/Day):

Sea State or Tide:

Ending Location: lat lat long

End Total

Time Sampling

-



Figure 5

Suggested data form for collecting surface samples of small debris.

The major cost of the project is ship time, as discussed in sighting surveys (Chapter 2). For sampling inshore waters and harbors, smaller boats may be used, thus reducing costs as noted in Chapter 2. For example, the U.S. Environmental Protection Agency (1990b) used $5 \mathrm{~m}$ (17 ft) Boston Whaler skiffs in some of the harbor surveys. In all cases, the ship must have a retractable boom for net deployment or must have the capacity for a fixed boom (Figure 4).

Required personnel include researchers who are experienced in or trained in the use of a surface sampler. Training in safety issues is essential, including potential health risks from handling landbased wastes such as hypodermic needles. 


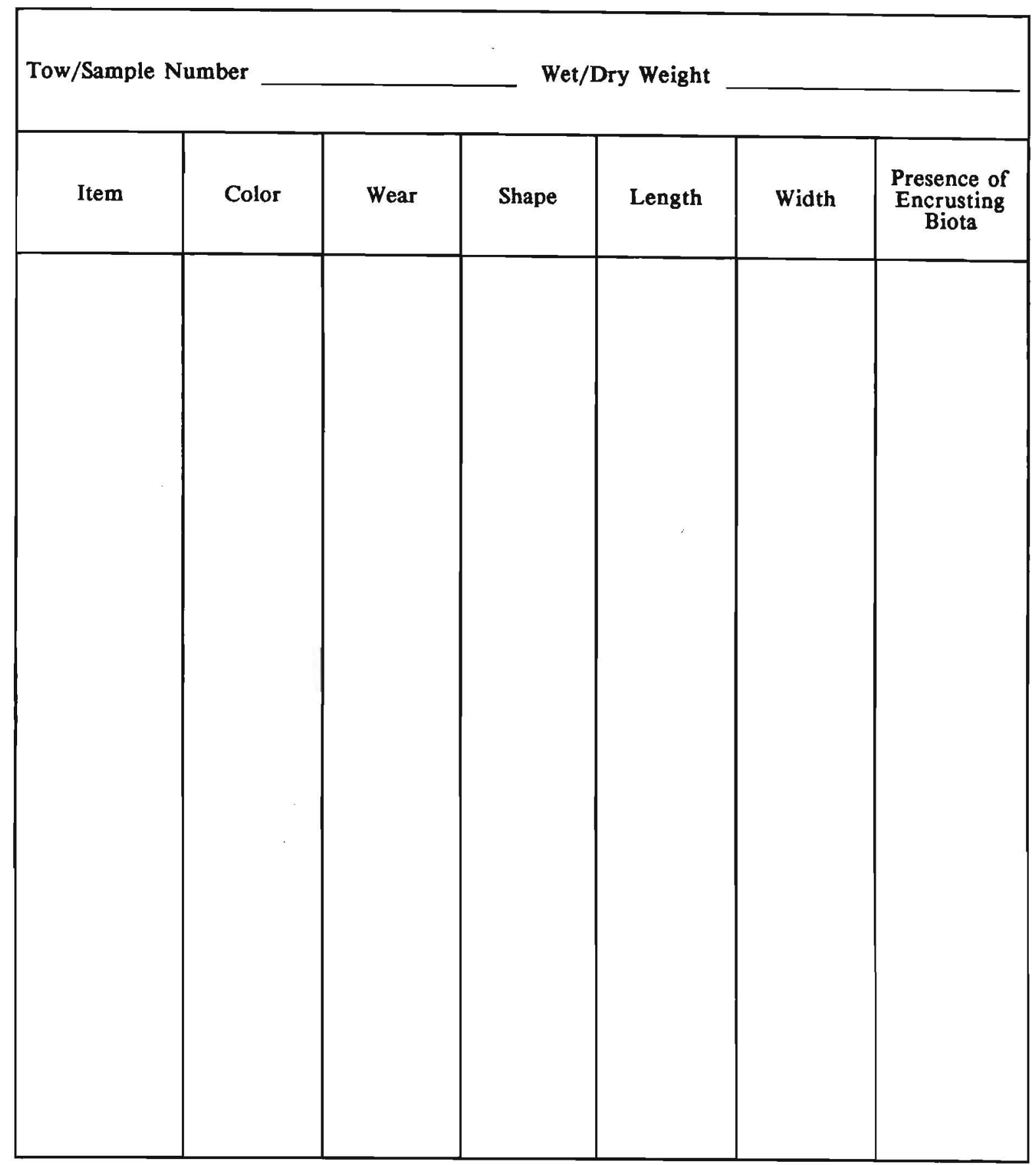

Figure 6

Suggested data form for analysis of surface samples of small debris.

\section{Quality Assurance Program}

Most published papers give enough information to understand how the study was done. Putting the information into a standard format would facilitate comparison between studies. Suggested information in a quality assurance program plan includes the following:
- choice of the population of interest and any restrictions to it

- details on sampling design

- description of sampler including dimensions, mesh size, and net maker

- definition of tow length

- how the tows were carried out (ship's speed, transect duration, net deployment) 
- sorting/handling of materials (sorting and storage), including proper handling of hazardous wastes

- key for identifying material

- storage of material (who is responsible and the location of material)

- data handling (checking and storage of data, sample tracking)

- data analysis procedures

The EPA's Office of Marine and Estuarine Protection has a Standard Operating Procedure for the Collection and At-Sea Processing of Neuston Samples (SOP No. 4-35) (U.S. EPA 1987). We modified this SOP to reflect marine debris. Appendix Figure B (this chapter) contains a suggested SOP potentially applicable to collecting small floating debris.

\section{Field Sampling Designs}

Ribic and Bledsoe $(1986,1990)$ addressed the question of sample sizes for small debris surveys. They assumed that the small debris was randomly distributed in the ocean and was not concentrated in any areas. However, some evidence suggests that debris can be concentrated in certain areas by currents and other oceanographic and weather conditions. Random samples from nonuniformly distributed debris will yield tows with varying amounts of material, and the variance estimate from the tows will be large. Because sample size calculations depend on an estimate of variability, large variance estimates increase the number of required samples, a problem that has been noted by researchers studying tar balls (Butler and Morris 1974). For obvious debris concentrations such as drift lines, Carpenter (1976) recommended sampling perpendicular to the concentration or doing circular transects. An alternative is to collect more samples in the concentrated areas to better define the area of concentration, and then to use declustering techniques (Isaaks and Srivastava 1989) to make an overall assessment. If the objective of the study is just to find out what is in an area to determine types of debris, sampling the concentrations will be useful (e.g., U.S. EPA 1990b).

Because most researchers rarely do both sighting surveys for large debris and surface sampling for small debris (exceptions are Day and Shaw 1987; and Day et al. 1990, a and b), the sampling designs for the two techniques are often considered separately. However, the sampling designs discussed in Chapter 2 for sighting surveys can be used for surface sampling of small debris. Since many of the vessels of opportunity used for small debris sampling were governmental research ships carrying out large-scale fish egg and larvae surveys (Colton et al. 1974; Carpenter et al. 1982; Ryan 1988a), the design used for the small debris surveys was the same as the fish egg and larvae surveys: systematic sampling in a grid. Sampling both large debris and small debris would be possible using a systematic sample on a grid. An important design consideration would be the distance between the sampling stations (i.e., the possibility of sighting the same piece of large debris from two different stations should be zero). But one potential sampling design would be to sample the small debris at the points on the grid and carry out sighting surveys as the ship is in transit between points. A second possibility would be concurrent sampling, which may be possible depending on the amount of debris in the area. For example, if the small debris surface sampler is towed for 1 hour, then sighting surveys may be done concurrently. Alternatively, if the surface tow is only made for $10 \mathrm{~min}$, concurrent sighting surveys would be questionable, particularly if the density of larger debris was low (i.e., few larger debris items would be seen in $10 \mathrm{~min}$ ).

\section{Analytical Procedures}

\section{Handling of Material}

After collecting a sample, most researchers washed it and put it into a bottle for further analysis (see Table 6 for references). A few researchers froze the sample or fixed it in a seawater-formalin mixture or in alcohol (e.g., $70 \%$ ethanol). Preservation is preferable to freezing because freezing may crack the debris, changing its size. The material in each tow was classified as to category and measured. Table 3 (Chapter 1) lists some categories that could be used in sample analysis. We recommend that the material be classified as to color and, if possible, wear. Encrusting biota (which indicate length of time at sea) also should be noted. The material in each tow should be weighed and counted. Most studies have not specified wet or dry weight. We recommend using dry weight measurements, but in all cases investigators should indicate whether wet or dry weights are used. When dry weight was specified, material was dried at room temperature for 1 day (van Dolah et al. 1980) to 1 week (Day et al. 1985). Figure 6 contains a suggested sample analysis form.

\section{Analysis of Data}

Data are transformed into estimates of density (number or weight $/ \mathrm{km}^{2}$ ). The equation for density follows 
the strip transect estimate given in Chapter 2. There are two ways to determine length of the tow $(\mathrm{km})$ :

1. (duration of sampling) (speed of vessel), or

2. straight-line distance between the starting and ending coordinates (adjusted for distance the net was not sampling).

The density of $(\hat{D})$ (amount $/ \mathrm{km}^{2}$ ) is as follows:

$$
\hat{D}=\frac{n}{L w}
$$

where $w=$ width of the mouth of the net $(\mathrm{km})$,

$L=$ total length of all the tows $(\mathrm{km})$, and

$n=$ number or weight $(\mathrm{g})$ of collected debris in all trawls.

The variability of $(\hat{D})$ (Burnham et al. 1980) can be calculated as:

$$
\hat{\operatorname{Var}}(\hat{D})=\frac{\left.\sum_{i=1}^{R} l_{i} \hat{D}_{i}-\hat{D}\right)^{2}}{L(R-1)}
$$

where $l_{i}=$ length of tow $i(\mathrm{~km})$,

$D_{i}=$ density estimate for tow $i$ (in $\mathrm{km} 2$ ),

$R=$ total number of tows, and

$L=$ total length of all the tows $(\mathrm{km})$.

The data can be analyzed in a variety of ways depending on the study objectives. General descriptive statistics (such as percent composition of the debris from each sample or percent composition of all debris from a harbor) are useful as are maps; exploratory data analysis can be used to look at differences between areas and over time. Confidence intervals for the density estimate can be calculated (Burnham et al. 1980) or various hypotheses concerning density can be tested with parametric or nonparametric analyses, depending on the objectives of the study. Data collected from different areas in different years should not be compared because area differences cannot be distinguished from yearly differences. For data collected on a grid, geostatistical techniques may be useful for estimating density over large areas (Isaaks and Srivastava 1989).

\section{Summary}

- Density of small debris (number/weight per $\mathrm{km}^{2}$ ) is the preferred field measurement.

- The mesh of the sampling unit should be 0.333 $\mathrm{mm}$, which will sample most small debris of interest.

- Tows should be made at speeds of 2 knots for at least $10 \mathrm{~min}$. The duration of the tow will be influenced by the amount of debris and ship operations.

- Cost considerations make dedicated surveys for baseline studies unlikely.

- If the restriction to the population of interest is acceptable, vessels of opportunity that sample the same large oceanic area over multiple years should be useful for assessment studies.

- Variability in amounts of debris per tow can be large, thus increasing the required sample size (number of tows) for a given level of confidence.

- The data are collected with a strip transect methodology, with the width of the net defining the width of the strip.

- A quality assurance program plan should be prepared that details sample design, sample collection, sample processing, and data analysis.

- A statistician should be consulted at the survey planning stage and should be involved through the completion of the study. Experienced researchers should be consulted concerning the use of equipment (e.g., surface samplers, boat handling). 
Appendix

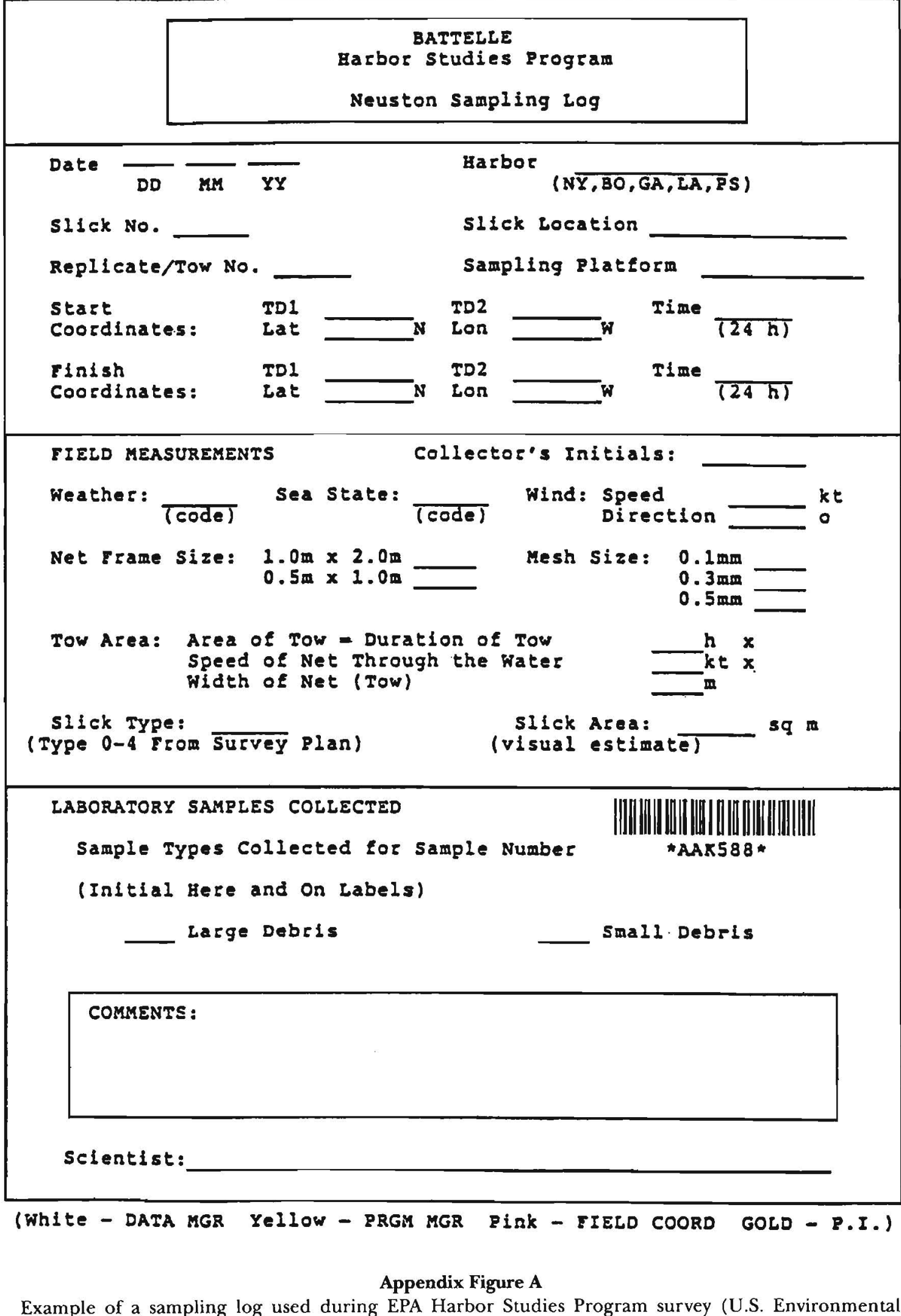
Protection Agency 1990b) 


\section{Preparation}

\section{Supplies and Equipment}

1. Two aluminum neuston net frames, $0.83 \mathrm{~m} \times$ $1.85 \mathrm{~m} \times 0.04 \mathrm{~m}$

2. Two nylon neuston nets, 0.333 -mm mesh size (must fit aluminum frame)

3. Laundry detergent

4. Stainless steel bridle (for each neuston net and frame)
5. Shackles $(0.63 \mathrm{~cm}$ or $1 / 4 \mathrm{in})$

6. Kevlar cable-0.95 cm (3/8 in), or $0.95 \mathrm{~cm}$ $(3 / 8$ in) nylon line

7. Nylon braided line $(0.32 \mathrm{~cm}$ or $1 / 8 \mathrm{in})$

8. Hose clamps (various sizes)

9. Plastic jar (1 L)

10. Sorting trays

11. Forceps

12. Squirt bottles (for rinsing nets)

13. Clear tape

14. Labels

15. Log sheets

16. Cod-end bottle (i.e., $500 \mathrm{ml}$ teflon) (also called a "net bucket")
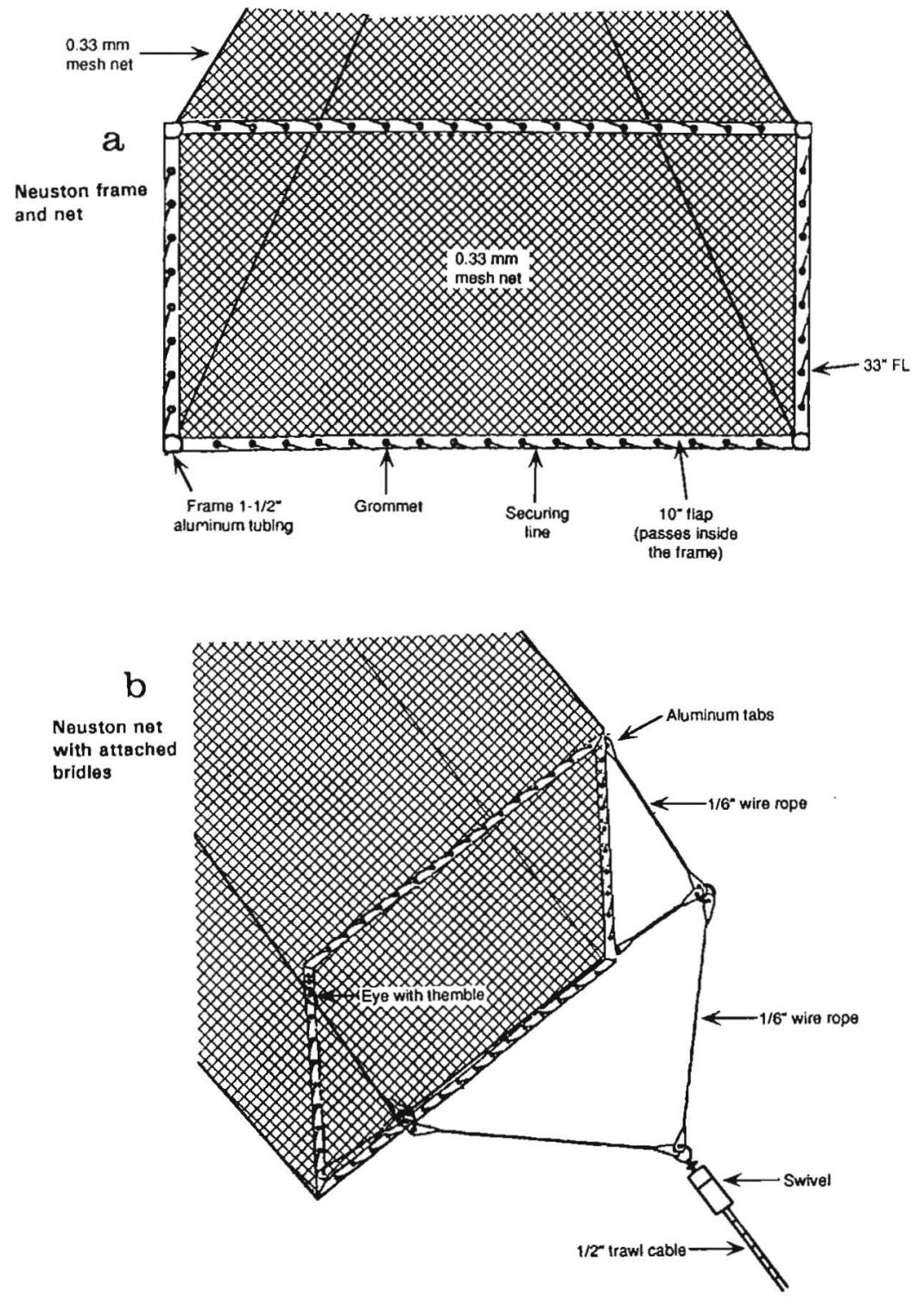

Appendix Figure B

Preliminary standard operations procedures for sampling surface small debris. Adapted from the plan described in the U.S. Environmental Protection Agency (1990b) Harbor Studies Program. 
The registered trademarks and materials suppliers are referenced for reader convenience in replicating experiments and do not represent endorsement by the U.S. Environmental Protection Agency.

\section{Cleaning}

No special cleaning procedures are required for collecting neuston samples for small debris analysis. Equipment can be washed with detergent at the end of the sampling period. Netting may also be solvent-cleaned if soiled with grease or tar.

\section{Assembly of Net and Frame}

1. Match each pair of the four flaps bordered with grommets at the mouth of the neuston net $(2$ opposed flaps $=0.9 \mathrm{~m}$ and 2 opposed flaps $=1.9 \mathrm{~m}$ ) with the appropriate sides of the neuston frame as shown in Figure a.

2. By threading the $0.32 \mathrm{~cm}(1 / 8$ in) braid through the grommets and around the frame, secure the flaps of the net to the aluminum frame. Ensure that the frame attaches to the outer surface of the net flaps. The net passes through the frame as shown in Figure a.

3. After securing the net to the frame, remove the two $0.63 \mathrm{~cm}(1 / 4 \mathrm{in})$ stainless steel bridles (Fig. b) from the case.

4. Arrange the two towing bridles so that the longest cables (one for each bridle) are directed away from the net and so that the short cables (two for each bridle) are directed toward the net.

5. With $0.63 \mathrm{~cm}(1 / 4 \mathrm{in})$ shackles, connect the two short cables of each bridle to the aluminum tabs provided on each corner of the neuston net. Shackle the short cables of one bridle to the left side of the frame and the short cables of the other bridle to the right side of the frame.

6. With a $0.63 \mathrm{~cm}(1 / 4 \mathrm{in})$ shackle, connect the free ends of the bridles together (if not already done).

7. With a stainless steel hose clamp, attach a 1-L precleaned glass jar to the cod end of the nylon neuston net.

8. With $0.79 \mathrm{~cm}(5 / 16 \mathrm{in})$ cable clamps and thimbles, terminate each end of the $45 \mathrm{~m}$ (150 ft) section of Kevlar cable or nylon line with an eye splice.

9. With a $0.79 \mathrm{~cm}(5 / 16$ in) shackle, attach one end of the Kevlar cable to the $0.63 \mathrm{~cm}(1 / 4$ in) shackle that joins the two bridles.

\section{Preparations for Deploying the Net and Components to be Used for Collecting Samples}

1. Request that the Captain slow the ship to towing speed ( 2 knots) before arriving on station.

2. Rig the main towing sheave to the last segment of the telescoping boom.

3. Carry the assembled net, bridle, and tow cable (or nylon line) to the area of deployment.

4. Thread the tow cable or nylon line through the sheave mounted on the boom.

5. Take up the slack (by hand) and tie off the tow cable (or nylon line) to the bits, forward of the deployment area.

\section{Net Deployment}

1. With the boom fully extended, signal the winch operator to lower the boom over the side of the ship. This procedure will lower the net into the water and extend it well beyond the wake of the ship.

2. After the boom has been completely lowered, deploy the Kevlar or nylon tow cable until half of the neuston frame $(0.42 \mathrm{~m})$ remains submerged below the surface of the ocean.

3. Inform the bridge to mark the time for the start of the neuston tow.

4. Record the requested information on a Neuston Sample Log form.

5. Tow the net for 10 -min at a speed of 2 knots or until full. In rough seas, estimate the time the net completely leaves the water or completely submerges while being towed.

\section{Net Retrieval}

At the end of the $10 \mathrm{~min}$ towing period, retrieve the net using the tow cable (or line).

\section{Processing Samples}

1. Discard all water retained in the jar at the cod end of the net. 
2. Loosen the hose clamp that secures the cod end to the net.

3. Support the cod end of the net over a tray and separate the cod end from the net.

4. Empty the contents of the jar and net into the tray. Larger material may have to be removed from the mouth end because it cannot pass through the cod end.

5. Rinse all net surfaces into the tray.

6. Transfer contents of the net into prelabeled jars (l L) or bags.

7. Precautions:

a. Small and lightweight items are easily lost in windy conditions and extra care must be taken.

b. Rubber gloves and protective clothing should be worn because of possible diseasebearing debris (e.g., from combined sewer overflow systems).

\section{Documentation and Labeling}

Record all required information on a Neuston Sample Log. If, during a neuston tow, it becomes necessary to alter the procedures outlined in the SOP or to deviate from the guidelines appearing in the quality assurance program plan, make sure that a Sample Alteration Form (U.S. EPA 1990b) is completed for that particular tow.

\section{Training}

All personnel responsible for the collection and preservation of samples must perform satisfactorily under the direct supervision of a qualified supervisor. This includes the proper implementation of safety guidelines.

The proficiency of the trainee will be observed throughout the entire survey. The supervisor will judge the ability of the trainee to process debris samples. 


\section{Chapter 4}

\section{Beach Surveys \\ for Small to Large Debris Items}

\section{General Description}

On-land or beach surveys can be classified into two types: 1) where debris on a particular beach is of intrinsic interest (beach-focused studies); and 2) where debris on the beach is an indicator of oceanic conditions (ocean-focused studies) (Ribic and Johnson 1990). Beach surveys are known to give a distorted picture of the composition of marine debris owing to different fates of materials at sea (Dixon and Dixon 1981a). To date, no attempts have been made to assess what proportion of debris discharged from ships at sea later washes ashore. Some surface drift experiments using plastic and glass bottles (i.e., the release of bottles at sea and their recovery on land) have achieved high recovery rates in the North Sea (Dixon and Cooke 1977). Beach surveys integrated with at-sea surveys are a potentially powerful tool.

To assess marine debris on a beach, surveyors count and classify individual debris items or record them as present or absent. Debris may or may not be removed from the beaches depending on study objectives. Entire beaches or smaller sections (transects) may be surveyed. Individual pieces of small debris are usually counted within randomly placed or predetermined transects; small debris generally is not removed.

This chapter addresses both beach-focused and ocean-focused studies considering vessel-source debris and landbased debris. New international and national disposal restrictions have increased interest in using ocean-focused studies to detect changes in vessel-source debris on beaches. Therefore, additional attention is given to the use of beach surveys to monitor vessel-source debris. This will be done by presenting two case studies using beach surveys to detect changes in vessel-source debris. The first is a program developed by Theodore Merrell and Scott Johnson (NOAA, National Marine Fisheries Service, Auke Bay, Alaska) to study very large debris (i.e., trawl web net fragments). The second is the program developed by the Tidy Britain Group in England to study large debris (i.e., plastic containers). The developers of the two programs have published extensively on their study designs and methods, and their results have been used in this chapter for recommendations and guidance. Information from these two programs is summarized here because much of the written material is difficult to acquire (e.g., government reports) and spans some 20 years. For people planning a survey, this information can aid in project development, show how initial study designs are influenced by the debris types, and explain how programs may change over time.

\section{Objectives and Purpose}

There are two general objectives of on-land (beach) surveys for marine debris:

1. To determine the types and amounts of debris on beaches in a specified geographical area at a certain time. This objective is generally associated with baseline studies and is beach-focused.

2. To determine how types and amounts (or both) of debris on beaches change over time. This objective is associated with assessment studies (usually trend assessment), and can consider vessel-source debris or specific landbased debris such as sewage items and medical wastes (i.e., ocean-focused studies).

These two objectives require different field designs, as noted by the Assessment Working Group (Ribic 1990). For the first objective, standard survey sampling techniques can be applied (Gilbert 1987). For the second objective, the Assessment Working Group (Ribic 1990) recommended that selected beaches be monitored over time. The selection of the beaches for monitoring should be guided by statistical sampling techniques such as stratification and randomness (Gilbert 1987). This is similar to a timeseries approach used in water quality monitoring (Lettenmaier 1978).

\section{Population of Interest}

For baseline, beach-focused studies, the population of interest is all or some subset of debris on all the beaches in a defined geographic area at a particular 
time. Debris can be landbased or vessel-source. Restrictions to the population of interest are generally due to access problems (e.g., private beaches, remote areas). Consideration of how debris types or amounts may be different on the restricted beaches compared to the unrestricted beaches is necessary to decide if problems will occur. For trend assessment, ocean-focused studies, the population of interest is the amount of marine debris in an unspecified area of the adjoining water mass that is swept onto beaches after a certain time interval. Vessel-source or specific landbased debris on beaches is being used as an indicator of the oceanic debris condition. The degree to which beach debris reflects marine debris conditions in the open water is not commonly evaluated. For both types of studies, beach dynamics, such as deposition rates and current influences, need to be understood.

\section{Historical Information}

\section{Baseline Studies}

Because baseline studies focus on beaches, information on the numbers and types of beaches in the population of interest is necessary. Other variables such as distance to urban centers, coastal dumps and landfills, recreational centers (e.g., campgrounds), and other debris sources would be useful to identify possible stratification variables to be used in study design and to help in interpreting the data. Previous records of types of debris may be useful in determining whether the majority of debris is landbased or vessel-source.

\section{Trend Assessment Studies}

Many studies have commented on factors that restrict the choice of beaches when the objective is trend assessment. The debris of interest may be either vessel-source debris or landbased debris (specifically sewage-related items or medical waste).

To use beach surveys as indicators of oceanic conditions, indicator beaches must meet the following conditions:

1. have known oceanic influences (e.g., currents running past or converging in the area) or be open to the marine environment (e.g., not sheltered by a breakwater, island, or land promontory). Oceanic influences may be documented from recent hydrographic studies, such as surface drift experiments;

2. collect vessel-source debris (due to physical characteristics of the beach, such as substrate type and slope); and

3. be remote from populated areas (urban sources of pollution, recreation areas) and estuarine areas (e.g., no known or limited landbased sources of debris), unless methods are available for clearly identifying each source of debris.

Information on oceanic current patterns and vessel traffic information (Requirement 1) can be used to identify beaches that are more likely than others to collect vessel-source debris. Information on currents is often used after a study has been done to interpret the results.

If fulfilling the third requirement is impossible, some a priori decision must be made about differentiating between vessel-source and landbased debris. For example, O'Hara (1989) used indicator items such as galley wastes, fishing/boating gear, and other characteristic operational wastes for vessel-source debris information. The Food and Agricultural Organization (FAO 1989) decided that metal and glass debris are probably landbased because, given their weight, they likely would sink soon after being discharged from ships. However, on the shores of the North Sea, it was clear that metal and glass did wash ashore from ships (Dixon and Dixon 1981). Furthermore, metal and glass containers were found to be prominent components of ships' garbage (Horsman 1982). Any approaches and assumptions made to distinguish landbased and vessel-source debris should be described explicitly.

The conditions for using beaches to indicate landbased marine debris are the same as the first two conditions for vessel-source debris indicator beaches. Oceanic influences will be important to predict which areas of the coast may be vulnerable to landbased debris (e.g., landbased debris coming from harbors, river mouths, or offshore dumping areas). This information would be directly relevant as a stratifying variable for the survey design. The potential beaches to be used for landbased marine debris do not have the remoteness condition necessary for vessel-source debris indicator beaches (Condition 3 ). Since landbased debris is generated by humans in populated areas, the potential beaches should not be isolated from areas of known human influence, such as urban sources (e.g., sewage and industrial outfalls, harbors) or estuaries. The potential indicator beaches must collect landbased debris, so variables 
affecting the choice of beaches would be the same for both types of surveys.

Variables to consider when doing beach surveys are the physical characteristics of the beach (slope, substrate, composition, uniformity), prevailing weather factors (onshore winds, frequency of storms), beach accessibility (private, public; roads and parking nearby), and composition of debris on beach (landbased and vessel-source categories). The physical characteristics and accessibility of beaches influence the number of potential beaches that can be used for sampling. For example, beaches with low or very steep gradients, or beaches consisting of boulders, should not be candidates for sampling. Low-gradient beaches are especially unsuitable because storm winds and surf scatter debris inland, where it becomes hidden in vegetation. Boulder as well as bedrock beaches also are unsuitable: debris between boulders is difficult to see; bedrock beaches are often too steep for walking and do not accumulate debris. In the United States, preferred beaches for marine debris surveys have moderate-to-steep slopes, have sand or gravel substrate, and are exposed to the open ocean. In addition, beaches should not be cleaned during annual "beach cleanups" (unless the beach cleanup matches the sampling frequency of the planned study).

Physical characteristics of beaches affect debris turnover time (i.e., the rate of disappearance of debris from the beach), which is important for determining sampling frequency, especially when measuring standing stock. For frequent sampling, weather factors influence the timing of sampling (e.g., sampling should not be done during periods of offshore winds or during storms). Beach accessibility is important because private beaches usually have restricted access; beaches in remote areas, as in Alaska, may be prohibitively expensive to reach regularly. Debris composition will affect what is measured (standing stock or accumulation rate) as well as what the sampling unit should be (e.g., the entire beach or transects). Sampling multiple high tide lines over a reasonably narrow beach profile is ideal for getting a good sample of the debris composition in a sampling unit.

\section{Field Measurement}

Two basic variables can be measured: accumulation rate and standing stock. A choice must be made between the two because both cannot be measured on the same sampling unit.
Accumulation rate is the amount of debris that washes and stays ashore on the sampling unit over a certain time period. In order to measure this, the sampling unit must be cleared of all debris at the start of the sampling time period. This variable is actually the accumulation rate of visible materials. Many items become buried on beaches soon after deposition, particularly the heavier items. In an ideal situation, observations should be made daily in order to produce the most accurate data.

Standing stock is the amount of material on the sampling unit at a given point in time. In general, the sampling unit is not cleared of debris (this is discussed further under Field Sampling Designs).

In some surveys, the variable that was measured was unclear (FAO 1989). This becomes an important consideration because of the increased popularity of beach cleanups (CEE 1987b, 1988; O'Hara and Debenham 1989; O'Hara and Younger 1990). Beaches with a cleanup history will only be suitable for measuring accumulation rate since the last cleanup.

For small debris, standing stock usually is measured because of the difficulty involved in removing such items from the sampling unit. Accumulation rates are more easily measured for larger debris. Accumulation rate is the preferred measurement variable, particularly for trend assessment studies, because it will be more sensitive to changing oceanic conditions (see Golik [1982] for discussion in relation to tar balls).

Choices must be made concerning what particular debris items to study. In some cases, focusing on a particular debris type will be as informative as enumerating all debris types. This is particularly important for ocean-focused studies where studying a known vessel-source or landbased debris type is important. Fishing gear such as trawl web (e.g., Merrell 1985) and plastic containers (e.g., Dixon and Cooke 1977) have been successfully used in ocean-focused, vessel-source debris studies. The advantage of studying plastic containers is that they can be aged by codes molded into the plastic body. Also, in some cases, origin can be identified by codes on the container. Information on manufacturing dates and country of origin can help in assessing changing accumulation rates.

\section{Material and Personnel}

Following is a list of suggested basic equipment for an on-land (beach) survey. 
- Metric measurement tapes

- Metric ruler

- Stakes, flagging tape, PVC (polyvinyl chloride) pipe

- Topographical map

- Tags and paint for marking very large debris

- Waterproof data forms and clipboard

- Random number table or calculator with random number generator

- Knife/scissors

- Heavy work gloves

- Small and large garbage bags

- Scales: Spring scales of three sizes are adequate

- Jars with labels

- Camera and film

- Prismatic compass

A budget of $\$ 500-1,000$ should cover the basic equipment.

At least two trained people should participate in each survey; one to process debris and the other to record data. The alternative is to use one person to process debris and record the data into a tape recorder. In Alaska, $\$ 25,000$ per year is the total budget for beach surveys run by the National Marine Fisheries Service Auke Bay Laboratory (S. Johnson, NMFS Auke Bay Laboratory, AK, pers. commun. April 1991). That budget allows two people to carry out a total of 10 surveys on two or three islands in southeast Alaska.

The major expenses of landbased surveys will be transportation to remote sites and personnel expenses (including salary, lodging, and meals). The use of volunteers to collect data will reduce person- nel costs, but more supervision and training will be necessary to ensure quality of collected data. Beach surveys are considerably less costly than open-water sighting surveys.

\section{Data Collection}

Suggested information to collect includes the following:

1. Date

2. Time (start and end)

3. Location

4. Weather conditions

5. List of debris items by type and number (see Appendix Figures A-D [this chapter])

6. Volume or approximate weight of large objects

7. Containers-geographical origins, bottlemaker imprints

8. Beach conditions (slope, substrate, etc.)

The specific data to collect will depend on the objectives of the beach survey. Most studies list all debris items and then, during the data analysis phase, put the debris items into function or material-type categories or both. Some studies focusing on indicator items or particular problems (e.g., entanglement) may list the debris categories before the data are collected. Some general categories used by researchers were listed in Table 2 (Chapter 1). Few researchers had defined landbased and vessel-source debris categories a priori.

Examples of forms used to collect data are in Appendix Figures, A-D (this chapter). Because of the differences in survey objectives, no generic form can be suggested for all studies. Figure 7 contains a suggested template that can be adapted for specific objectives. As noted in Chapter 1, we recommend the approach used by the Center for Marine Conservation whereby subcategories describing function/ manufactured use are grouped under a set of material-type categories.

\section{Pilot Studies}

Many of the factors listed in the third guideline (Historical Information) are often not known before a study starts. But if the study is long-term, this information is necessary to determine a successful design. Some information, such as location of dumping sites, may be available from governmental agencies or universities, but other information may not. Pilot studies will be important if nothing is known about the oceanographic influences to the beaches as well as 
Observers:

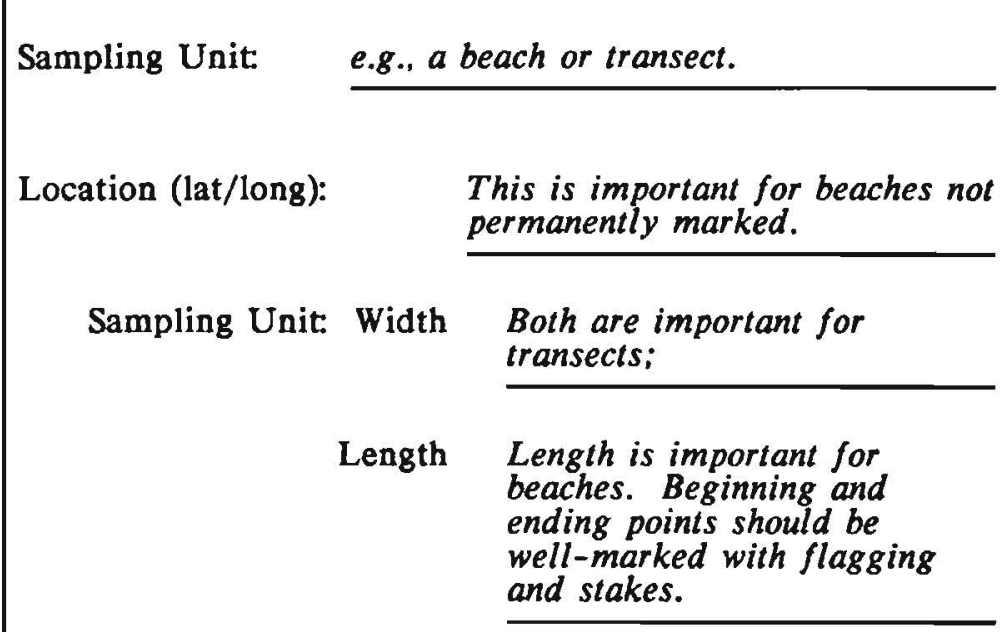

Date: Year/Month/Date

Time: $\quad$ Start

End

Tide:

Weather:

Beach Condition: Slope

Substrate

Comments:

\begin{tabular}{|c|c|c|c|}
\hline Item & Number & Weight & Dimensions (length/width) \\
\hline $\begin{array}{l}\text { This can either be a } \\
\text { list like that of the } \\
\text { Center for Marine } \\
\text { Conservation (1991) } \\
\text { and Cole et al. } \\
\text { (1990) or just } \\
\text { general categories } \\
\text { like those of FAO } \\
\text { (1989). [See forms } \\
\text { in Appendix } 4 \text { ] }\end{array}$ & & & \\
\hline
\end{tabular}

Figure 7

Suggested template for beach survey forms.

beach characteristics. For example, Johnson (1989) marked trawl net fragments to investigate seasonal turnover rates on Alaska beaches. As another example, the Tidy Britain Group measured turnover rate (shore retention rate) of containers by marking plastic and glass bottles. Pilot studies will be necessary to develop techniques to differentiate between vessel-source and landbased debris for specific geographical areas, particularly if plastic containers are the debris type of interest (Dixon and Cooke 1977). 


\section{Quality Assurance Program}

Information concerning quality assurance program plans for beach surveys is scarce. For studies in which data are collected by volunteers, a training session to guarantee the quality of the data is imperative. Common problems with data collected by volunteers are an overrepresentation of plastic and an underestimation of vessel-source debris (T. Dixon, unpubl. data). Merrell's (1985) detailed beach survey is the closest thing to instructions for a quality assurance program plan that has been published to date.

Generally, the following details should be included in a quality assurance program plan for on-land surveys: objective of study; choice of population of interest and any restrictions; choice of debris items to be studied; details of the sampling design; definition of the sampling unit; sample size calculations; how sampling units are chosen; how sampling units are marked (if permanent units); how surveys are carried out in detail; how data are recorded, stored, and checked for errors; and how analyses are performed.

\section{Field Sampling Designs}

Beach surveys have been developed featuring many different objectives and field sampling designs. Key features of selected studies are listed in Table 7. Few surveys have been designed for trend assessment (Merrell 1985, FAO 1989, Cole et al. 1990). The field designs for three trend assessment studies are presented in Table 8.

Differences in field sampling designs are attributable to differences in objectives and the types of debris common to the areas. Merrell (1985) empha-

Table 7

Key features of selected beach surveys for marine debris.

\begin{tabular}{|c|c|c|c|c|c|}
\hline \multirow[b]{2}{*}{ Reference } & \multirow[b]{2}{*}{ Purpose } & \multirow[b]{2}{*}{ Variable } & \multicolumn{2}{|c|}{ Sampling } & \multirow[b]{2}{*}{ Notes } \\
\hline & & & Unit & Interval & \\
\hline $\begin{array}{l}\text { Vauk and } \\
\text { Schrey (1987) }\end{array}$ & $\begin{array}{l}\text { (1) Characterize debris } \\
\text { on beach; (2) Use as } \\
\text { an indication of } \\
\text { problems at sea }\end{array}$ & $\begin{array}{l}\text { Accumulation } \\
\text { rate }\end{array}$ & $\begin{array}{l}60 \text {-m length } \\
\text { of beach } \\
\text { (high tide } \\
\text { line) }\end{array}$ & $\begin{array}{l}\text { Every } \\
3 \text { days }\end{array}$ & $\begin{array}{l}\text { Sandy beach; } \\
\text { area not used for } \\
\text { recreation; wind } \\
\text { direction monitored. }\end{array}$ \\
\hline $\begin{array}{l}\text { Willoughby } \\
(1986)\end{array}$ & $\begin{array}{l}\text { Characterize litter on } \\
\text { islands }\end{array}$ & $\begin{array}{l}\text { Standing } \\
\text { stock }\end{array}$ & $\begin{array}{l}50 \mathrm{~m} \text { of } \\
\text { high tide } \\
\text { line }\end{array}$ & Once & $\begin{array}{l}\text { Systematic sampling } \\
\text { of entire high } \\
\text { tide line of } \\
\text { representative islands } \\
\text { in archipelago: } \\
50-250 \mathrm{~m} \text { between transects. }\end{array}$ \\
\hline $\begin{array}{l}\text { Cole et al. } \\
(1990) ; \text { Manski } \\
\text { et al. (1991) }\end{array}$ & $\begin{array}{l}\text { (1) Characterize debris } \\
\text { on beaches; ( } 2 \text { ) monitor } \\
\text { at-sea debris }\end{array}$ & $\begin{array}{l}\text { Standing } \\
\text { stock in some } \\
\text { areas; accu- } \\
\text { mulation rate } \\
\text { in others }\end{array}$ & $\begin{array}{l}3-5 \text { sections } \\
\text { at } 100-1000 \\
m \text { of } 42 \\
\text { beaches in } \\
8 \text { parks }\end{array}$ & $\begin{array}{l}3-4 \\
\text { times a } \\
\text { year }\end{array}$ & $\begin{array}{l}\text { Variable substrate; } \\
\text { recreational use; } \\
\text { different debris } \\
\text { types recorded }\end{array}$ \\
\hline Merrell (1985) & $\begin{array}{l}\text { Monitor for entangling } \\
\text { debris }\end{array}$ & $\begin{array}{l}\text { Standing } \\
\text { stock }\end{array}$ & $\begin{array}{l}\text { 1) beaches } \\
\text { (1 km each) } \\
\text { surveyed }\end{array}$ & Annually & $\begin{array}{l}\text { Beaches remote } \\
\text { from populated } \\
\text { areas; sand and } \\
\text { boulder/cobble } \\
\text { substrate, moderate } \\
\text { to steep slopes }\end{array}$ \\
\hline $\begin{array}{l}\text { Henderson et } \\
\text { al. (1987); } \\
\text { Henderson } \\
\text { (1988) }\end{array}$ & $\begin{array}{l}\text { Characterize fishing net } \\
\text { washed ashore on } \\
\text { beaches }\end{array}$ & Not stated & $\begin{array}{l}\text { All beaches } \\
\text { on six atolls }\end{array}$ & $\begin{array}{l}\text { Regularly } \\
\text { patrolled }\end{array}$ & \\
\hline $\begin{array}{l}\text { Manville II } \\
(1990)\end{array}$ & $\begin{array}{l}\text { Characterize plastic } \\
\text { debris }\end{array}$ & $\begin{array}{l}\text { Standing } \\
\text { stock }\end{array}$ & 25 beaches & Once & $\begin{array}{l}\text { Surveys opportunistic, } \\
\text { beaches randomly } \\
\text { chosen; outer Aleutian } \\
\text { Islands surveyed }\end{array}$ \\
\hline
\end{tabular}


Table 7 (continued)

\begin{tabular}{|c|c|c|c|c|c|}
\hline \multirow[b]{2}{*}{ Reference } & \multirow[b]{2}{*}{ Purpose } & \multirow[b]{2}{*}{ Variable } & \multicolumn{2}{|c|}{ Sampling } & \multirow[b]{2}{*}{ Notes } \\
\hline & & & Unit & Interval & \\
\hline $\begin{array}{l}\text { Duronslet et al. } \\
\text { (1991) }\end{array}$ & $\begin{array}{l}\text { Document types and } \\
\text { amounts of man-made } \\
\text { debris }\end{array}$ & $\begin{array}{l}\text { Standing } \\
\text { stock in } \\
\text { some areas; } \\
\text { accumulation } \\
\text { rate in others }\end{array}$ & $\begin{array}{l}3-4 \text { transects } \\
3.3 \text { m wide in } \\
6 \text { zones }\end{array}$ & Monthly & $\begin{array}{l}\text { Part of a study } \\
\text { dealing with strandings } \\
\text { of sea turtles; some } \\
\text { transects randomly } \\
\text { chosen; other, fixed; } \\
\text { length was variable, } \\
\text { depending on } \\
\text { first storm line and } \\
\text { tide stage }\end{array}$ \\
\hline FAO (1989) & $\begin{array}{l}\text { Pilot monitoring } \\
\text { program for marine- } \\
\text { based litter }\end{array}$ & $\begin{array}{l}\text { Standing } \\
\text { stock in } 4 \text { of } \\
5 \text { countries; } \\
\text { accumulation } \\
\text { rate in } 1 \text { of } 5 \\
\text { countries }\end{array}$ & $\begin{array}{l}1-6 \text { beaches } \\
\text { in } 5 \text { coun- } \\
\text { tries; } 2-11 \\
\text { transects per } \\
\text { beach; } 1-\text { to } \\
100 \text {-m wide } \\
\text { transects }\end{array}$ & $\begin{array}{l}\text { Monthly } \\
\text { in } 4 \text { of } 5 \\
\text { countries; } \\
\text { weekly/ } \\
\text { biweekly } \\
\text { in } 1 \text { of } 5 \\
\text { countries }\end{array}$ & $\begin{array}{l}\text { All transects run } \\
\text { from low water line } \\
\text { to back end of } \\
\text { beach; substrate } \\
\text { variable; varying } \\
\text { recreational use; } \\
\text { choice of beaches } \\
\text { restricted by funding } \\
\text { and availability of } \\
\text { labs to carry out } \\
\text { monitoring }\end{array}$ \\
\hline $\begin{array}{l}\text { Lindstedt and } \\
\text { Holmes (1989) }\end{array}$ & $\begin{array}{l}\text { Characterize debris } \\
\text { on beaches }\end{array}$ & $\begin{array}{l}\text { Standing } \\
\text { stock }\end{array}$ & $\begin{array}{l}6 \text { beaches; } \\
3 \text { established } \\
\text { transects; } 50 \\
\mathrm{~m} \text { in length, } \\
10-77 \mathrm{~m} \text { in } \\
\text { width }\end{array}$ & Quarterly & $\begin{array}{l}4 \text { beaches had } \\
\text { high recreational } \\
\text { use; } 2 \text { had low use }\end{array}$ \\
\hline $\begin{array}{l}\text { Gregory et al. } \\
(1984)\end{array}$ & $\begin{array}{l}\text { Characterize debris } \\
\text { on beaches }\end{array}$ & Not stated & $\begin{array}{l}\text { All accessible } \\
\text { beaches and } \\
\text { low rocky } \\
\text { shores } \\
\text { searched }\end{array}$ & $\begin{array}{l}\text { Not } \\
\text { stated }\end{array}$ & \\
\hline $\begin{array}{l}\text { Golik and } \\
\text { Gertner (1990) }\end{array}$ & $\begin{array}{l}\text { 1. Evaluate the quan- } \\
\text { tity of coastal litter, } \\
\text { 2. determine the relation- } \\
\text { ship between beach } \\
\text { morphology or use } \\
\text { and litter, } 3 \text {. identify } \\
\text { litter as landbased or } \\
\text { sea-based }\end{array}$ & $\begin{array}{l}\text { Standing } \\
\text { stock }\end{array}$ & $\begin{array}{l}6 \text { beaches; } \\
5-8 \text { random } \\
\text { transects; } \\
\text { each transect } \\
5 \mathrm{~m} \text { wide, } \\
\text { length from } \\
\text { water line to } \\
\text { back of beach } \\
\text { (start of } \\
\text { vegetation) }\end{array}$ & Monthly & $\begin{array}{l}\text { Counted all litter } \\
\text { greater than } 2 \mathrm{~cm} \text {; } \\
\text { beaches differ in } \\
\text { morphology, substrate, } \\
\text { and use }\end{array}$ \\
\hline $\begin{array}{l}\text { Center for } \\
\text { Environmental } \\
\text { Education } \\
\text { (1988) }\end{array}$ & $\begin{array}{l}\text { Characterize debris on } \\
\text { beaches }\end{array}$ & $\begin{array}{l}\text { Accumulation } \\
\text { rate }\end{array}$ & $\begin{array}{l}\text { Beaches } \\
\text { along Texas } \\
\text { shore }\end{array}$ & $\begin{array}{l}\text { Yearly } \\
\text { (some had } \\
\text { additional } \\
\text { cleanups) }\end{array}$ & $\begin{array}{l}\text { Volunteer program, } \\
\text { return of data cards } \\
\text { is voluntary }\end{array}$ \\
\hline Cundell (1973) & $\begin{array}{l}\text { Determine whether } \\
\text { debris on beaches is } \\
\text { marine-based or } \\
\text { landbased }\end{array}$ & $\begin{array}{l}\text { Accumulation } \\
\text { rate of } \\
\text { plastics }\end{array}$ & I beach & Once & $\begin{array}{l}\text { Beach selected } \\
\text { due to location at } \\
\text { entrance of bay and } \\
\text { its northerly aspect }\end{array}$ \\
\hline
\end{tabular}


Table 7 (continued)

\begin{tabular}{|c|c|c|c|c|c|}
\hline \multirow[b]{2}{*}{ Reference } & \multirow[b]{2}{*}{ Purpose } & \multirow[b]{2}{*}{ Variable } & \multicolumn{2}{|c|}{ Sampling } & \multirow[b]{2}{*}{ Notes } \\
\hline & & & Unit & Interval & \\
\hline $\begin{array}{l}\text { Dixon and } \\
\text { Cooke (1977) }\end{array}$ & $\begin{array}{l}\text { Monitor discarded } \\
\text { plastic containers in } \\
\text { the marine environment }\end{array}$ & $\begin{array}{l}\text { Accumulation } \\
\text { rate }\end{array}$ & $\begin{array}{l}3 \text { sectors } \\
(1.6 \mathrm{~km} \text { ea.) } \\
\text { of shoreline } \\
\text { with } \mathrm{N} / \mathrm{S} \\
\text { orientation }\end{array}$ & $\begin{array}{l}\text { Periods } \\
\text { of on- } \\
\text { shore } \\
\text { winds }\end{array}$ & $\begin{array}{l}\text { Variable beach } \\
\text { types, high fre- } \\
\text { quency of onshore } \\
\text { winds, lack of } \\
\text { human disturbance } \\
\text { during winter months, } \\
\text { in close proximity to } \\
\text { Straits of Dover }\end{array}$ \\
\hline $\begin{array}{l}\text { Slip and Burton } \\
(1990)\end{array}$ & $\begin{array}{l}\text { Identify types and ori- } \\
\text { gins of litter on beaches }\end{array}$ & $\begin{array}{l}\text { Standing } \\
\text { stock }\end{array}$ & $\begin{array}{l}\text { Entire coast- } \\
\text { line }(94 \mathrm{~km}) \text { of } \\
\text { Macquarie } \\
\text { Island }\end{array}$ & Once & $\begin{array}{l}\text { First survey-litter } \\
\text { removed, wooden } \\
\text { objects not included } \\
\text { owing to presence } \\
\text { of old shipwrecks and } \\
\text { past sealing activities }\end{array}$ \\
\hline $\begin{array}{l}\text { Caulton and } \\
\text { Mocogni (1987) }\end{array}$ & Monitor maritime litter & $\begin{array}{l}\text { Standing } \\
\text { stock }\end{array}$ & $\begin{array}{l}300 \mathrm{~m} \text { length } \\
\text { of beach } \\
\text { divided into } \\
\text { three } 100 \mathrm{~m} \\
\text { areas; } 5 \\
\text { parallel-strip } \\
\text { transects, } 1 \mathrm{~m} \\
\text { wide at } 5 \mathrm{~m} \\
\text { intervals for } \\
\text { each area }\end{array}$ & $\begin{array}{l}\text { Systematic; } \\
\text { weekly } \\
\text { for } 6 \\
\text { months }\end{array}$ & $\begin{array}{l}\text { Surveyed just after } \\
\text { high tide; heavy } \\
\text { recreational use }\end{array}$ \\
\hline $\begin{array}{l}\text { Wong et al. } \\
(1976)\end{array}$ & $\begin{array}{l}\text { Baseline measurements } \\
\text { of pollution in marine } \\
\text { environment }\end{array}$ & Not stated & $\begin{array}{l}\text { Selected } \\
\text { stretches of } \\
\text { beach to } \\
\text { collect plastic }\end{array}$ & Annual & \\
\hline $\begin{array}{l}\text { Scott } \\
(1972,1975)\end{array}$ & $\begin{array}{l}\text { Determine whether } \\
\text { plastic debris was land- } \\
\text { based or marine-based }\end{array}$ & $\begin{array}{l}\text { Standing } \\
\text { stock }\end{array}$ & $\begin{array}{l}2 \text { areas } \\
(1-100 \mathrm{yds} \\
1-50 \mathrm{yds})\end{array}$ & $\begin{array}{l}100 \text { yds } \\
\text { once; } 50 \\
\text { yds twice } \\
\text { (3 years } \\
\text { apart) }\end{array}$ & $\begin{array}{l}\text { Used inaccessible } \\
\text { stretches of rocky } \\
\text { shore }\end{array}$ \\
\hline Wilber (1987) & $\begin{array}{l}\text { Monitor amount of } \\
\text { plastic in marine } \\
\text { environment }\end{array}$ & $\begin{array}{l}\text { Standing } \\
\text { stock }\end{array}$ & $\begin{array}{l}30 \mathrm{~cm} \times \\
30 \mathrm{~cm} \\
\text { quadrats }\end{array}$ & $\begin{array}{l}\text { Not } \\
\text { stated }\end{array}$ & \\
\hline $\begin{array}{l}\text { Gregory ( } 1977 \text {, } \\
1978 \text {, a and b, } \\
1983 \text { ) }\end{array}$ & $\begin{array}{l}\text { Monitor amount of } \\
\text { plastic pellets on } \\
\text { beaches }\end{array}$ & $\begin{array}{l}\text { Standing } \\
\text { stock }\end{array}$ & $\begin{array}{l}\text { l-m-wide } \\
\text { transects } \\
\text { along high } \\
\text { tide line }\end{array}$ & $\begin{array}{l}\text { Not } \\
\text { stated }\end{array}$ & \\
\hline $\begin{array}{l}\text { Shiber } \\
(1979,1982)\end{array}$ & $\begin{array}{l}\text { Monitor amount of } \\
\text { plastic pellets on } \\
\text { beaches }\end{array}$ & $\begin{array}{l}\text { Standing } \\
\text { stock }\end{array}$ & $\begin{array}{l}\text { Hand } \\
\text { collections } \\
\text { on multiple } \\
\text { beaches }\end{array}$ & $\begin{array}{l}\text { Not } \\
\text { stated }\end{array}$ & \\
\hline
\end{tabular}

sized very large debris, especially trawl web, which would be difficult to subsample in transects. FAO (1989), however, was interested in medium and large debris; thus, subsampling was used. Because the Tidy Britain Group (see Case Studies, this chapter) was in- terested in plastic containers (large debris), sub- sampling was used along with surveys of the high tide line for plastic containers. Differences in the designs are numerous; Merrell (1985) emphasized the actual field work, FAO (1989) gave more guidance as to sta- 
Table 8

Outline of three field surveys for trend assessment of small to large beach debris items.

Alaska
(Merrell 1985)

$1 \mathrm{~km}$ of beach surveyed from water's edge to seaward limit of terrestrial vegetation at the upper limit of normal high tides. Beach permanently marked and photographed.

Standing stock $(\# / \mathrm{km})$. Count all items greater than $5 \mathrm{~mm}$ in size; tabulate and estimate weights of partially buried net fragments.

Sampling frequency not stated.

Each item is listed.

Recommended log form.

Mediterranean
Sea (FAO 1989)

At least 2 beaches that differ in morphology, sedimentology, and type of use. Beaches should not be regularly cleaned.

Per beach: Ac least 4 transects of 5-m width; each transect randomly chosen. Length of transect: low water line to back end of the beach

Standing stock (\# or weight) meter). Collect and weigh all visible persistent litter greater than $1-2 \mathrm{~cm}$.

Sampling frequency: at least monthly.

Nine categories used.

Recommended log form.
North Sea

(Tidy Britain Group Case Study)
Study site chosen according to following characteristics:

- Typical examples of open coastal locations or relation

to semi-enclosed or oceanic water masses.

- Presence of sandy beaches with shallow slope, welldefined backshore zone, and accumulated debris.

- Surface currents that run toward or parallel to the study site.

- Situated in close proximity to major shipping routes or fishing grounds or both.

Within the area of the population of interest, a minimum of 40 sampling units (beaches) chosen in the following way:

- Divide the area of the population of interest into at least 8 subareas that contain beaches with the required characteristics; the 8 subareas should be distributed throughout the area of the population of interest.

- Within each subarea, identify all potential beaches from maps. Delete beaches that are inaccessible and that have major sources of obviously land-generated debris (camping, bathing areas).

- Randomly select 5 beaches from all the porential beaches.

Per beach: Identify and photograph permanent features Three transects of 5-m randomly chosen. Length of transect: low water line to high water marks plus $30-\mathrm{m}$ into the foredunes of the backshore zone when present. Walk $1 \mathrm{~km}$ parallel to strandline, tabulate all containers, and collect representative specimens.

Standing stock $\left(\mathrm{g} / \mathrm{m}^{2}\right)$. Per transect: Tabulate and weigh all materials $<15 \mathrm{~kg}$, excluding timber or driftwood. Age and note geographical origin and original contents of all containers. Note the distribution of containers along the transect line.

Sampling frequency: Between October and April during or after spells of persistent onshore winds $(>96 \mathrm{~h}$ ) with velocities $>8 \mathrm{~m} / \mathrm{s}$.

Each item listed.

Recommended $\log$ form. tistical details, and the Tidy Britain Group gave extreme detail in choosing beaches. The studies of Merrell (1985) and the Tidy Britain Group are discussed further in the Case Studies portion of this chapter.

The framework proposed by Ribic and Johnson (1990) for developing beach survey sampling designs is recommended with some modifications to address baseline and trend assessment studies (Table 9). This suggested framework can be used for any type of marine debris. Design differences are due to variable study objectives.
Baseline surveys with the objective of estimating the amount of total debris on the beaches of a geographical area at a particular time pose a classical sampling problem. With this objective, a new set of beaches to sample that fit the conditions listed previously should be randomly chosen each time a survey is made. The sample size estimation (i.e., number of beaches to survey) is based on equations taking into account spatial correlation (correlation between beaches). More complicated approaches are available that take into account time and space correlations (Gilbert 1987). 
Table 9

Framework detailing alternative sampling design for beach surveys.

Study design

Objective

Variable

Sampling unit

Field design
Standing stock (mean \#/km)

Beach

Stratified random sampling of beaches:

- Beaches: Appropriate beach topography and morphology, no access restrictions.

- Stratify on amount of debris on the beaches (low, medium, high)

- Number of beaches dependent on variability of debris on beaches, specified precision of estimate, correlation between beaches.

- Cost of survey built into some sample size equations.

\begin{tabular}{|c|c|}
\hline $\begin{array}{l}\text { With subsampling } \\
\text { of beach }\end{array}$ & $\begin{array}{c}\text { Without } \\
\text { subsampling } \\
\text { of beach }\end{array}$ \\
\hline $\begin{array}{l}\text { FAO ( } 1989) \text { : } \\
\text { - At least } 4 \text { randomly } \\
\text { placed transects per } \\
\text { beach. } \\
\text { - Each transect } 5 \text {-m in } \\
\text { width, length is from } \\
\text { water's edge to mean } \\
\text { high tide. }\end{array}$ & $\begin{array}{l}\text { Merrell ( } 1985 \text { ): } \\
\text { - Count all debris on entire } \\
\text { beach from water's edge to } \\
\text { mean high tide line. } \\
\text { Tidy Britain Group Case } \\
\text { Scudy: } \\
\text { - Count all debris on entire } \\
\text { beach from water's edge to } \\
30 \text {-m into vegetation. }\end{array}$ \\
\hline
\end{tabular}

Alternative:

Gregory (1978a): Sample

high tide line; transects:

3-m width, 25-m length

Measure variable of choice (e.g., counts, weights)

Estimate mean, variance, and confidence intervals for standing stock

Generalize to specific geographical area for specified time frame

\section{Trend assessment}

Estimate the trend in the amount of marinebased debris on beaches of a specified area during a specified time period as an indicator of oceanic trends.

Accumulation rate (\#, weight/time interval) or standing stock $(\# / \mathrm{km})$

Beach

Random choice of indicator beaches:

To ensure geographic representation, follow a "stratified" approach (Dixon and Dixon 1981; Ribic 1991.)

- Indicator beaches: accumulators of large amounts of marine-based debris, no access restrictions, appropriate beach topography and morphology.

- Number of beaches and sampling interval depend on detection of specified change over time periods using specified model, also influenced by resource allocation.

$\begin{array}{cc}\text { With } & \text { Without } \\ \text { subsampling } & \text { subsampling } \\ \text { of beach } & \text { of beach }\end{array}$

Golik (1982): Clean entire beach

Systematically placed transects: $100-\mathrm{m}$ in

length, from water's edge to mean high tide line, cleaned of all debris.
Resurvey at established time periods; clean each time; count and weight chosen marine-based debris, age containers

Look at changes over time

Generalize to oceanic conditions

Common survey sampling techniques like stratification (Gilbert 1987) can be used to obtain more precise debris estimates. For example, beaches that have the characteristics defined earlier in this chapter (Historical Information) could be classified as having low, medium, or high amounts of debris. The number of sampling units to survey from each of these categories could be based on the proportion of beaches falling into each of the categories. A discussion of the usefulness of stratification can be found 
in Gilbert (1987). In addition, differences in beach lengths can be accounted for using probability proportional to length of the beach in the choice of survey units.

With trend assessment, individual beaches are monitored over time. Sample frequency per beach will be high, particularly if a time series approach is taken (Ribic 1991). The effects of environmental variables (such as wind, tide, etc.) can be controlled through selection of candidate beaches and sampling period. The actual beaches that would be followed over time would be chosen randomly from the group of candidate beaches. Accumulation rate is the more important variable of interest, though, of course, standing stock can be measured. For medium to very large debris surveys, all debris items can be counted or, alternatively, the survey may focus on certain indicator items. If vessel-source debris is of interest, care must be taken to determine any landbased fraction of such debris. An important difference between sampling large debris and small debris is the use of subsampling; typically, there is too much small and medium debris to count or collect in any reasonable amount of time.

\section{Analytical Procedures}

Caution must be used in comparing sites if standardized field techniques are not used. Debris accumulation rate and standing stock measurements are not comparable; that is, if one study measures the accumulation rate and another measures standing stock, then the two sites cannot be compared. If plastic containers are used as indicators of vessel-source debris, analysis of container ages may directly measure accumulation rate in the marine environment, avoiding the problems of comparing indirect beachbased measures.

To compare accumulation rates between different studies, the sampling frequency must be the same. For example, if one study measures accumulation rate for 3 months and another for 6 months, the results are not comparable. In order to compare the sites, the rates have to be put on the same time scale (e.g., the amount of debris per month). This makes the assumption that the rate of accumulation within the sampling interval is uniform in all the studies (this assumption may not be justified).

In measuring both the accumulation rate and standing stock, it is inappropriate to add together the amounts of debris found at a site during several sampling efforts at short intervals to determine total amount of debris over a longer time interval. As an example, the sum of all debris found during each of four quarterly surveys will not equal the amount found during one annual survey. This is because the amount of debris found on the beach at any one time is the result of the dynamic process of beach deposition, burial, and loss (e.g., a piece of debris washed up on the beach in April may or may not be on the beach in September).

For baseline studies, confidence intervals can be used for comparisons between areas and years. Data are commonly summarized with pie charts and histograms of debris types. For studies where sampling units are randomly chosen, hypotheses can be tested with a variety of nonparametric and parametric tests.

Properly planned trend assessment studies can be analyzed in a time-series framework. Lettenmaier (1978) suggested that monthly samples taken for 5 years will give a minimum sample size for time-series analysis. All the assumptions behind this approach will have to be checked (Brockwell and Davis 1989). An alternative to time-series analysis is the nonparametric analysis for trend (Hirsch et al. 1982; Gilbert 1987). However, for a short time series (on the order of 5 years), these techniques may have low power (Hirsch and Slack 1984). Another alternative is to use a within-subjects analysis of variance model (Keppel 1982) where beaches are the "subjects" and the time period when measurements were taken are the "treatments." Various adjustments can be made for violations of the typical analysis of variance assumptions (Keppel 1982). This is basically the alternative considered by Ribic and Johnson (1990) although they use a randomized block in time design where beaches were blocks. The simplest approacha "before and after" comparison of specific beaches-is also possible (see Case Study: The Tidy Britain Group, this chapter). Because of the potential complications in the analysis of trend assessment data, a statistician should be involved from the onset of planning the study through the analysis stage.

\section{Case Studies}

Two case studies are presented to demonstrate the different ways the marine debris problem can be studied. In both cases, concerns about aesthetics initiated the work. The field survey designs were influenced by geographical variables and the major debris items found in areas. Both studies standardized sampling protocols early on and continued to follow basic protocols throughout the studies. Finally, both studies have changed and refined their objectives as more was learned about their particular problems and as control measures (e.g., MARPOL Annex V) were implemented. 


\begin{tabular}{|c|c|}
\hline & $\begin{array}{c}\text { Table } 10 \\
\text { Outline and chronology for Alaska beach surveys. }\end{array}$ \\
\hline $1972-1974$ & $\begin{array}{l}\text { Surveys started at Amchitka Island during course of an unrelated project } \\
\text { Predominant debris was related to fishing industry } \\
\text { Standardized methodology established (outlined in Table 8) } \\
\text { Standing stock primary variable }\end{array}$ \\
\hline 1974-1980s & Decrease in fishing effort off Alaska \\
\hline 1982 & $\begin{array}{l}\text { Original Amchitka Island beaches resurveyed to assess prediction of decrease in amount of debris on Amchitka } \\
\text { Island } \\
\text { Focus on debris related to fishing industry } \\
\text { Standing stock primary variable }\end{array}$ \\
\hline 1 & \\
\hline Early 1980 s & Entanglement in fishing gear identified as possible causes of northern fur seal decline \\
\hline 1984 & $\begin{array}{l}\text { Seven islands in southeastern Alaska surveyed for entangling debris; prediction is that there is less fishing in } \\
\text { southeastern Alaska and, therefore, there should be less debris } \\
\text { Standing stock primary variable }\end{array}$ \\
\hline \multirow[t]{2}{*}{1985} & $\begin{array}{l}\text { Sampling design emphasizes entangling debris } \\
\text { Two islands of original seven in southeastern Alaska the focus } \\
\text { Aleutian Islands (including Amchitka Island) surveyed }\end{array}$ \\
\hline & $\begin{array}{l}\text { Standing stock still primary variable } \\
\text { Design modified to assess accumulation rate } \\
\text { Beach dynamics of plastic debris investigated }\end{array}$ \\
\hline 1986 & $\begin{array}{l}\text { Focus on two islands in southeastern Alaska } \\
\text { Standing stock and accumulation rate being measured on different beaches } \\
\text { Beach dynamics-emphasis on trawl web }\end{array}$ \\
\hline Mid-1980s & Education efforts begun to discourage disposal of fishing nets in North Pacific \\
\hline \multirow[t]{3}{*}{1989} & $\begin{array}{l}\text { Two islands in southeastern Alaska the focus } \\
\text { First island: surveyed twice, accumulation rate measured } \\
\text { Second island: surveyed annually, standing stock measured }\end{array}$ \\
\hline & Emphasis on trawl web dynamics on second island to assess impact of MARPOL Annex $V$ \\
\hline & MARPOL Annex V enters into force 31 December 1988 \\
\hline
\end{tabular}

\section{Alaska Beach Surveys}

Alaska beach surveys of marine debris are being done by researchers within the National Marine Fisheries Service. The chronology of the Alaska beach survey studies is presented in Table 10. The following information was derived from Merrell (1980, 1984, 1985), Merrell and Johnson (1987), Johnson (1988; 1989; 1990, a and b), and Johnson and Merrell (1988).

The initial work on beach surveys in 1972 was started by Theodore Merrell (NOAA, National Marine Fisheries Service, Auke Bay, AK) on Amchitka Island in the western Aleutian Islands of Alaska. This work was started as an opportunistic study during Merrell's stay on the island for another project. The choice was fortuitous because Amchitka Island is situated in the North Pacific Ocean (one side facing the
Gulf of Alaska, the other the Bering Sea) away from major sources of landbased debris. Most debris proved to be vessel-source (e.g., fishing nets, floats, cargo-related ropes, strapping bands). In the absence of a standard survey methodology, Merrell developed an approach that is still appropriate to this day (see Table 8 and Merrell 1985). The sampling unit was an entire beach because the beaches on Amchitka Island are relatively small and discrete (i.e., bounded by rocky headlands.

In 1984, a temporary shift was made to sample southeast Alaska beaches. Merrell (1985) did not provide the rationale for selecting those beaches; however, they were generally known to collect debris. Because many outer coast beaches in southeast Alaska are steep bedrock and not suitable for debris surveys, the selected southeast Alaska survey beaches 
were among the few beaches with suitable substrate, slope, and access characteristics (S. Johnson, National Marine Fisheries Service, Auke Bay Laboratory, AK, pers. commun. April 1991). In 1985, the emphasis shifted to entanglement debris (fishing nets and strapping bands) as concern increased about the impact of entanglement of marine animals in such debris. In 1985 , focus on trawl web started and, in 1989, the researchers shifted their studies to use trawl web as an indicator of the impact of MARPOL Annex V.

Thus, there has been a change in measurement variables as the survey has evolved. Standing stock (both type and and amount of debris) was of initial interest. Beach dynamics of debris (primarily trawl web) and measurements of accumulation rates have become increasingly important. Studies of the movement and fate of trawl web and other plastics have been conducted by mark-recapture studies. Tagging or removal of trawl web from the beaches is now routine, as is the removal of rope, gillnets, and strapping (S. Johnson, National Marine Fisheries Service, Auke Bay Laboratory, AK, pers. commun. April 1991). In terms of sizes of debris, the surveys emphasized large and very large debris.

During this series of surveys, objectives have been refined and the sampling design, field measurements, and data analyses altered accordingly. Despite refinements, however, the basic field methodology has remained unchanged. The data collection by one person and his training of other surveyors reduced the problems of inter-observer variability and helped insure continuity between studies. This will make comparisons between previous surveys valid. The interest in a specific type of debris-entangling debris-is also a strong point because of the way this interest was used to focus the research.

\section{The Tidy Britain Group}

The following study is based on Dixon and Cooke (1977), Dixon and Dixon (1980, 1981a; 1983), and Dixon and Hawksley (1980).

The Tidy Britain Group is the United Kingdom's national litter abatement agency. It has a broad membership including national and local governmental agencies, industry, commerce, and voluntary organizations. The Group functions primarily as an advisory body, but also offers a wide range of practical programs dealing with litter problems on land, or more recently, at sea.

The Group's approach to deal with litter problems involves tackling two main causes: first, the attitudes and behavior of people towards littering and the environment; and second, the correct and incorrect ways of handling debris and waste. This has been achieved by a series of educational and public involvement programs directed toward the entire community. A chronology of the beach survey studies undertaken by the Tidy Britain Group is presented in Table 11 .

The Tidy Britain Group supports a Marine Litter Research Program as an integral part of its approach towards litter abatement. The Program was established in 1973 in response to numerous complaints about increasing quantities of all types of litter on the United Kingdom's beaches, frequent reports of injuries sustained by bathers owing to encounters with broken glass and sharp pieces of metal, and general dissatisfaction with declining aesthetic conditions of primary bathing beaches.

The Development of Beach Survey Techniques and Analytical Methods for the Surveillance of Marine Litter-In the early 1970s, few references in the literature described systematic studies of marine litter. Consequently, the research program first sought to develop suitable beach survey techniques and analytical methods. Preliminary observations at several locations around the United Kingdom coastline suggested that glass, paperboard, metal, and plastic containers were the main components of marine litter. Plastic containers were therefore selected as the debris type of primary interest. The initial studies had the following objectives:

- Determine the main kinds of containers and their relative abundance;

- identify the range of geographical origins;

- quantify container retention rates on different beach types; and

- assess the persistence of plastic debris in the marine environment.

The initial observations were undertaken on a 4.8 $\mathrm{km}$ stretch of Dover Strait coastline. This was chosen as a long-term reference area because it included a variety of beach types, had a relatively high frequency of onshore winds during all seasons, was in close proximity to major shipping lanes, and recreational boats operated offshore throughout the year. In addition, there was evidence of litter originating from landbased sources, including beach users, sewage outfalls, rivers, and a nearby coastal landfill site.

Use of Comtainers as Indicators - The observations in the reference area suggested that plastic containers were the most common type of debris. They were deposited along high tide lines at a rate up to $80 \mathrm{~km}^{-1}$ $\mathrm{day}^{-1}$, and were therefore suitable indicators, identifying the major sources and subsequent movements of 
Table 11

Chronology for Tidy Britain Group surveys.

Marine Litter Research Programme established in response to apparent increasing quantities of litter on the United
Kingdom's beaches

Purpose-Generate systematic data showing qualitatively and quantitatively the nature and scope of the problem

Primary components of marine debris identified as containers

Single sampling unit chosen as a long-term reference area; it consists of varying beach types, high frequency of onshore winds during all seasons, known high density of shipping operating offshore; also accumulates landbased debris

Containers collected, contents, ages, and manufacturers identified

Retention rates assessed, beach dynamic studies undertaken with mark-recapture experiments

1978-1980 Populacion of interest redefined to a large area; to assess large-scale trends, survey design further developed and reassessed to identify limitations (outlined in Table 8)

MARPOL Annex $\mathrm{V}$ becoming an issue

Field sampling design changed to include the following:

- single subsample per site

- increased container samples

- distribution of containers on beach omitted

1980 on New program to assess impact of MARPOL Annex V

Two studies developed:

1. Source-specific beach debris surveys to detect changes in at-sea waste disposal due to MARPOL Annex V; arranged surveys as "before" and "after" entry into force of the Annex at same sampling units and times of year:

- Emphasis on plastic containers (geographical origin, ages, original contents)

- 185 sampling units (not all fulfill previous substrate requirements)

2. Assessments of the provision and use of reception facilities in ports and marinas for disposal of ships' garbage ashore.

MARPOL Annex $V$ enters into force on 31 December

vessel-source debris. Consequently, technical support networks previously established with packaging and product manufacturers, especially plastic bottle makers, were considerably extended on a global basis. A detailed database was compiled for the most frequently observed containers, incorporating data on packaging histories. The data base continues to be updated regularly.

Beach Type and Litter Assessments-Given the marked relationship between beach form and retention rates of containers found in the reference area, sandy beaches were identified for more detailed observations. Further mark-recapture studies were undertaken, providing a clear understanding of the processes by which materials were removed from the beaches and later deposited elsewhere. Containers and other types of plastic litter were often recovered from the backshore zone, where they had been de- posited by the wind. Glass and metal items, in contrast, were more likely to become buried "in situ," in close proximity to high tide lines, and later exposed by wave action. All types of litter were found mixed with algal materials. Longshore movements by wind, currents, and wave action were also evident, often causing litter to be washed from beaches, transported seawards, and deposited elsewhere.

Optimum Sampling Period and Frequency-An optimum sampling period was apparent for assessing litter originating from sources other than beach users. This period was during or immediately after spells of persistent onshore winds ( $>96 \mathrm{~h}$ ), with velocities $>8 \mathrm{~m} \mathrm{~s}^{-1}$, between October and April. Tidal stage did not affect this optimum sampling period. Daily inspections of foreshore high tide lines and backshore zones enabled collection of accurate data on the types and quantities of deposited litter. 
In contrast, assessments during the remainder of the year, particularly during or at the end of the bathing season, generally identified a small residual proportion of litter deposited earlier. This was composed largely of plastics mixed with the more recent discards of beach users.

Large-Scale Beach Litter Surveys on the Shores of the English Channel, North Sea, and North Atlantic Ocean-Between August 1978 and July 1980, new sampling units were chosen from the beaches of Cherbourg Peninsula, France, west Jutland in Denmark, Portugal, and the Western Isles of Scotland. A total of 170 sampling units were examined.

The goals of this expanded program of beach litter surveys were as follows:

- Assess large-scale trends in the composition, geographical origin, distribution, and persistence of marine debris in the coastal and oceanic waters of western Europe; and

- develop a standardized method for assessing vessel-source debris from beach surveys on the shores of different water masses, and subsequently identify any limitations.

The survey program sought to produce data of sufficient accuracy drawn from a sufficiently large geographical area such that results could alert national authorities and intergovernmental organizations of the consequences to uncontrolled solid waste discharges into the marine environment.

Accordingly, specific survey objectives were as follows:

- Identify the major sources and relative distributions of marine debris in the semi-enclosed and open ocean waters of western Europe;

- assess the persistence of plastics and other types of solid wastes in these waters;

- document the environmental impacts of marine debris;

- adapt the methodologies and techniques developed in earlier pilot studies for use on a larger scale;

- determine the most appropriate statistical methods for analyzing data from large-scale beach debris surveys; and

- improve as possible the survey design including spatial sampling considerations.

To achieve these objectives, the sampling units were selected on the basis of the following biophysical and anthropogenic factors.

- their relative geographical positions on the shores of semi-enclosed and oceanic water masses, as typical examples of open coastal locations
- the presence of sandy beaches, with shallowly inclined beach face gradients and well-defined backshore zones, on which marine debris was known to accumulate in the short term

- exposure to surface currents running towards or parallel with the coastline, and the relatively high frequencies of onshore winds, favoring the stranding of debris

- close proximity to major shipping routes or fishing grounds or both

Careful consideration was given to the spatial distribution of the sampling units throughout the population of interest. However, from a practical viewpoint, the duration of each survey was largely determined by the level of funding available. Therefore, it was decided that a minimum of 40 sampling units should be examined with a team of between two and four observers. A method of multistage stratified random sampling was employed in selecting the sampling units. The selection process is detailed in Table 8.

On arrival at each sampling unit, permanent features or fixed points were identified on or near the shoreline and photographed. The locations of transect lines were fixed using two-digit random numbers (from tables) that represented a linear distance down the beach from the fixed points.

Each survey on a sampling unit lasted between 14 and 18 days following spells of onshore winds; two were completed in March or April, and the remainder in July or August. In the case of the latter surveys, sites where substantial numbers of beach users were likely to congregate were avoided.

At each sampling unit, subsampling was done using three 5-m strip transects established at right angles to the shore using measuring tapes and markers. Each transect extended from the water line across the foreshore to include all visible high tide marks, and an additional distance of up to $30 \mathrm{~m}$ into the foredunes of the backshore zone, when present.

The following data were recorded within each transect.

- total wet weights of the main fabrication materials and the density of all litter in each foreshore transect, excluding items $>15 \mathrm{~kg}$, and timber or driftwood

- frequency, fabrication materials, geographical origins, ages, and original contents of containers

- the distribution of containers within the transects

- the distribution of plastic fragments by their presence or absence in $1 \mathrm{~m}^{2}$ plots along the transect line

More extensive searches beyond the transect boundaries were employed to collect samples of con- 
tainers for dating. For this purpose, at each sampling unit two to four observers walked along the foreshore parallel to high tide lines for a distance of up to 1 $\mathrm{km}$. All containers were examined and samples collected. The procedure was then repeated in the foredunes of the backshore zone of each site.

The Use of Large-scale Litter Surveys in Programs Designed to Assess the Effectiveness of MARPOL Annex V-In anticipation of the expected entry into force of MARPOL Annex V by the mid-1980s, the program strategy was revised. In order of priority, the new program strategy had the following objectives.

- assist in implementing the Annex by raising public awareness of the need to protect the marine environment;

- evaluate the effectiveness of the various regulatory and other measures designed to reduce garbage discharge at sea;

- determine the types and amounts of marine litter entering the marine environment from sources other than ships' discharges.

At the planning stage of this new program, it was recognized that at least two complementary data sets were necessary to fulfill the revised objectives: First, data documenting the availability and use of reception facilities in ports and marinas for the disposal ashore of shipboard generated wastes, notably plastics; second, beach survey data of specific debris types organized in an appropriate time series to document improved waste disposal practices at sea.

In order for a port and marina reception facilities study (which is presently underway) to be supported, a national beach litter survey commenced in 1980 . The aim was to identify any significant long-term changes in the quantities and types of beach litter originating from ships' discharges on varying geographical scales.

Determining the most suitable spatial sampling design was necessary at the outset for comparative purposes. A number of different approaches were considered; for example, "before" and "after" surveys organized separately using different sampling units (where "before" and "after" refers to the date MARPOL Annex $V$ went into effect).

An alternative approach that was chosen was the use of paired observations, "before" and "after," on the same sampling units. This sampling design would control for influences from variables such as beach type or topography, hydrographic features of water masses, and different amenity values of sampling units. Consequently, the following specific survey objectives were identified on regional and national geographical scales:
- Generate statistics to detect any major reductions in the overall quantities or types of litter, notably plastics;

- detect changes in at-sea disposal practices from a detailed study of the container proportion of beach litter; and

- relate the data obtained in the first two objectives to trends in the availability on use of port reception facilities.

The debris in the respective water masses around the coastline of the United Kingdom was the population of interest. One-hundred eighty-five sampling units were chosen using a multi-stage stratified random sampling scheme.

Northeast Atlantic Ocean 66 sampling units in the Western Isles of Scotland and Cornwall

Irish Sea 22 sampling units in Cardigan Bay

North Sea

65 sampling units in northeast Scotland, Cleveland, Yorkshire, Humberside, and Norfolk

English Channel 32 sampling units on the Isle of Wight

The timing and duration of surveys at each sampling unit used the procedures described earlier. The baseline surveys (i.e., before MARPOL Annex V entered into force) were undertaken between 1980 and 1987, usually in March or April, following spells of onshore winds and before the commencement of regular summer beach cleaning operations.

The survey methods were the same as those described previously, with the following exceptions:

- Total debris weight and that of each of the main items were derived from a single transect at each site, and

- observations relating to the distributions of containers and other types of debris across beach faces were omitted.

These minor adjustments were made to increase the number of sampling units that could be surveyed and to ensure the optimum use of resources.

Data on debris weight within transects will be analyzed by comparisons of means (before and after MARPOL Annex $\mathrm{V}$ entered into force), with particular reference to plastic debris categories, and comparisons of spatial distributions and associated relative weight differences will be evaluated based on data collected before and after MARPOL Annex V entered into force. The major parameters used in comparing the container data are listed below. 
- original contents classifications, the common products in the baseline surveys being typical of those used on ships

- geographical origins, with particular reference to changes in the relative proportions of samples that are foreign in origin

- age classes, with an emphasis on changes in distributions following the entry into force of MARPOL Annex V

- varying combinations of the above, analyzed regionally and nationally

The remaining non-container debris observed in transects will be compared on the basis of frequencies of occurrence for each type, notably fishing gear debris. The "after" surveys (surveys made after MARPOL Annex $V$ entered into force) will be completed over the next 5 years, and the results published periodically on a survey-by-survey basis followed by a national review. Reports will be submitted to the appropriate regulatory authorities, governmental departments, and the shipping industry.

No major difficulties have been encountered to date in the organization of surveys or subsequent analysis of data. However, in numerous instances, ideal beaches have not been located and, therefore, other beaches, primarily sand backed by shingle, cobbles, rocks, and cliffs, have been used. In identifying long-term trends, allowances have been made for changes in the patterns and densities of offshore shipping operations.

Following the broad guidelines contained in the revised beach survey program, the future work program will focus primarily upon compliance monitoring in connection with MARPOL 73/78 Annexes III and V, and assessing inputs of debris into the marine environment from sources other than ships. As noted above, an examination of the efficiency and availability of port reception facilities for ships' garbage is already underway, and findings from the beach surveys will be considered with the port reception facility surveys to facilitate an overall appraisal of the effectiveness of the Annex $\mathrm{V}$ regulations.

In spring 1991, an extensive study of packaged dangerous and hazardous goods recovered on beaches commenced. The analysis of the data will generate statistics concerning the efficacy of ship reporting systems for lost cargoes, changes in substance identification markings used on packages, and other aspects of the regulations contained in MARPOL Annex III and the recently revised IMDG (International Maritime Dangerous goods) Code. Provision will also be made within the survey objectives to compile information on medical wastes and other potentially hazardous materials, which are being found in increasing quantities on beaches.

Over the next 3 years, inputs of debris to the marine environment from nonship sources will be examined in more detail. Particular attention will be given to landbased debris, such as sewage items, and the development of suitable methodologies for measuring riverine discharges of debris to the marine environment. In addition, joint studies with local authorities and other interested groups will examine the most effective means of preventing beach users from discarding debris.

\section{Summary}

- There are two types of objectives commonly encountered in beach surveys: 1) baseline (studies documenting types and amount of debris on beaches); and 2) trend assessment (long-term studies to detect changes in overall amounts of specific debris types).

- Different survey designs are necessary to address the two objectives. Remote sites are ideal for trend assessment of vessel-source debris because the source of debris is readily identified as vesselsource.

- Baseline studies with multi-source debris must be able to discriminate between landbased and vessel-source debris. Beaches meeting basic criteria should be randomly chosen each time a survey is made if the focus is on the beach rather than the beach as an indicator of oceanic conditions.

- Trends in oceanic conditions are best assessed by using indicator beaches of interest and measuring the same beaches over time. The indicator beaches are randomly chosen from a list of beaches meeting basic criteria. Indicator items, such as plastic containers or sewage items, can be used to assess accumulation rates and long-term trends in occurrence.

- Well-conceived field sampling designs are imperative in all cases. Studies with multiple and conflicting objectives, if not recognized as such, can cause design problems.

- The cost of a beach survey for trend assessment is generally low compared to directly assessing marine debris conditions in the open water (at-sea programs).

- The two case studies demonstrate different ways of studying the marine debris problem with beach surveys. The case studies illustrate how geography and differences in major marine debris types greatly influenced the study designs.

- A statistician should be consulted at the onset of survey planning and be involved through the completion of the study. 


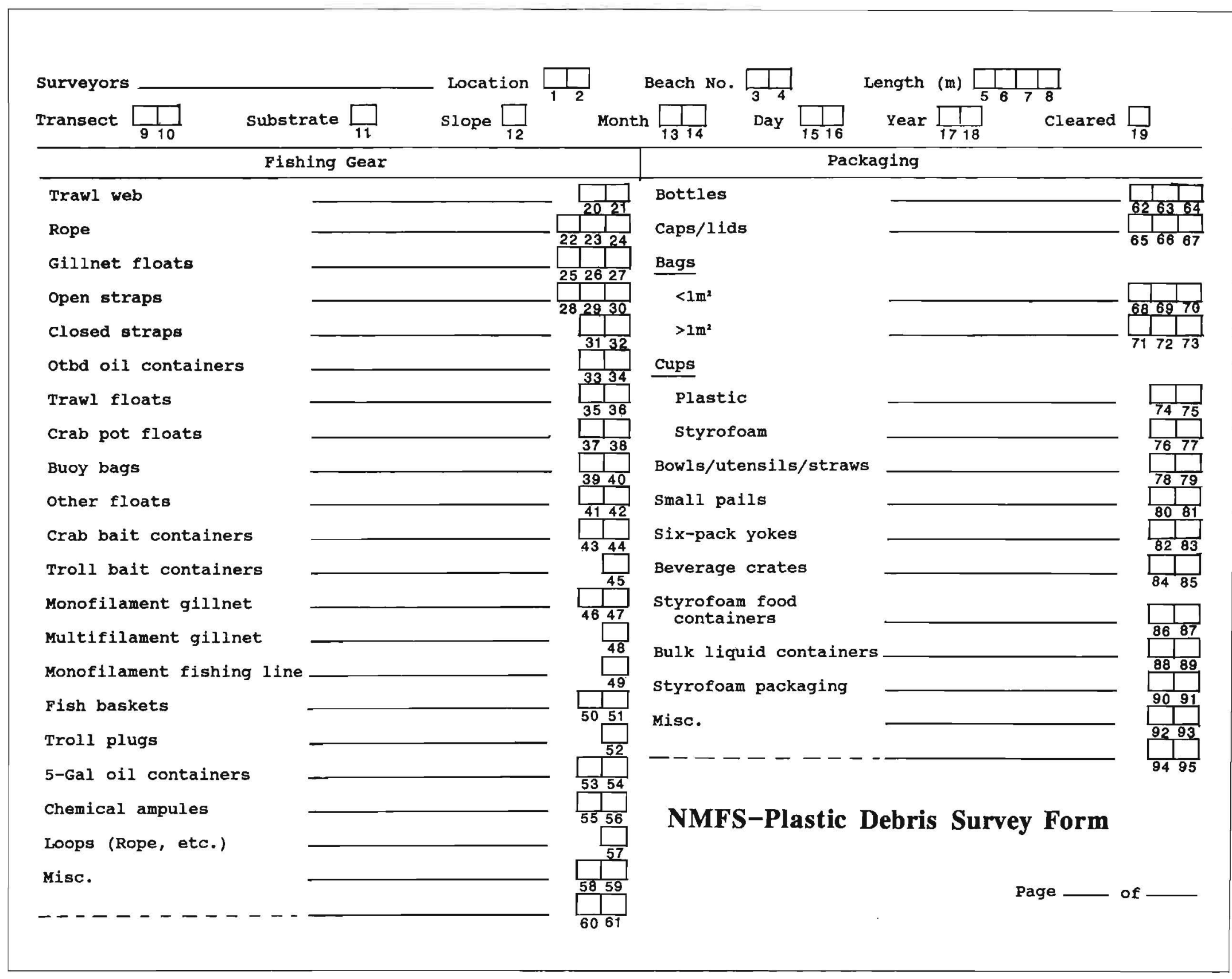




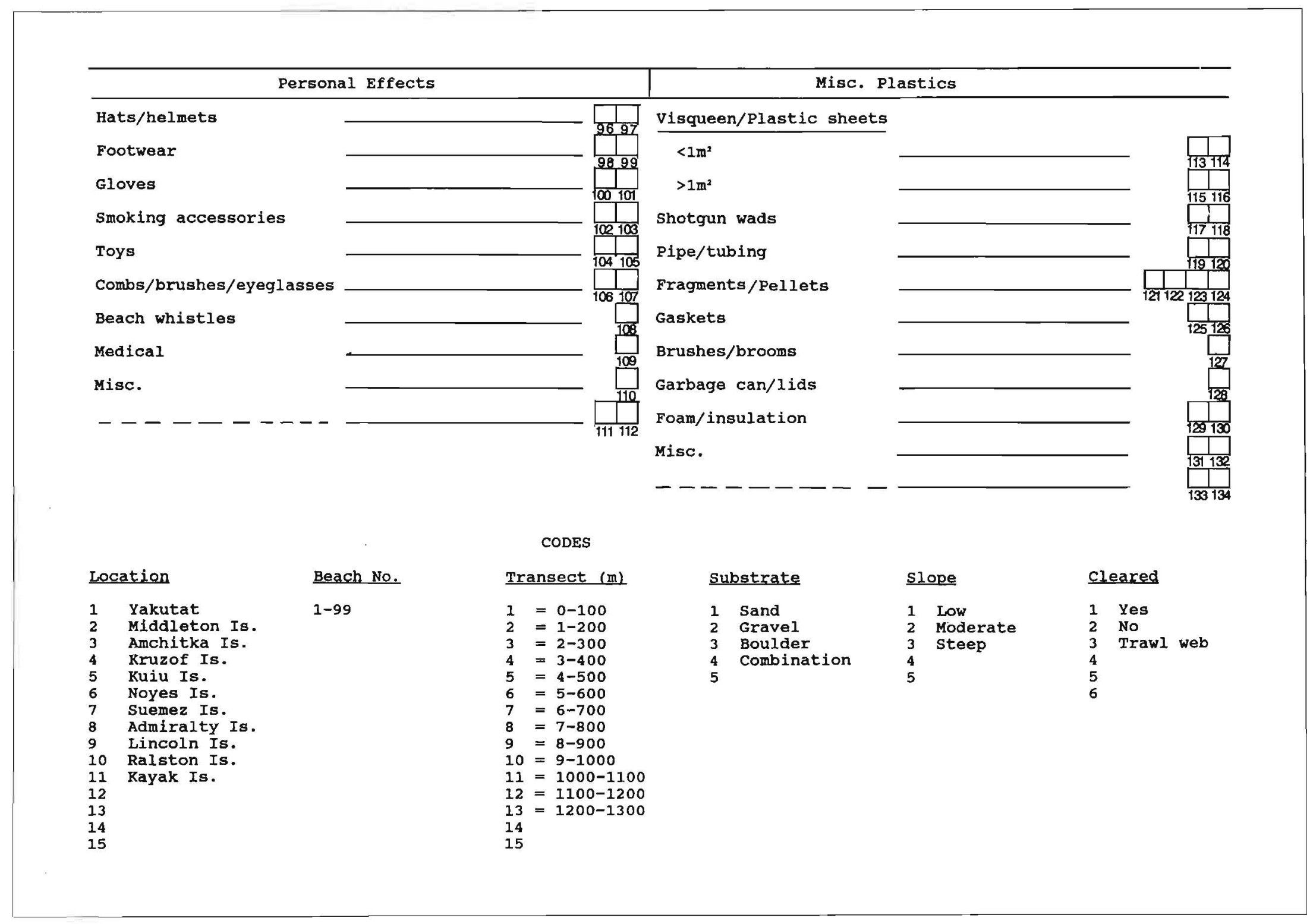

Appendix Figure A (continued) 


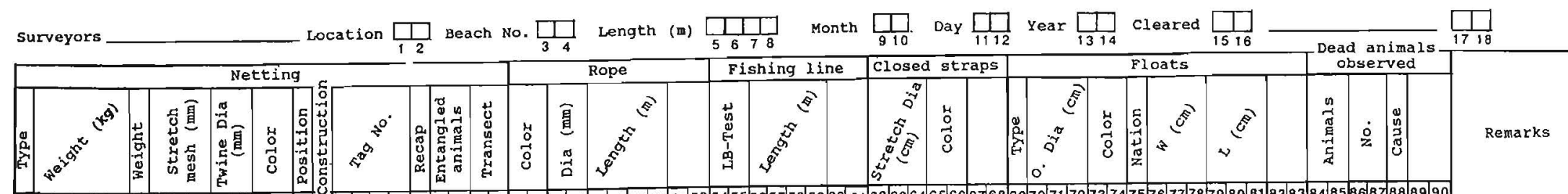

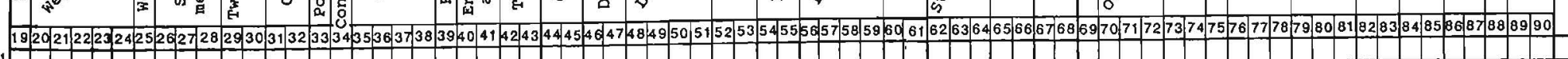
2
3

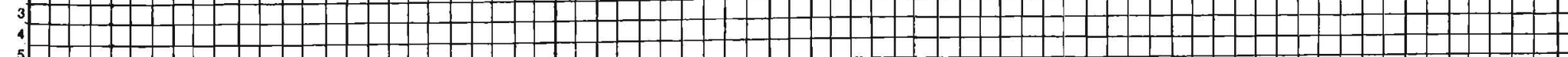

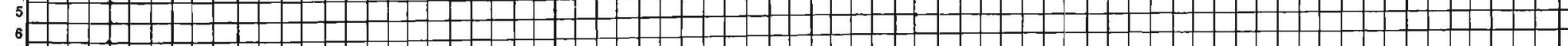

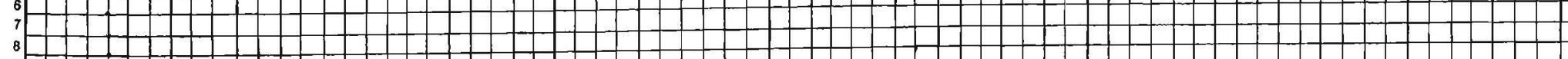

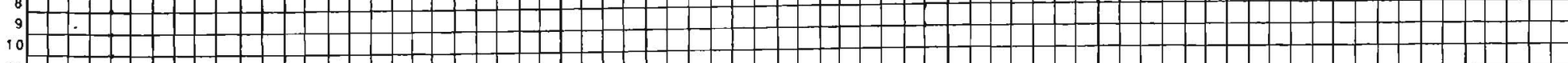

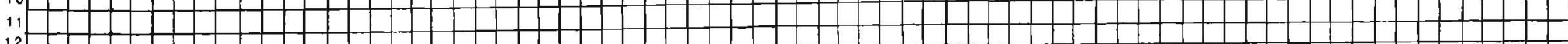

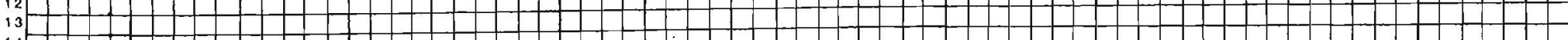
is

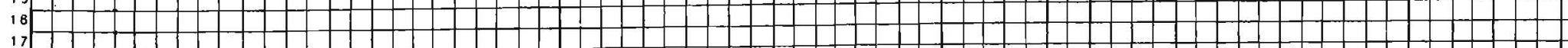
17
19
20

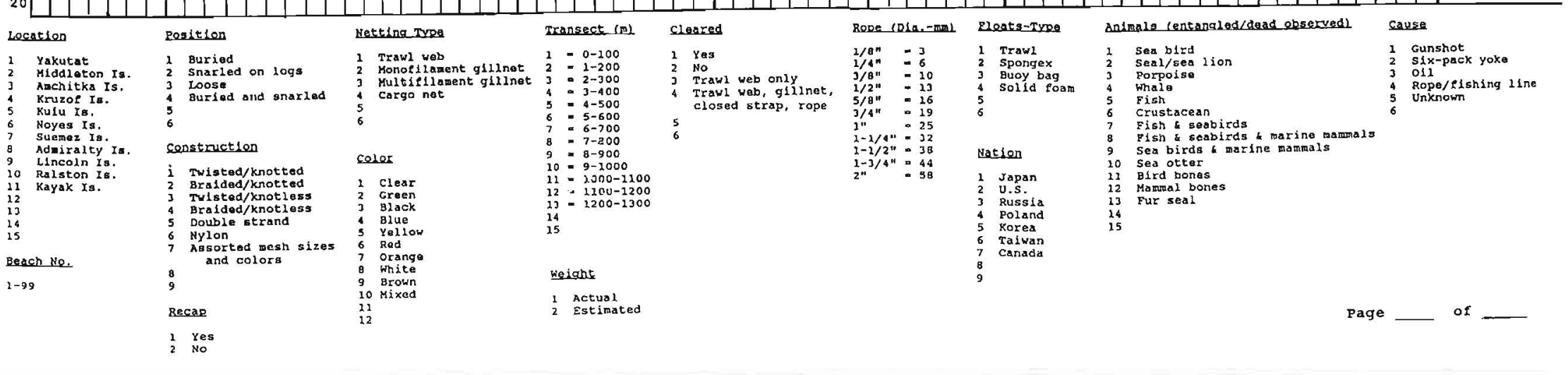

Data form for beach surveys of debris. National Marine Fisheries Service-plastic measurement form. 


\section{BEACH CLEANUP DATA CARD}

Thank you for completing this data card. Answer the questions and return to your area coordinator or to the address at the bottom of this card. This information will be used in the Center for Marine Conservation's National Marine Debris Data Base and Report to help develop solutions to stopping marine debris.

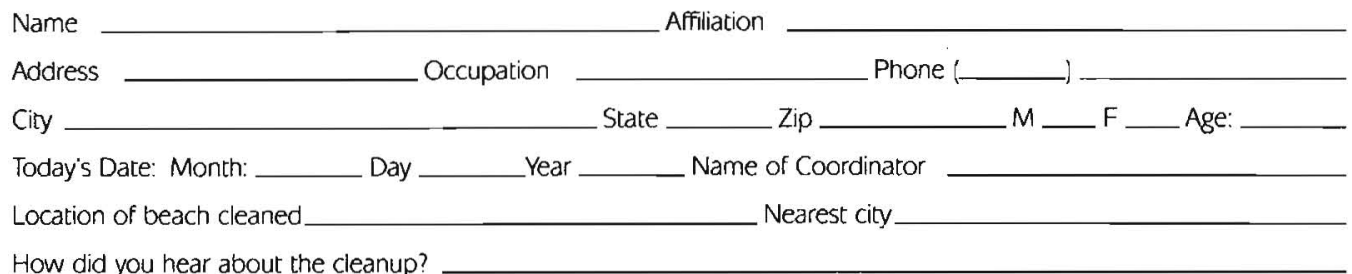

How did you hear about the cleanup?

\section{SAFETY TIPS}

1. Do not go near any large drums.

2. Be careful with sharp objects.

3. Wear gloves.

4. Stay out of the dune areas.

5. Watch out for snakes.

6. Don't lift anything too heavy. WE WANT YOU TO BE SAFE

Number of people working together on this data card

Esbimated distance of beach cleaned

Number of bags filled

SOURCES OF DEBRIS. Please list all items with foreign labels (such as plastic bleach bottles from Mexico) or other markings that indicate the item's origin (such as cruise line names, military identification or debris with names and/or address of shipping/freighting or fishing companies, or oil/gas exploration activities).

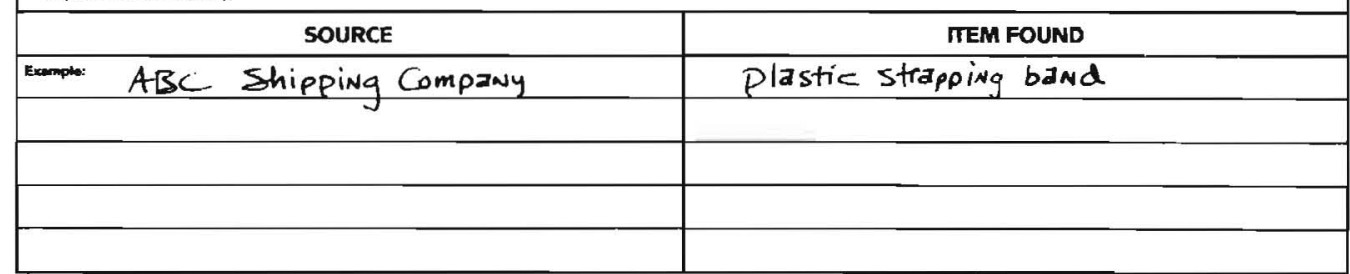

STRANDED AND/OR ENTANGLED ANIMALS (Please describe type of animal and type of entangling debris. Be as speciñc as you can.)

What was the most peculiar item you collected?

Comments

\section{Thank you!}

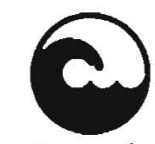

Center for

Marine Conservation Unined Sustes

Formerly Center for Emironmental Education, Est. b7

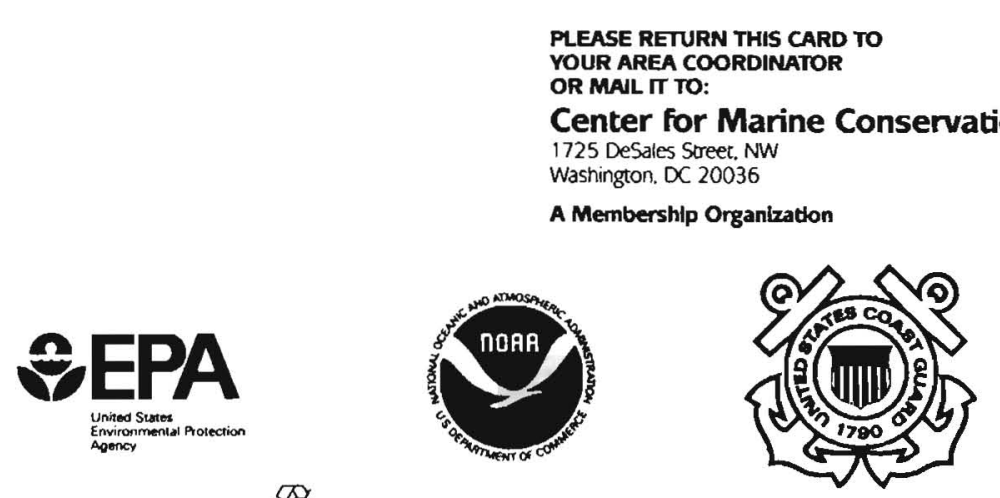

8 Printed on recycled paper. (c) 1990 Center for Marine Conservation
Appendix Figure $\mathrm{C}$ Data form for beach surveys of debris. Center for Marine Conservation - beach cleanup data card. 
ITEMS COLLECTED

You may find it helpful to work with a buddy as you clean the beach, one of you picking up trash and the other taking notes. An easy way to keep track of the items you find is by mating tick marks. The box is for total items; see sample betow.

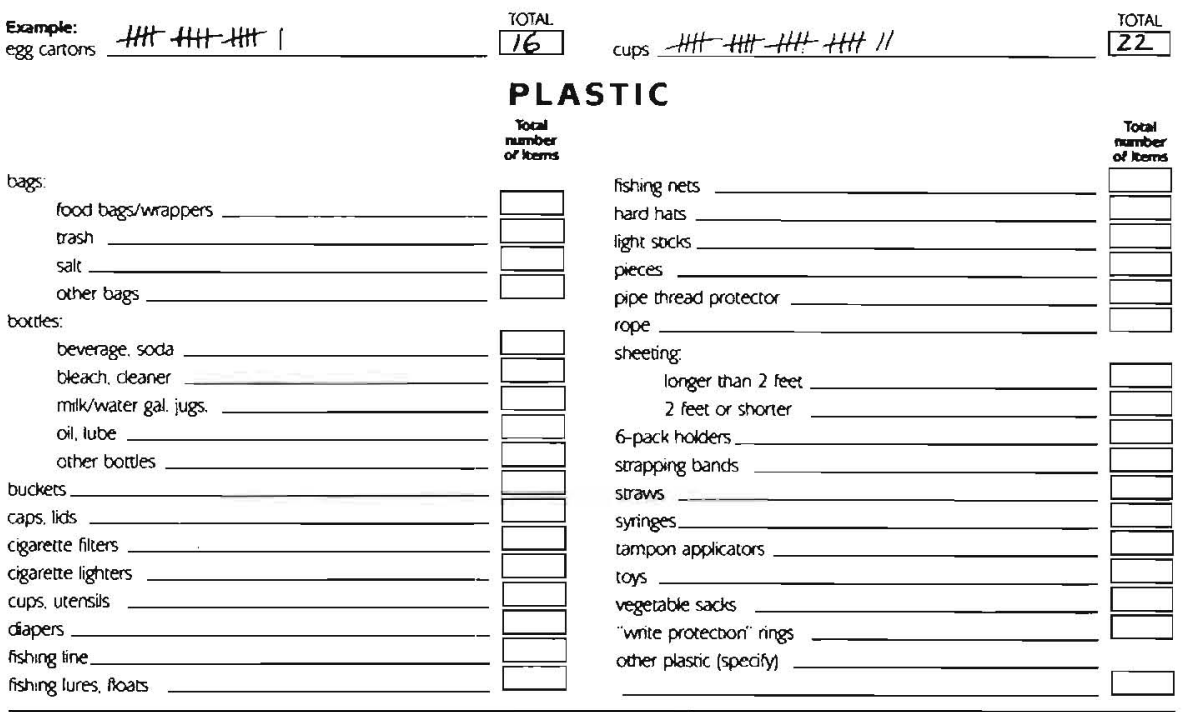

$$
\text { fishing lures. Rloats }
$$

\section{STYROFOAM}

(or other plastic loam)

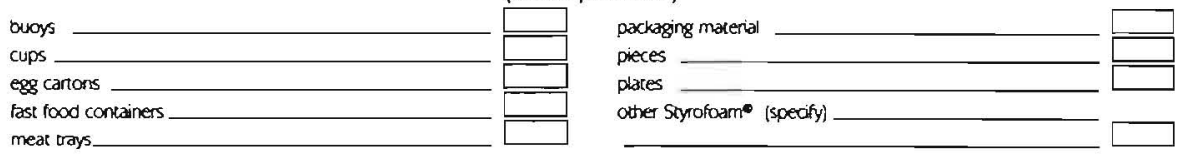

\section{FOLD MLONG THS LNE}

GLASS

bottes/ars:

beverage bortles

food jars

aher bottes/gars

nuorescent light tube

hight buibs

pieces

other glass (specify)

\section{RUBBER}

balloons

condoms

groves

tires

other rubber (specify)

METAL

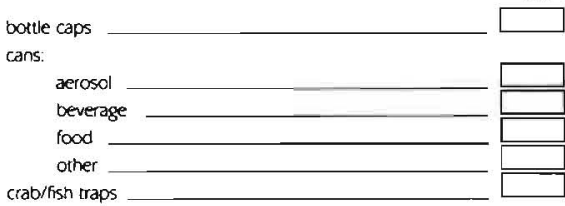

55 galion drums:

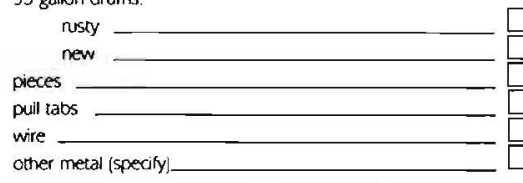

PAPER

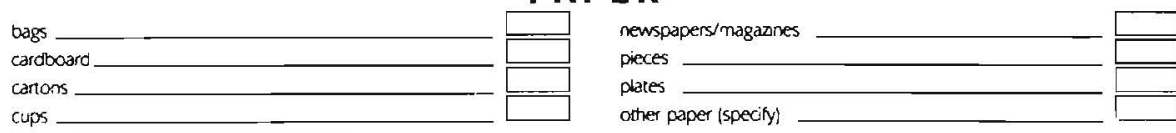

cups

WOO D

leave dnftwood on the beach)

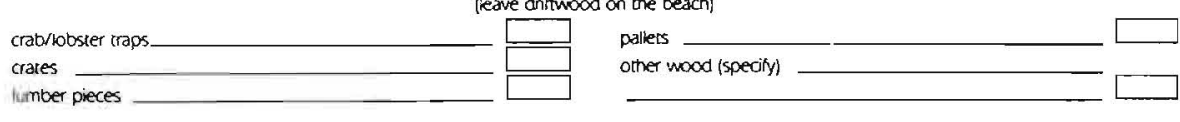

\section{CLOTH}

clorhing/pieces $\square$

Remember to tum the card over and fill out your name and address and to record sources and entangled wildlife!

Appendix Figure C (continued) 


\begin{tabular}{l|l|l|} 
Name & Address & The Tidy Britain Group: Marine Litter Research Programme \\
\hline $\begin{array}{l}\text { LOCATION OF BEACH (please } \\
\text { state county and nearest town) }\end{array}$ & TYPE OF BEACH (sand, shlngle or mud, etc) & Office Use Omly \\
\hline DATE OF SURVEY & $\begin{array}{l}\text { IS THIS PART OF A REGULAR } \\
\text { SURVEY? } \\
\text { YES/NO (please underline your answer) }\end{array}$ & \\
\hline
\end{tabular}

PART 1: Containers Found Please only record containers, if any, from w1thin your survey area.

\begin{tabular}{ll|l|l|l} 
MATERIAL \& COLOUR" & B. ORIGINAL CONTENTS & C. COUNTRY OF ORIGIN & D. OTHER MARKINGS SUCH \\
OR NAME OF PRODUCT & &
\end{tabular}

\begin{tabular}{l|l|l|l}
\hline $\begin{array}{l}\text { Example } \\
\text { White Plactic Bottle. }\end{array}$ & Bleach. & France. & TODES, AND COMMENTS \\
\hline & & & \\
\hline & & & \\
\hline & & & \\
\hline & & &
\end{tabular}

PART 2 Other Litter (Excluding Containers)
Tick each time you find an 1 tem. If very common, write in "WIDESPREAD". Please add any general
comments to the reverse of this sheet.

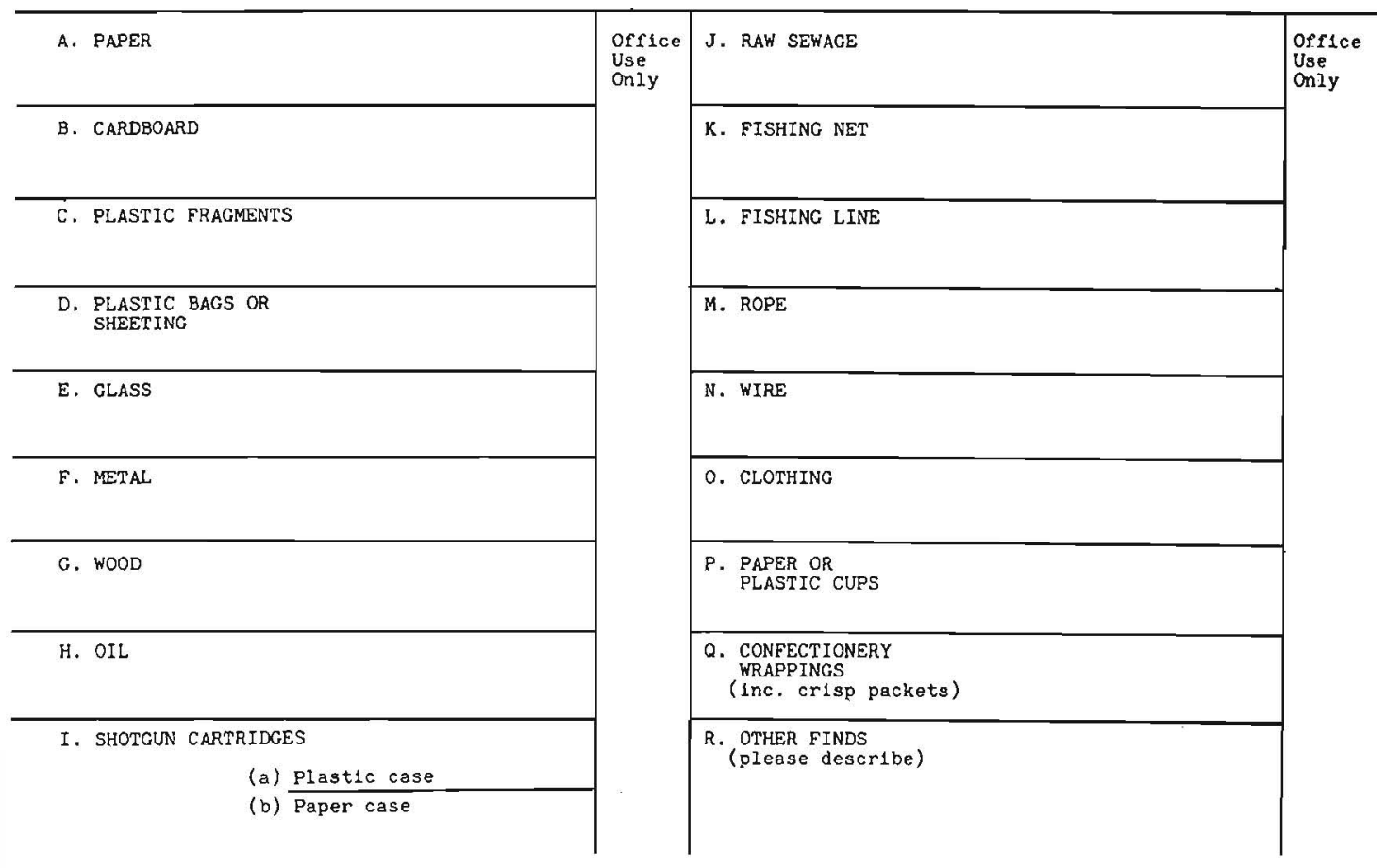

\section{Appendix Figure D}

Data form for beach surveys of debis. The Tidy Britain Group-survey form. 
When Was It Made?
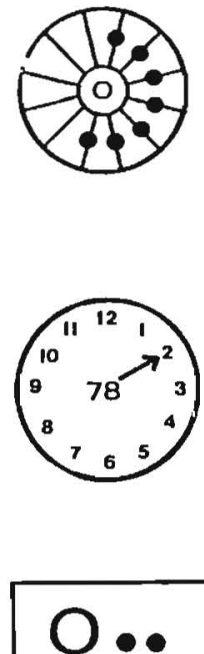

Plastic bottles are dated in several different ways. The most common is known as a CLOCK CODE. The year in whlch the bottle was made 18 shown by the number in the ceatre or the circle. $0=1980,1=1981,9=1979$ and so on. The month of bottle production is shown by the number of dots on the radiating lines. In this example, there are seven dots, the month or production was the fth month July. The number in the centre of the clrcle is 0 , July 1980 .

This is another type of clock code frequently used outside the United Kingdom. The last 2 digits of the year of production are found in the centre and an arrow points to a single number on the outside of the circle, representing the month. In this example, the container was made in February 1978 .

Dots and number in a row are another type of date code. The number a the end or beginning of the row represents the last digit of the year or production. For example, $7=1977$ and so on. The dots show the month in the year when the contalner was made. One dot is removed for each wonth, so 12 dots ls January, 9 do April, and so on. In the example. the date of prodi

\section{Bar Codes}

These consist of a series of numbers and parallel vertical lines. Each product sold in a supermarket will eventually have its own code. The first two numbers show the nationality of the 'number bank'. The next five numbers show the manufacturer and the last live show the product.

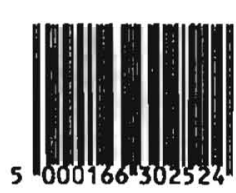

$$
\begin{aligned}
& \text { 00-09 USA + Canada } \\
& \text { 30-37 } \text { France } \\
& 40-43 \text { West Germany } \\
& 49 \quad \text { Japan } \\
& 50 \quad \text { UK } \\
& 54 \quad \text { Belglum } \\
& 57 \quad \text { Denmark } \\
& 64 \quad \text { Finland }
\end{aligned}
$$$$
70
$$$$
\text { Norway }
$$$$
73
$$$$
73 \text { Sweden }
$$

Example:

$64 \quad$ Finland

5000317002013 - Paperboard carton. Longlife Milk. 1 pint. UK Please record ald numbers on the survey form.

\section{STOP PRESS!}

Please keep a special watch for any pink plastic cylinders in your study area. Their shape and dimensions are show in the diagram. If you find any, please record the number found in your study area in Section $R$ (other finds)
of part 2 (other litter).

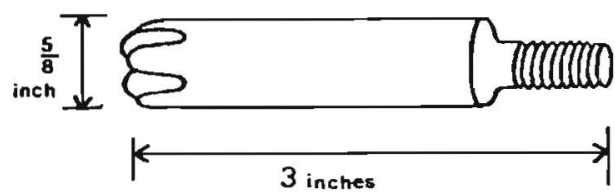

WHERE WAS

IT MADE?

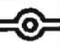

FRANCE

(SY)

FRANCE

WF

FRANCE

$\mathrm{PP}$

IRELAND

STAR IRELAND

UPLA PORTUGAL

(DRG) SOUTH

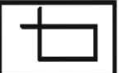

BELGium

IN BELGIUM

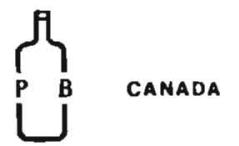

HP

DENMARK

HAUSTRUP

PLASTIC

DENMARK

VANGUARDIA SPAIN

JEYES UNITED KINGDOM

( UNITED KINGDOM

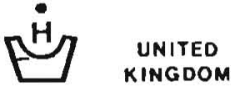

CASCELLOID UNITED

MONSANTO USA

C USA

Appendix Figure D (continued) 


\section{Chapter 5}

\section{Benthic Surveys \\ for Large Submerged Debris Items}

\section{General Description}

Benthic surveys for medium to very large debris items involve counting, classifying, and, in some cases, collecting items that have sunk to the sea floor. Only small sections of the population of interest will be surveyed, but results can be extrapolated to the total area. Collection and disposal of debris will depend on the technique used for collection and the size of the debris.

Three survey techniques are discussed in this chapter.

1. trawl surveys

2. submersible surveys

3. diving surveys

Trawl surveys, which have been used most often for assessing types and amounts of benthic marine debris (Holmström 1975; Jewett 1976; Feder et al. 1978; Berger and Armistead 1987; Bingel et al. 1987; FAO 1989; June 1990), are the main focus of this chapter. Because of their high costs and limited availability, remotely operated vehicles (ROVs) and manned submersibles have been used only in a few studies on benthic marine debris (Carr et al. 1985; High 1985). Divers using scuba equipment have assessed the effects of "ghost fishing" by lost nets (Carr et al. 1985) in the North Atlantic Ocean and benthic debris in McMurdo Sound, Antarctica (Lenihan et al. 1990). Note that all of these techniques are still in an experimental stage. Further, repeated and repeatable studies are needed.

\section{Objectives and Purpose}

Benthic surveys can be used to provide information on the distribution and amount of debris on the ocean floor for a specific area. The debris of interest is usually large to very large and often of a particular type (e.g., lost fishing nets). Few baseline surveys have been done for benthic debris (FAO 1989, June 1990). Other studies noted marine debris found while collecting other benthic samples (Holmström 1975; Jewett 1976; Feder et al. 1978; Bingel et al. 1987).

\section{Population of Interest}

The population of interest is the amount of debris on the bottom of a specific area of ocean at a specified time. The population of interest can be as small as the bottom of a bay or cove, or as large as an ocean basin. Restrictions to the population of interest may occur because of floor composition (i.e., substrate and topography), depth, fauna, flora, and use patterns of the area (e.g., cargo shipping lanes, fishing grounds, or recreational areas).

Restrictions to the population of interest may be a result of the survey technique more than any other reason. For example, if the survey technique must be a trawl survey, then even if the population of interest was benthic debris in the Great Barrier Reef of Australia, the population of interest would have to be changed because trawl surveys are not possible in that area.

\section{Historical Information}

The factors that may effect the trawl survey technique are as follows:

- depth (e.g., this affects the amount of cable needed for trawls)

- slope (e.g., a bottom with a steep slope cannot be sampled by a trawl)

- substrate composition (e.g., areas with large rocks and pinnacles can damage the trawl net)

- currents (e.g., cross-currents can cause fouling of the trawl net)

- dump sites (e.g., areas for oceanic dumping by cities should be avoided)

- local fishing practices (e.g., areas with crab or lobster traps may pose a hazard to trawls)

For the other two survey techniques, bottom depth and ocean currents will be the most important factors. In addition, visibility will be an important factor (e.g., high plankton density will make underwater navigation and debris counts impractical).

From Guideline 4 to Guideline 8 (see page 62) the three survey techniques are quite different. The manual will first look at the guidelines in relation to 
trawl surveys, since trawls are most often used. Submersible surveys will be second, followed by diving surveys.

\section{Trawl Surveys}

\section{Field Measurement}

Trawl surveys usually seek to measure benthic debris (number of items, density, or wet/dry weight per trawl).

Description-The ship slows to a "trawl speed" (this varies with the type of boat, type of net and sea conditions), at which time the trawl is released from the stern of the ship, either over a stern wheel or down a ramp. The net is extended such that the footrope is on the bottom. The footrope should be a "hard bottom" type with very small bobbins or a metal bar. Once the trawl net reaches the bottom, the time is recorded. The ship maintains the trawl speed for the duration of the trawl. After a prespecified time has elapsed, the trawl net is retrieved and the time recorded (Fig. 8). From the length of time on the sea bottom and average ship speed, the distance trawled can be measured. Most trawling vessels have LORAN $\mathrm{C}$ or GPS navigation equipment, which will make distance an easy measurement.

The same trawling procedure should be repeated at each predetermined sampling point. The speed and time towed should be the same for all trawls.

\section{Variables to Consider-}

Vessel Variability-Different ships will tow more effectively than others. This variability is due to the ability of the ship and crew to identically reproduce tows, stay on track, and handle variability (such as a crab pot encountered in the middle of a tow).

Net Variability-The size of mesh is the most important net variable to consider. Tows cannot be compared unless the meshes are the same, owing to differential escapement of debris (unless all debris below a certain size is not considered). Other netrelated variables are the sweep area and volume of the net. Acoustic mensuration systems are available that measure both horizontal and vertical net openings constantly during the tow, so differences between nets used can be quantified. However, changes in these variables may cause problems in standardizing tows.

Footrope Variability-"Hard bottom" nets should be used with only the smallest bobbin size. Many bottom trawl nets are designed to scare fish and do not "dig" sufficiently (if at all) into the sea floor (due to large bobbins) to "catch" many kinds of marine debris (i.e., pipes, heavy cans, large plastic sheets).

Depth Variability - If minor increases in depth occur during a tow (e.g., $5-10 \mathrm{~m}$ on a $100-200 \mathrm{~m}$ depth tow), the net may list off the bottom. Compensations should be made so that the bottom is followed at all times. As with net variability, acoustic and mechanical devices are available that detect contact of the footrope with the bottom during the tow.

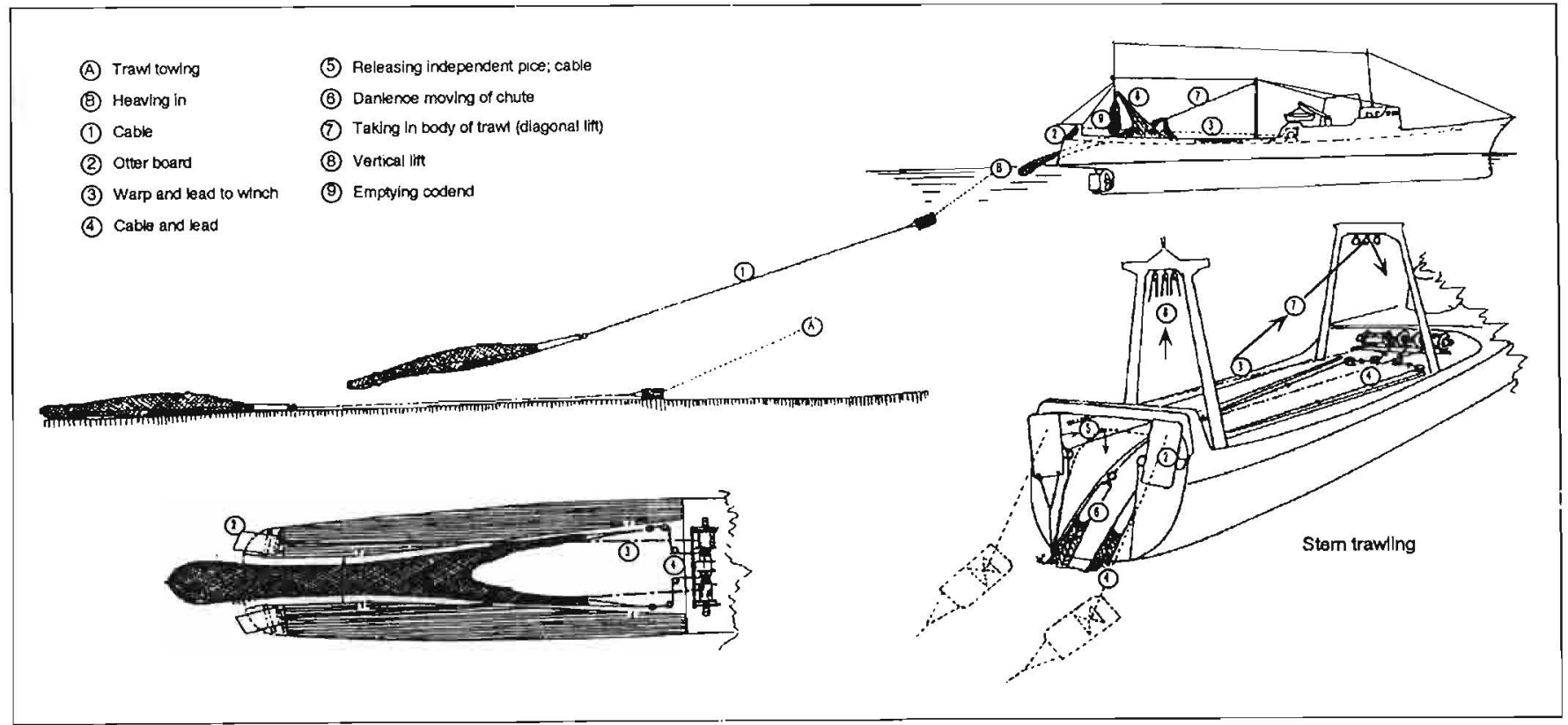

Figure 8

Method of heaving gear aboard a stern trawler (adapied from Garner 1967). 
Weather-Rough sea conditions can cause net entanglement, loss of debris from the net, or lift the net off the sea floor.

Measurement Variability-The above factors all contribute to measurement variability. In addition, errors in sorting large tows (especially when tows are done in cooperation with fishery trawl surveys) can be a problem when measuring debris.

Data Collection-Data collected with respect to categories of debris are similar to those in the previous chapters (see Chapter 1, Categories of Marine Debris). Specifically, the following information should be collected at each tow.

- date

- time tow started

- time tow stopped

- exact location (either latitude/longitude of each trawl [e.g., $60^{\circ} \mathrm{N}$ by $175^{\circ} \mathrm{W}$ ] or distance traveled between each trawl (e.g., $5.2 \mathrm{mi}$ from trawl 3))

- speed of ship during trawl

- weather conditions throughout trawl

- any holes in the net at the end of the trawl

- any trawl period during which the net is not dragging the bottom

Few data forms are available for benthic debris surveys (see Appendix Figures A-C (this chapter). Forms for other trawl surveys may be adapted for debris purposes. Appendix Figures A and B (this chapter) comprises forms used by the National Marine Fisheries Service for demersal trawl surveys for bottom fish. Figure 9 depicts a suggested data form for trawl surveys.

Material and Personnel-The basic equipment needed for trawl surveys is categorized by two objectives:

- Sample collection

a bottom trawl net and all equipment needed for the deployment of the net log forms for sample collection

- Trawl analysis

large bags ( $\geq 103 \mathrm{~L})$ to pile and store debris

scales for weighing debris $(0-100 \mathrm{~kg})$

protective gloves for handling samples

data sheets (sample analysis)

The greatest expense is the cost for the ship and the net. A large net designed for marine debris studies is about $4 \mathrm{~m}$ high and $12 \mathrm{~m}$ across and will cost about $\$ 20,000-\$ 30,000$ (Net Systems, Inc., Bainbridge Island, WA). It may be possible to obtain nets through an interagency loan (e.g., National Marine
Fisheries Service), with only the shipping and insurance fees to pay (which will depend on the location of the trawl survey).

The cost of the ship will depend on the population of interest and the size of the net. To charter a ship about 30 -m long to perform a bottom trawl survey in the eastern Bering Sea will cost around $\$ 3,500$ $\$ 4,000 /$ day, excluding fuel. Fuel costs will be about $\$ 300-\$ 350 /$ day when trawling. While in transit, fuel costs will be about $\$ 500-\$ 600 /$ day. A 30 -day cruise could therefore cost around $\$ 110,000$, excluding net and the personnel costs. The cost will increase dramatically if the ship is larger. The size of the vessel needed will vary depending upon the following:

- the size of the net-the larger the net, the more horsepower needed to pull the net;

- depth of the area to be trawled-the greater the depth, the more cable needed to reach the bottom. The ratio of cable to depth is usually considered to be 3:1, i.e., a trawl depth of 100 meters needs 300 meters of cable. A 30 -m ship can only trawl to about $200 \mathrm{~m}$ owing to the amount of cable it can hold; and

- distance from shore-a large vessel, $60 \mathrm{~m}$ or better, is needed for high-seas trawling.

The crew will handle the deploying and retrieving of the net in most cases, but the sorting of debris once on deck must be handled by the investigator or assisting personnel. For assisting personnel, the cost is similar to the National Marine Fisheries Service marine mammal observer program: the salary will run around $\$ 3,000 /$ mo plus travel expenses (room and board may be additional, if not included in the price of the ship charter).

On the basis of the preceding information, the typical price of an entire 30-day cruise, including the cost of the net, may well be $\$ 150,000$ or more. Though the net can be reused, the cost for continued trawling still will be quite high. Using a vessel of opportunity can reduce costs to those associated with the personnel required for sorting the debris, travel to and from the ship, and room and board.

\section{Quality Assurance Program}

Because of the number of trawls likely to be performed, a quality assurance/quality control program plan is one of the most important aspects of the trawl survey. For example, the National Marine Fisheries Service has been performing trawl surveys in the Eastern Bering Sea since 1973 and has a detailed 


Vessel Name
Date (Yr/Mo/Day)
Gear Depth (in m)
Bottom Depth (in m)
Sea State (Beaufort)

Starting Location (lat/long)

Ending Location (lat/long)

Loran Start

Loran End

Time: Start Trawl (24-hr time)

Time: End Trawl (24-hr time)

Bottom Type (hard, rocky, mud, silt)

Area Use Type (commercial fishing, shipping lane, pleasure craft, etc.)

Net:

Net Type

Door Description (width, height in $\mathrm{m}$ )

Mesh Size (mm stretched):

Wings

Body

Liner

Cod End

Footrope:

Bobbin Size (in cm)

Chain Size (in mm)

Bar Size (in meters)

Wireout (in meters)

Average Trawl Net Horizontal Opening (in meters)

Percent of Time with Bottom Contact

Figure 9

Suggested template for trawl survey forms.

document describing exactly how trawl surveys should be performed.

As noted previously, surveys should use the same trawling procedure at each station. A set procedure is not only good on a day-to-day basis but on a year-toyear basis as well. For comparisons to be meaningful, the trawls must be as similar as possible, and any differences must be noted. A set sampling procedure cannot be done without a strict quality assurance program plan in effect.
The items listed below should be included in the quality assurance plan.

- specific boundary of the population of interest

- all aspects of the net (e.g., door width, mesh size, volume)

- specific points trawled (e.g., accurate location coordinates)

- categories used to sort debris

- data analysis details 


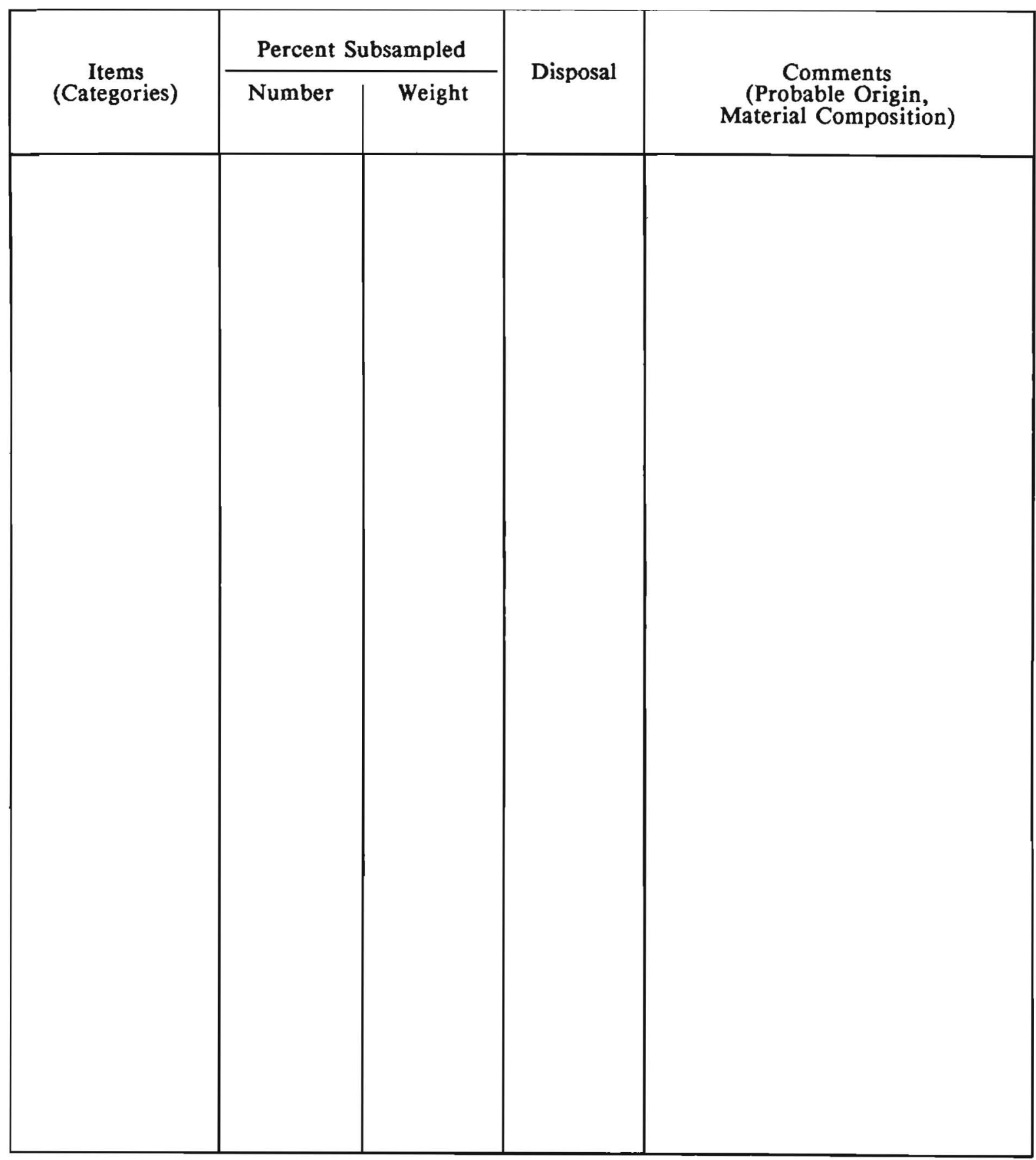

Figure 9 (Continued)

- ship and accessory gear description

- crew efficiency at handling trawl

- subsampling and sorting procedures

\section{Field Sampling Designs}

As with floating small debris, one cannot assume that the materials will be randomly distributed through- out the population of interest. Certain large areas will have virtually no debris while other areas will have significant amounts, which is why the historical information on the population of interest is particularly important.

If a study is meant to give a baseline assessment or a year-to-year assessment of the type and amount of benthic debris found in the population of interest, then a regular systematic or random sample will give 
a good assessment of the amount. If, however, a study is meant to assess changes in benthic debris over space and time due to legislation, then one should concentrate samples in areas where a change is most likely to be detected.

In either case, multiple techniques for benthic marine debris assessment would increase the information about the population of interest. For example, a study might use a trawl survey of an area followed up by an ROV survey.

\section{Analytical Procedures}

Many standardized techniques for analyzing biological data can be obtained from systematic or stratified trawl surveys or both (Doubleday and Rivard 1981). These techniques may be adapted for analyzing benthic debris survey data. One difference will be the need to disregard factors correcting for "animal movement." Otherwise, the statistical techniques will be the same when assessing standing stock.

There are no "standard" techniques available to perform analyses dealing with changing accumulation of debris. Research is being conducted on how to evaluate this kind of data and the effects associated with it (June 1990). The problem of clustering samples and assessing changes over time must be taken into account:

To assessing the amount of benthic debris in an area of a random sample or a strata of a sample, the estimate is made using standard fisheries trawl survey procedures (Jones 1990) in the following manner:

For each haul, catch per unit effort (CPUE) is measured, usually the amount (either number or weight of pieces) per area swept (usually in ha or $\mathrm{nmi}^{2}$, e.g., $100 \mathrm{~kg} / \mathrm{ha}$ ). The area swept is the distance trawled multiplied by net width. CPUE is calculated from a trawl survey $i$ for a debris type $j$ as follows:

$$
\mathrm{CPUE}_{i j}=\frac{W_{i j}}{D_{i} F_{i j} P_{i}}
$$

where $W_{i j}=$ weight (or number) of debris type $j$ on trawl $i(\mathrm{~kg})$,

$D_{i}=$ distance trawled on trawl $i(\mathrm{~km})$

$P_{i}=$ effective trawl width for trawl $i(\mathrm{~km})$, and

$F_{i j}=$ relative "fishing" power correction factor (which is how well one ship's efficiency at "catching" debris is compared to another ship's in the same area) for trawl $i$ in respect to debris type $j$.
Note: The "fishing" power correction factor has not been computed for any debris type, so in most cases it will be assumed to be 1.0 .

For an overall mean CPUE and its variance for the population of interest of a specific strata:

$$
\text { Mean CPUE }=\overline{\mathrm{CPUE}}=\frac{\sum_{i=1}^{N}\left(\mathrm{CPUE}_{i}\right)}{N}
$$

$$
\text { Variance CPUE }=S_{\mathrm{CPUE}}^{2}=\frac{\sum_{i=1}^{\mathrm{N}}\left(\mathrm{CPUE}_{i}-\overline{\mathrm{CPUE}}\right)^{2}}{N(N-1)}
$$

where $N=$ the number of hauls in the area.

To determine the total weight of debris in an area or strata, perform the following calculations:

$$
\begin{gathered}
\text { Total weight }=\mathrm{wt}_{T}=\frac{A}{c}(\mathrm{CPUE}) \\
\text { Variance weight }=S_{w t}^{2}=\frac{A^{2}}{c^{2}}\left(S_{\text {CPUE }}^{2}\right),
\end{gathered}
$$

where $A=$ specified area of interest (e.g., eastern Bering Sea), and

$c=$ vulnerability; the fraction caught versus the fraction missed during a trawl sweep.

Note: As with "fishing" power, vulnerability is assumed to be 1.0 for most debris items.

If using a stratified random sample, the overall mean would be calculated as follows:

$$
\begin{gathered}
\text { Overall } \overline{\mathrm{CPUE}}=\frac{\sum_{k=1}^{n}\left(A_{k} \overline{\mathrm{CPUE}_{k}}\right)}{\sum_{k=1}^{n}\left(A_{k}\right)} \\
\text { Overall } S_{\mathrm{CPUE}}^{2}=\frac{\sum_{k=1}^{n}\left(A_{k}^{2} S^{2} \overline{\mathrm{CPUE}}_{k}\right)}{\sum_{k=1}^{n}\left(A_{k}\right)^{2}},
\end{gathered}
$$

where $\quad n=$ number of strata, and

$A_{k}=$ area of each strata.

To find the total estimated weight of the area of a stratified sample, the following is performed:

$$
\begin{gathered}
\text { Total weight }=\mathrm{wt}_{T}=\sum_{i=1}^{n} \mathrm{wt}_{T_{i}} \\
\text { Overall } S_{\mathrm{wt}}^{2}=\sum_{i=1}^{n} S_{w t_{i}}^{2}
\end{gathered}
$$




\section{Submersible Surveys}

\section{Field Measurement}

The field measurements of importance are the number and, if possible, the type and size of the benthic debris observed in a strip transect, or per dive.

Description-The submersible is deployed from a mothership (the exact procedure depends on the type of submersible). Upon reaching the bottom, or more specifically, just above the bottom, the survey will start. The submersible should follow a predetermined transect as closely as possible, although this is often difficult to do (Caddy 1976). The debris is observed, counted, and classified, if possible, although rarely collected with the submersible manipulators. Debris may be observed directly from manned submersibles or via a camera. Unmanned submersibles with camera systems are also available. As with the trawl surveys, to calculate the area surveyed, the starting and ending time of the transect are recorded and the speed is held as constant as possible. If multiple transects are made to assess the population of interest, the procedures should be repeated as consistently as possible during each transect.

\section{Variables to Consider-}

Weather-Launching and retrieving of manned submersibles and large ROVs require a low sea state. State 3 is usually the upper limit for a safe launch (Keller 1977).

Vessel Variability-Different submersibles will have different areas of visibility and different degrees of mobility. Visibility will depend on the submersible lights, the size of the view port, and on the type of camera lens. Mobility will depend on whether the submersible is tethered or untethered, the type of servo propellers used, and the size of the vehicle.

Characteristics of marine debris-The color, size, shape, extent of encrustation, and degree of burial will affect the sightability of the debris.

Turbidity-Very turbid waters will reduce visibility to a few $\mathrm{cm}$ (Palmer 1977). At great depths $(>1000$ $\mathrm{m}$ ), however, visibility will be fairly clear (about 60 $\mathrm{m}$ ), which is due, in part, to the lack of life (Keller 1977).

Measurement Variability-As with trawl surveys, the variables listed above will limit an investigator's ability to classify debris as to type or size, or even limit the ability to detect debris. Errors in identifying what is debris and what is not will, however, depend greatly on the training and experience of the observer.
Data Collection-It may be difficult to categorize benthic debris accurately. Broad categories will usually be used. When actual collection by use of manipulators found on some submersibles is used, categories can be more narrow. The following data should be collected during each dive.

- date

- time the bottom or predetermined depth is reached

- time the ascent is started (i.e., end of the transect or course)

- exact location (either latitude/longitude [e.g., $60^{\circ} \mathrm{N}$ by $\left.175^{\circ} \mathrm{W}\right]$ at each dive or distance between each dive [5.2 miles $\mathrm{N}$ from last trawl])

- speed of submersible

- any changes of distance off bottom

- depth

- bottom topography and substrate type

- estimated range of visibility

- number, type, and size of debris observed

Noting any biological growth on the debris may help to determine the age of the debris (Carr et al. 1985). Figure 10 is a suggested data form for use with a submersible survey.

Material and Personnel-Besides the submersible and support vessel, the only materials necessary are the data forms for tabulating the survey. The submersible and support vessel are usually very expensive. The cost of a submersible will depend a great deal on the maximum working depth and whether a manned or unmanned submersible is needed. A manned submersible with a maximum working depth of $330 \mathrm{~m}$ and the necessary support vessel will likely cost more than $\$ 7,000 /$ day excluding fuel. An ROV with a maximum working depth of $2,000 \mathrm{~m}$ will run around $\$ 2,000 /$ day in addition to the support vessel at $\$ 10,000 /$ day excluding fuel. For very deep dives (e.g., $5,000 \mathrm{~m}$ ) the price could be over $\$ 10,000 /$ day for the ROV and $\$ 10,000 /$ day for the support vessel. To have a manned submersible capable of operating at depths over 2,000 m would cost much more than the ROVs. All these previous prices include the necessary crews but not necessarily an observer. The prices also do not include the transportation of the submersible to the dive location (shipping will vary greatly with the size of the submersible). Obviously, a submersible survey can be very expensive, unless a submersible is already owned by the institution or can be borrowed through an interagency loan (e.g., NOAA's West Coast National Underwater Research Centers). 


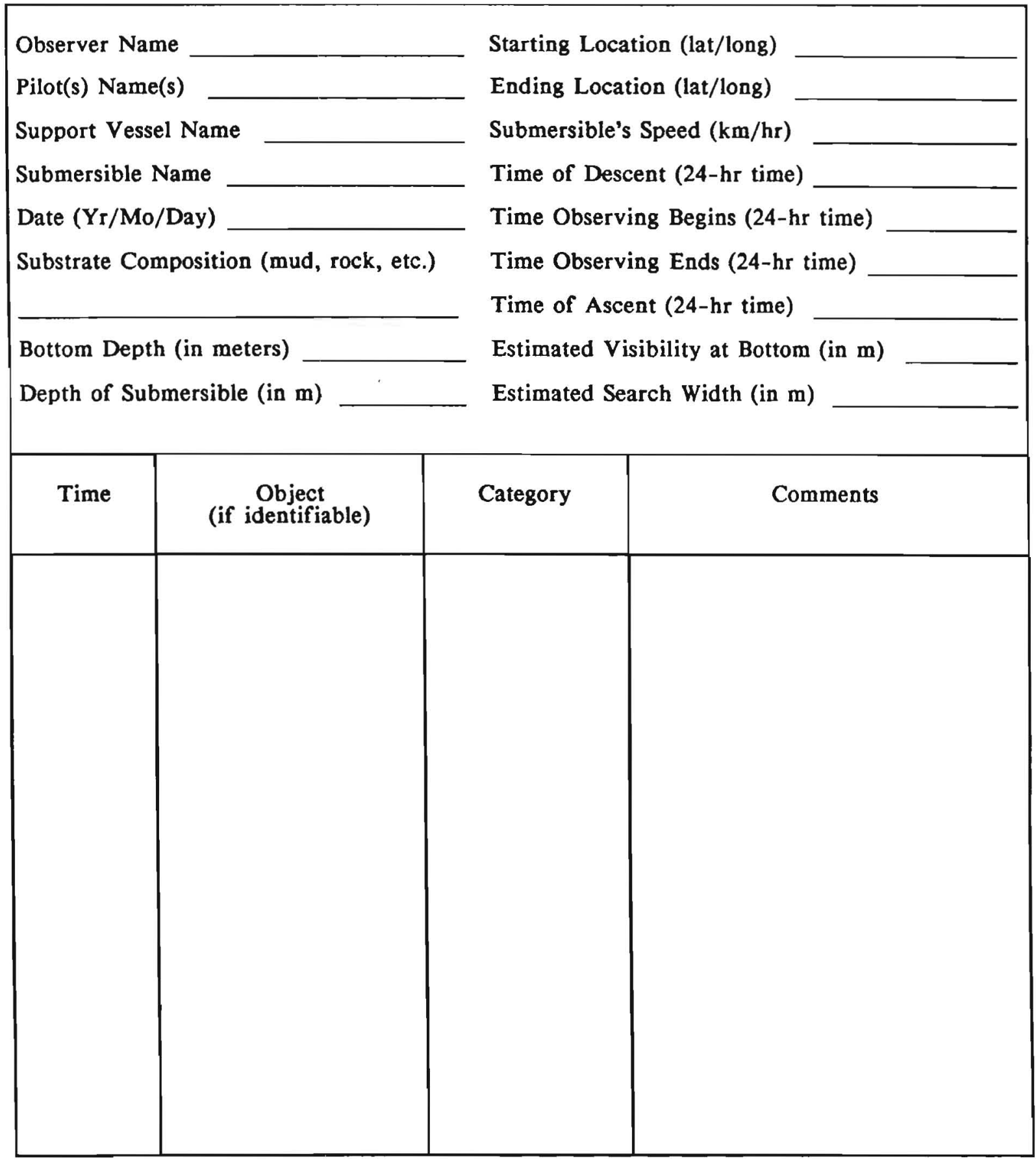

Figure 10

Suggested data form for submersible surveys.

\section{Quality Assurance Program}

Quality assurance/quality control program plans go beyond repeatability when dealing with submersibles. Because of danger to personnel, safety is a prime consideration. A good guide to safety in submersibleoriented research can be found in Pritzlaff (1979).
Beyond safety, the points noted for the trawl survey quality assurance program plan also apply to submersible surveys. Some items to be included in the quality assurance plan (not including safety, see Pritzlaff [1979], and excluding the specific guidelines set for the submersible to be used) are as follows: 
- specific boundary of the population of interest

- large physical features and substrata on the ocean floor

- predetermined course for the submersible

- actual course followed by the submersible

- means of determining visibility

- categories used for describing (sorting) debris

- Details of data analysis

- observer and pilot experience

- specifics about the submersible:

- manned or unmanned

-tethered or untethered

- size of observation port

-type of camera(s) used (including lens)

-manufacturer name of vessel

-any specific modifications used

\section{Field Sampling Designs}

As stated earlier in Trawl Surveys (this chapter) benthic debris is not likely to be randomly distributed throughout the population of interest. Depending on the type of study being performed, different sampling schemes should be used. Submersibles are very expensive, and thus, dive time must be used cost effectively. Limited search times may bias results, so declustering techniques (as described by Isaaks and Srivastava 1989) may be needed.

Transect methods will provide accurate data on debris for a small area and will be more appropriate than the procedure in the following discussion on accumulation studies. The transect method also can be used to give a continuous description of debris type and changes in composition throughout the population of interest.

CPUE methods will yield an overall estimate of how much debris is on the bottom but will yield little specific information on the composition of the benthic debris over the population of interest. A stratified sample would be best, using depth and area usage as the stratification variables.

\section{Analytical Procedures}

Procedures for data analysis are similar to the procedures used for the trawl surveys. The difference is that instead of strip width being the net width, it is the estimated width of the field of vision. Also, instead of the CPUE being $\mathrm{kg} / \mathrm{ha}$, the CPUE will be the amount of debris observed per area (e.g., 50.7 nets/ ha). This analytical procedure generally will be used when performing many dives in a large area.
When using transects, procedures in sighting surveys for floating debris (Chapter 2) can be employed. Strip transects will most likely be used. The reason for using strip transects instead of a line transect is twofold: first, determining distance underwater can be difficult at best; and second, the width of view may be a meter or less owing to the size of the observation port or the size of the lens on the camera. To calculate the density of debris in an area, see Chapter 2, Analytical Procedures. Strip transects are designed for smaller areas and fewer dives compared to the CPUE method.

\section{Diving Surveys}

\section{Field Measurement}

The field measurement for diving surveys is the amount (number of items or weight) of benthic debris per quadrat or transect. This method is particularly suitable for assessing medium to very large debris or when the population of interest is small (e.g., $<1 \mathrm{ha}$ ) or both.

Description-Two methods used for assessing populations of benthic organisms are the quadrat method and the transect method (Dart and Rainbow 1976; Hiscock 1987, 1989). While these techniques have not been tested for assessing marine debris, they merit discussion because neither trawl nor submersible surveys can be used in very shallow waters $(<5 \mathrm{~m})$.

\section{Options-}

Quadrat-A map of the chosen area has a uniform grid placed over it, often generated by computer. A sample of the squares (blocks) of the grid or the vertices of the grid are randomly selected, using a random number table or a random number generator on a computer or calculator. A team of at least two experienced divers with scuba or snorkeling equipment sample at the selected sites. A sample grid is marked on the bottom, using stakes and cord or a large, fabricated metal or PVC pipe square. The area within the square then is searched meticulously for all debris. Small pieces are collected for sorting and weighing on shore or on the deck of the boat. The larger pieces are recorded with an underwater pad and grease pencil or photographed with an underwater camera or both. Their type and estimated size should be recorded.

Transect-To conduct this type of survey, a weighted line is placed, as taut as possible, on the bottom. A pole (usually made of metal) is taken 
down to the line. As the diver moves along the line holding the pole parallel to the bottom, one end of the pole is always touching the line and the pole is held at at $90^{\circ}$ angle to the line. As in the quadrat technique, the diver monitors benthic debris occurring within the area swept by the pole. The procedure may then be repeated along the other side of the line.

The quadrat or transect procedures are repeated at each of the selected blocks, vertices, or points. Again, any new quadrats or transects must be the same size and configuration to ensure conformity.

\section{Variables to Consider-}

Weather-Getting in and out of the water from shore or a boat can be difficult in rough weather. Also, surges can make it difficult to run a transect or collect debris.

Characteristics of marine debris-As with submersible surveys, the color, size, shape, extent of encrustation, and degree of burial of objects will affect their sightability.

Turbidity-In highly turbid water, visibility will be reduced, thus increasing the likelihood that objects will be overlooked.

Equipment Variability-Generally, the larger the air tanks, the longer a person can stay submerged and thus a longer transect or a larger quadrat can be sampled.

Measurement Variability-Training and experience will affect the amount of debris seen in any given survey.

Data Collection-It should be possible to categorize and measure collected debris with a high degree of accuracy; however, the larger debris not brought up may be difficult to categorize due to algal growth and time allotted for each dive. Along with the sorting of the data, the following information should be collected at each dive.

- date

- exact location of dive (often distance from shore)

- sampling quadrat(s) or line segment(s) sampled

- visibility

- bottom topography (e.g., rocky or sandy)

- number, type, size, and condition of debris not collected

- depth

Suggested data forms for use in quadrat and transect techniques are presented in Figures 11 and 12 , respectively.

Material and Personnel-The necessary equipment will depend on the survey location. The following list indicates the necessary gear for diving surveys in cold water $<1.5 \mathrm{~km}$ offshore.

- data sheets

- underwater pad and grease pencil

- net bag with plastic liner

- cord (usually nylon) with weights

- stakes and hammer

- pole (for transect)

- flippers

- mask

- snorkel

- diver knife

- protective gloves

- weights and weight belt

- buoyancy compensator

- regulator

- depth gauge

- air tank

- camera

- wet or dry suit

- boat or ship (depending on the distance from shore)

As with other surveys, the most expensive item will likely be the ship or boat. Vessel costs will increase with the distance from shore. In dives close to shore, generally $<1.5 \mathrm{~km}$, or in bays or coves, a small boat, such as a double or triple hull Boston Whaler, may be suitable. A boat such as this may cost $\$ 50 /$ day to rent; however, it may be possible to borrow one through an interagency loan. A complete set of scuba equipment, excluding a wet or dry suit, will be about $\$ 50$ / day to rent or $\$ 1,500$ to purchase. A wet suit can be rented for about $\$ 10 /$ day and be purchased for about $\$ 400$. A dry suit can be rented for about $\$ 25$ / day and can be purchased for $\$ 500-1,000$. Owing to the variety of equipment, purchasing all the scuba equipment and suits is best to ensure proper function and fit.

The scuba divers should be experienced and have at least an open water certification. Commercial diver wages typically are $\$ 1,500 /$ week; given that safety rule:s generally require no less than two divers, a week-long survey will cost about $\$ 3,000$. Noncommercial divers are available for considerably less.

The total cost for a diving survey in cold water that uses commercial divers and is $<1.5 \mathrm{~km}$ from shore will run $\$ 3,600 /$ week based on daily equipment rental rates. For the same conditions and if all the equipment is purchased (except the boat, which is still rented), the cost will be about $\$ 5,700 /$ week (the equipment which may be reused will be about $\$ 2,400$ total). Diving is obviously the least expensive survey technique discussed in this chapter, but it is also the most limited. 


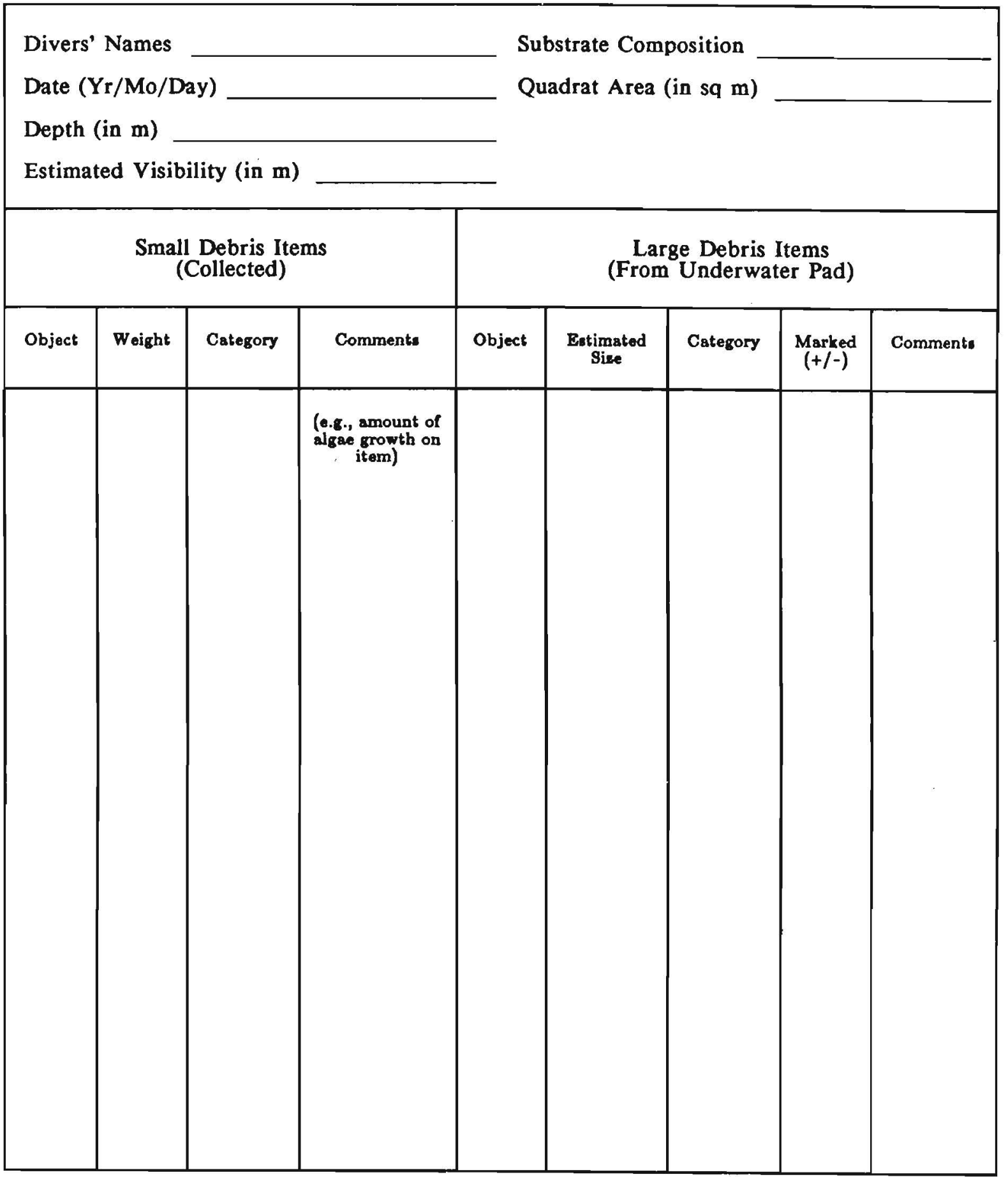

Figure 11

Suggested template for quadrat survey forms.

\section{Quality Assurance Program}

As with the quality assurance program plan for research in submersibles, the quality assurance program plan for diving surveys must consider the safety of the divers as well as the accuracy and repeatability of the data collection procedure.
Certified divers have safety training, but specific hazards and risks associated with each dive should also be considered. For reasons of safety and efficiency, a detailed pre-dive plan should be made. The plan should consider the following information: 


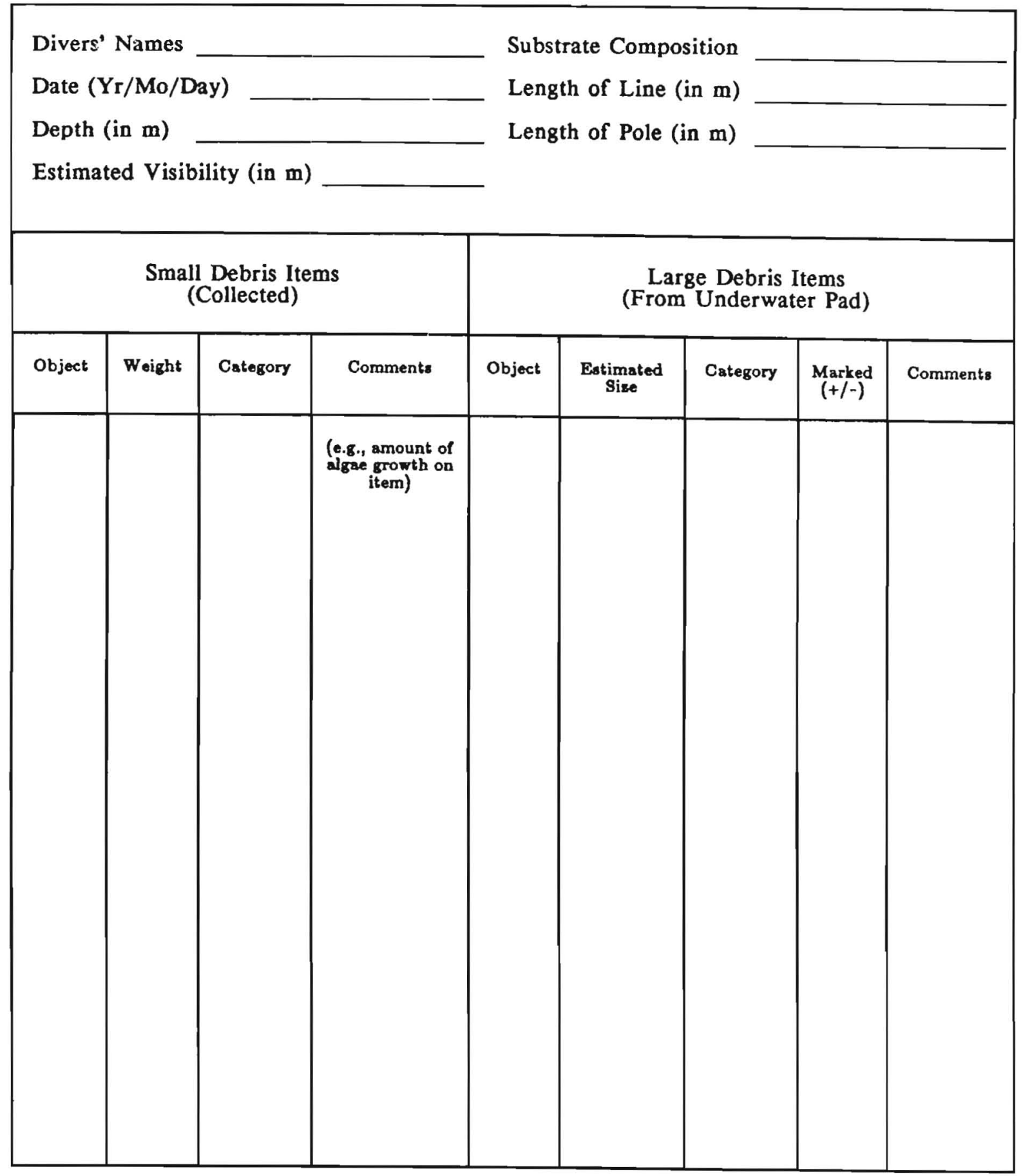

Figure 12

Suggested template for transect survey forms.

- How much time is needed to sample predetermined transects and quadrats?

- How much time is needed in transit between shore and site? Between sites?

- How much time is needed to set up quadrat or transect lines?
- How will emergency situations be handled?

- How much time is needed at each dive site? - How long will it take to decompress?

- How long will it take to get to and from the bottom?

- How long will it take to survey the transect or quadrat? 
- How much time can each diver spend in the water per day?

- How much time does each tank give each diver?

Items that might be included in the quality assurance program plan for the survey itself are as follows:

- categories used for describing (sorting) debris

- maximum size of debris to collect

- length of each transect or size of each quadrat

- measurement of visibility

- details of the data analysis

- diver experience

Repeatability should be ensured between the two plans listed previously. The importance of this repeatability cannot be overstressed.

\section{Analytical Procedures}

The two techniques-quadrat and transect-are similar. In each survey, the total number or weight (or both) of benthic debris in the population of interest is observed and collected if possible. The average number or weight (or both) of debris is calculated from all the samples and extrapolated to the total area. The analysis is very similar to that described for trawl surveys, except that each quadrat or transect should cover the same area, a, or bias can be introduced.

The following are calculations for quadrat surveys (Seber 1982):

$$
\begin{gathered}
\bar{X}=\frac{\sum_{i=1}^{n} X_{i}}{n}, R=\frac{A}{a} \\
\hat{N}=\bar{X} R \\
S^{2}=\frac{\sum_{i=1}^{n}\left(X_{i}-\bar{X}\right)^{2}}{n-1} \\
\hat{\sigma}_{\hat{N}}^{2}=R^{2} \frac{S^{2}}{n}\left(1-\frac{n}{R^{2}}\right),
\end{gathered}
$$

where $\bar{X}=$ average amount or weight per quadrat (\#/ha or $\mathrm{kg} / \mathrm{ha}$ ) or both,

$X_{i}=$ amount or weight in a specific quadrat (\#/ha or $\mathrm{kg} / \mathrm{ha}$ ) or both, $n=$ total number of quadrats,

$A=$ total area of study (ha),

$a=$ area of each quadrat (ha),

$R=$ ratio of total area to quadrat area,

$S^{2}=$ variance between quadrats $\left(\#^{2} / \mathrm{ha}^{2}\right.$ or $\left.\mathrm{kg}^{2} / \mathrm{ha}^{2}\right)$,

$\hat{N}=$ estimate of total amount or weight of debris in the area of study (\# or $\mathrm{kg}$ ) or both, and

$\hat{\sigma}_{\hat{N}}^{2}=$ variance associated with the estimate of debris $\left(\#^{2} / \mathrm{ha}^{2}\right.$ or $\left.\mathrm{kg}^{2} / \mathrm{ha}^{2}\right)$

The only difference in calculations for transect surveys is that the average number or weight of benthic debris per quadrat is now defined as the average number or weight of benthic debris per transect, and the area per transect is defined by the length of the cord multiplied by twice the width of the pole.

\section{Summary}

1. Three survey techniques are discussed: trawl, submersible, and diving surveys. Because of limited experience in using these three approaches when assessing benthic debris, all techniques should be considered experimental at this point, especially submersible and diving surveys.

2. The number or weight of benthic debris is the standard field measurement. Sampling results can be extrapolated to estimate the amount of benthic debris in the population of interest.

3. Of the three techniques, trawl surveys have been used the most often.

4. Trawl surveys are the least expensive technique to perform in deep water $(>50 \mathrm{~m})$, especially when taking advantage of vessels of opportunity.

5. Quality assurance/quality control program plans are extremely important for all aspects of each survey technique, with safety and repeatability being of highest priority.

6. A statistician, who has dealt with similar types of studies, should be consulted at the outset of survey planning and be involved through the completion of the study. 


\section{Appendix}

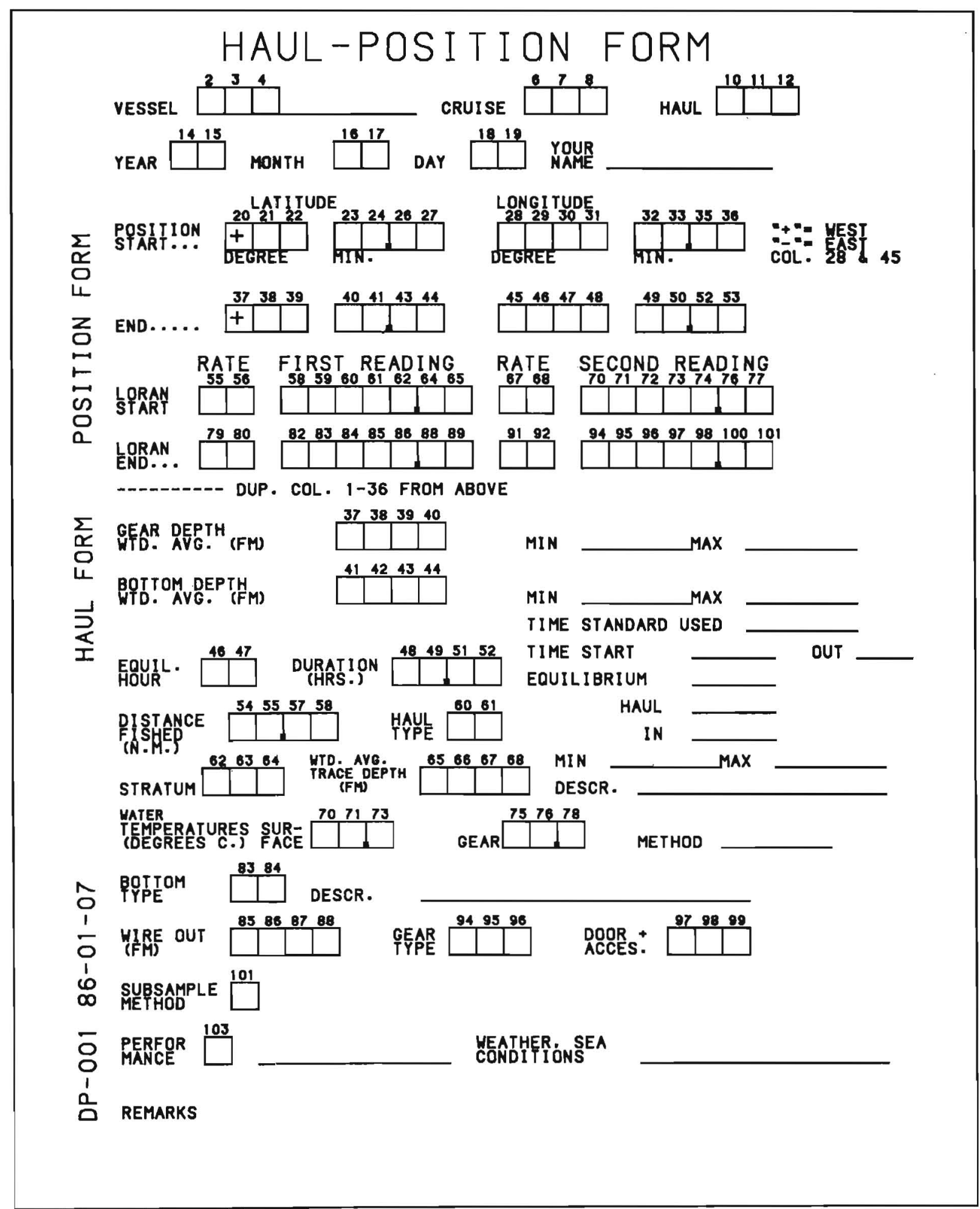

Appendix Figure A

Haul-position form used by the National Marine Fisheries Service during bottom trawl surveys in the Bering Sea. 


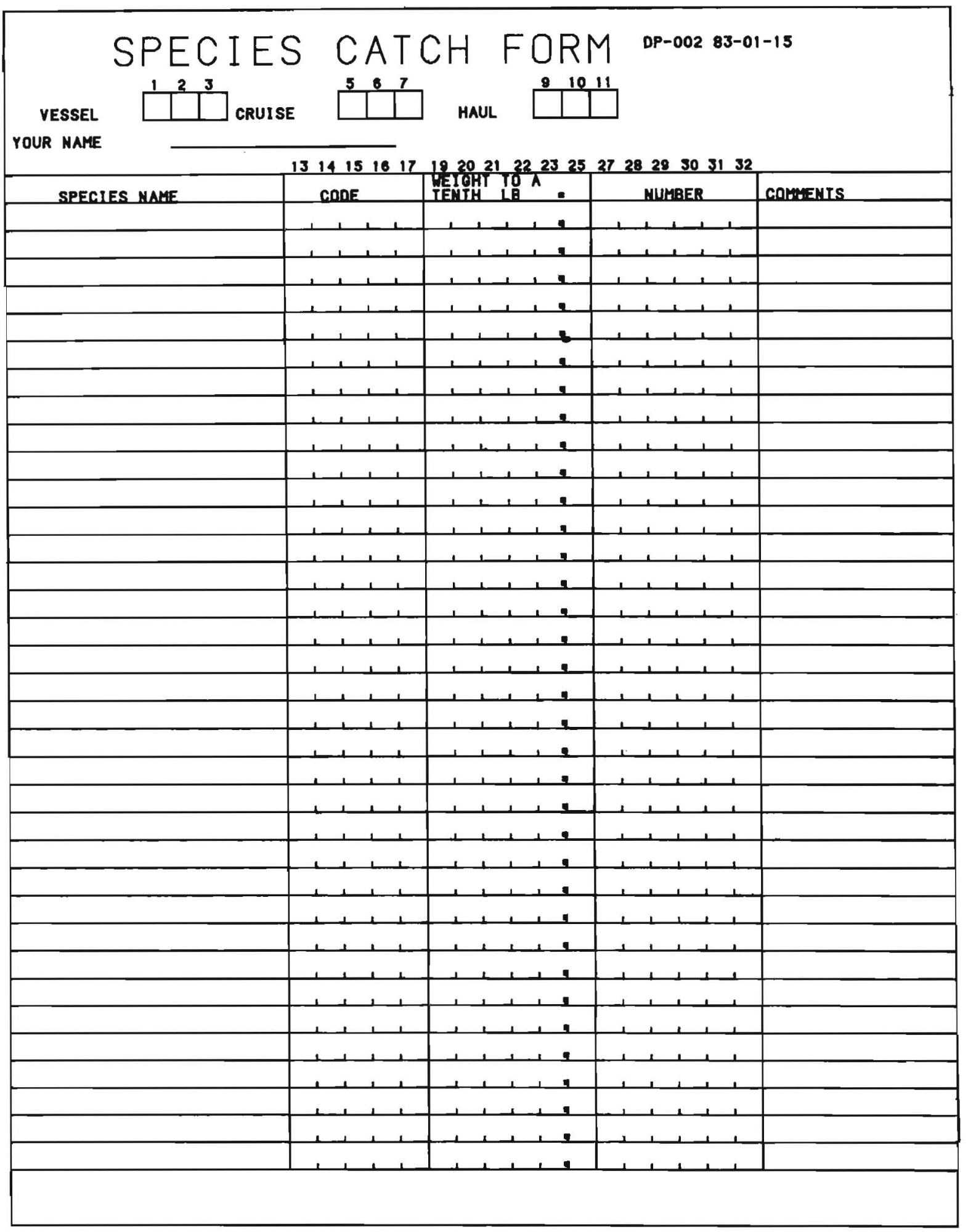

Appendix Figure B

Species catch form used by the National Marine Fisheries Service during bottom trawl surveys in the Bering Sea. 


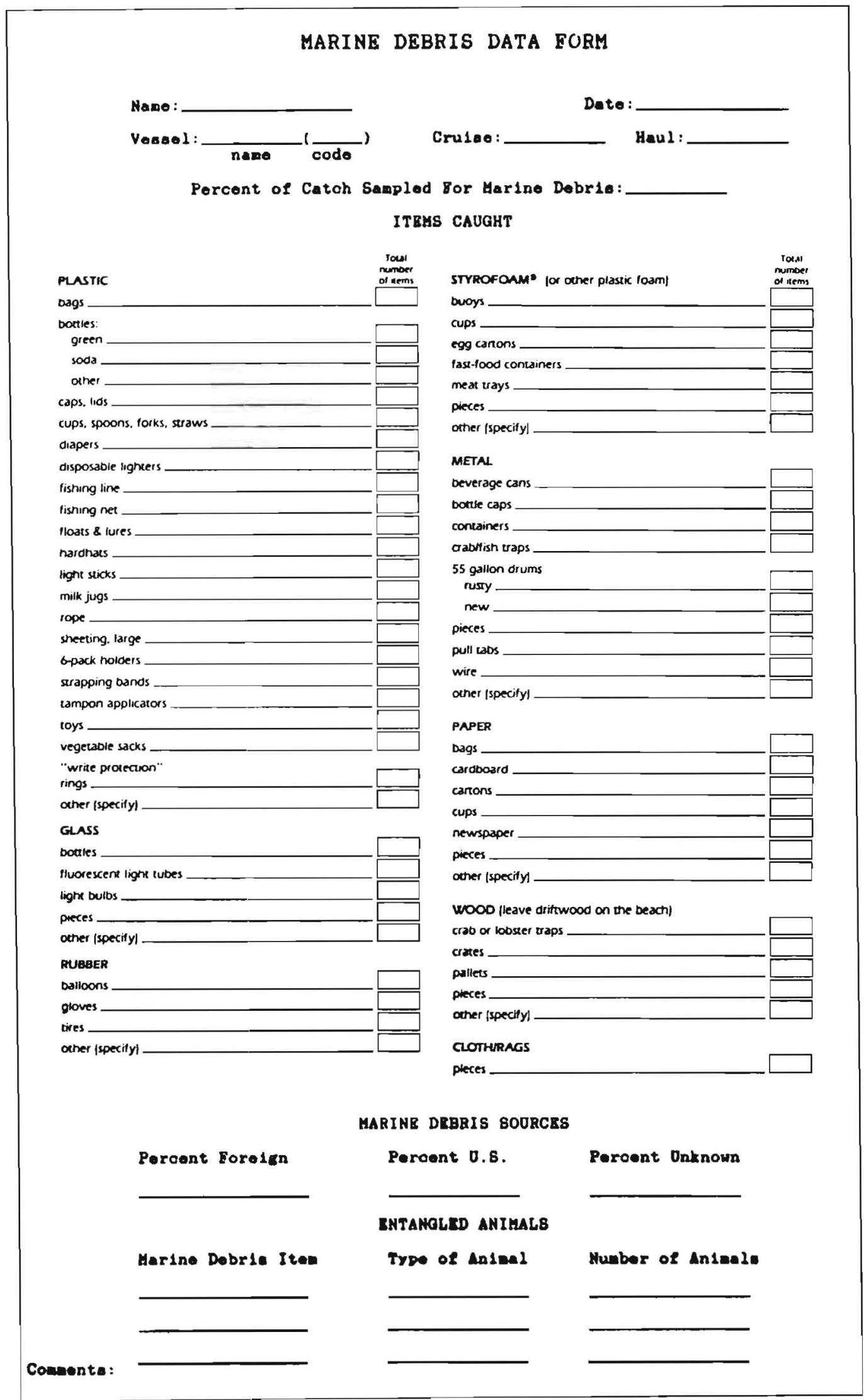

Appendix Figure $C$

Marine debris data form for bottom trawls (June 1990). 


\section{Chapter 6}

\section{Aerial Surveys}

Techniques used in other assessment problems have a potential for use in assessing marine debris problems. The Assessment Working Group mentioned two techniques (Ribic 1990): aerial surveys and remotely operated vehicles (ROVs). ROVs were described in Chapter 5. This chapter discusses aerial surveys.

\section{General Considerations}

Researchers have just started to investigate the use of aircraft to collect data on large to very large debris. Ryan (1988a) sighted large plastic objects (>200 mm in diameter) from an elevation of $130 \mathrm{~m}$ in a light aircraft during calm seas. S. Johnson (NMFS, Auke Bay, AK, pers. commun. August 1991) has used aircraft to assess quantities of trawl web on some Alaska beaches. The major advantage of aerial surveys is that large areas can be covered by aircraft in a relatively short period of time. The disadvantage for general use is the lack of consensus on the field methods and the cost of renting the aircraft. Because the technique is experimental, more research on field design will be needed before its usefulness can be established. For example, there is no consensus on the type of aircraft to use, at what elevation or speed to fly, what types of debris can be seen from the air (we expect that very large debris will be seen), or what the sampling design should be. Other areas to investigate include the use of aerial photography (see Golik and Rosenberg [1987] for tar balls) and aerial reconnaissance as a tool specifically for pilot studies for selecting beach or nearshore sites for other sampling techniques discussed in Chapters 2 and 4.

Typical aircraft used for marine mammal surveys are the Cessna 172 and the Twin Otter. Both are above-wing aircraft (an airplane with the wing located above the fuselage) with good visibility. The Cessna 172 should be used within $15 \mathrm{~km}$ of shore. The Twin Otter can be used up to $320 \mathrm{~km}$ offshore. The Twin Otter travels at faster speeds $(140-160 \mathrm{~km} /$ h) than does the Cessna $172(120-140 \mathrm{~km} / \mathrm{h})$. The Cessna has one engine and is safe to use in bays and sounds and near flat beaches. The Twin Otter, with two engines, is safer to use in the same areas as the Cessna as well as over offshore areas and along rocky coasts.

For safety reasons, both planes should be flown at $60 \mathrm{~m}$ or higher to reduce the effects of engine noise on the behavior of nearby animals. For marine mammal and marine bird surveys, typical flying elevations are 120-140 m. Assessments regarding optimal flying elevation and speed for sighting marine debris have not been done and will likely vary depending on survey objectives and sighting conditions.

The Cessna 172 seats a pilot and two observers; the Twin Otter seats up to six people. In either plane two people would be needed to make observations: one person to observe and the other to record data. A tape recorder may be used as a backup data recorder. In the Twin Otter, there could be three people with two making observations out of opposite windows while the third records the data.

Rental costs for a plane and pilot are $\$ 70-85 /$ hour for the Cessna 172 and $\$ 800-900 /$ hour for the Twin Otter (3-h minimum). If the survey takes more than 1 day, the pilot receives $\$ 200$ per diem.

\section{Aerial Photography}

Aerial photography would be useful primarily for concentrations of large to very large debris. Primarily, a photograph can be taken so that the concentration of debris can be analyzed in detail later. This procedure is typically done for concentrations of marine mammals such as dolphin species.

For aerial photography, a Twin Otter should be used because typically the survey planes have the camera mounts in place. A $9 \times 9 \mathrm{~T}-11$ camera can be rented for about $\$ 1,000 / \mathrm{mo}$, and film for this camera will cost about $\$ 1,000 /$ roll. This type of camera is suggested because of its ability to take photographs of large areas, with high resolution (which is in part due to the negatives being $22.9 \mathrm{~cm}^{2}$ ) (R. Grotefendt, Ebasco Environmental, Bellevue, WA, pers. commun. August 1991). Similar cameras of newer design may be used but will cost much more. The camera weighs $25 \mathrm{~kg}$ or more and will have to be 
shipped to the place of use. The cost of shipping is not covered in the monthly rental fee. The plane, which travels at speeds greater than $140 \mathrm{~km} / \mathrm{h}$, must fly higher than $60 \mathrm{~m}$ to get useful pictures (to prevent blurring of images and to cover a large enough area). The film development will be an additional cost.

\section{Conclusion}

More work must be done to assess the usefulness of aerial surveys for monitoring marine debris. Aerial photography may be particularly useful for surveying debris in coastal areas and on beaches where debris is concentrated. 


\section{Glossary}

Accumulation rate. Amount of debris added to a sampling unit during a specified time period (usually measured after cleaning of all debris).

Aerial survey. A survey made using an airplane or helicopter.

Assessment studies. Studies that seek to quantify distribution, movement, and/or trends in the type and amount of marine debris over space and/or time.

Backshore. Zone extending above normal high tide level, but innundated by exceptionally high tides or large waves during storms.

Baseline studies. Studies that describe the types and amount of debris over space and/or time to identify the magnitude of the marine debris problem.

Beach. Whole of the area affected by normal wave action, extending from a depth of $10 \mathrm{~m}$ below water level at the lowest tide to the edge of the permanent coast; beaches may be composed of mud, sand, gravel, boulders, and/or rock ledges.

Composite. A container made with a cardboard body and metal or plastic ends.

Diving survey. A survey made underwater by personnel using scuba or snorkeling equipment.

Fiberboard. Thick brown cardboard that may be used to package cases of cans.

Fishing gear. Any physical item or combination of items that is placed in the water for the intended purpose of capturing or controlling for subsequent capture, living marine or aquatic organisms (Coe 1986).

Foreshore. A zone that includes that part of the beach regularly covered and uncovered by high tides.

Gill net. Lightweight singlestrand or multistrand filament netting (Cole et al. 1990).

Gillnet floats. Small elongated rigid foamed floats that are grooved and have four holes for attachment to the "cork line" of a gill net (Cole et al. 1990).

Knot. A measure of speed equal to nautical miles per hour.

Laminate. A material made up of two or more components.

Landbased debris. Solid materials of human origin that reach the sea through waterways, domestic and industrial outfalls, or improper disposal on beaches.

Large debris. Solid waste of human origin or manufacture that is $>10 \mathrm{~cm}$ and $\leq 1 \mathrm{~m}$.
Marine debris (marine litter). Solid materials of human origin that are discarded at sea or reach the sea through waterways or through domestic and industrial outfalls (National Academy of Sciences 1975).

Medium debris. solid waste of human origin or manufacture that is $22.5 \mathrm{~cm}$ and $\leq 10 \mathrm{~cm}$.

Nautical mile. A measure of distance based on latitude and longitude; equal to $1.9 \mathrm{~km}$ (abbreviated as "nmi").

Nonparametric statistical method. A statistical method is nonparametric if it may be used on data with a nominal or ordinal scale of measurement and if no assumptions are made about the data (i.e., distribution-free methods). Nonparametric methods are often used in situations when data describe populations that are not normally distributed. Some methods are analogues of parametric tests. Examples include the Mann-Whitney $U$ test and the Kruskall-Wallis test.

Non-reusable. A manufactured product designed for one-time use (e.g., bottle, can) on which no deposit is normally charged.

Oceanic influences. A factor affecting a marine debris survey that is related to physical oceanographic processes such as tides and currents.

Open top cans. Completely sealed cans with no reclosable lid that may be opened with a can opener or have pull-off ends.

Parametric statistical method. A statistical method derived by assuming a specified theoretical model for the the data. The most common theoretical model used is the normal distribution. Many parametric tests have nonparametric analogues. Examples include the $t$-test and $F$-test.

Population of interest. All or a selected type of debris within an area defined in space and time and about which an inference is to be made.

Primary packaging. Any package that is in direct contact with the product and without which the product normally would not be sold.

Quality assurance program plan. An orderly collection of detailed and specific operational procedures that delineate how a project will be implemented and what quality control procedures will be employed to ensure that data of known and acceptable quality will be generated; it further specifies how data will be evaluated to ensure that it meets specified project goals (Verner 1990). 
Returnable. The general term used for a beverage container that is intended to be reused or recycled.

Sample mean. A measure of central tendency; the average of the measurements.

$$
\bar{x}=\frac{\sum x_{i}}{n}
$$

Sample variance. A measure of spread; the average squared deviation of the observations from their mean:

$$
s^{2}=\frac{\sum\left(x_{i}-\bar{x}\right)^{2}}{n-1} \quad \begin{array}{r}
\text { (unbiased } \\
\text { formula) }
\end{array}
$$

Sampling frame. A listing of all possible sampling units that can be defined in the target population; the sampling units used in the survey are randomly or systematically chosen from the sampling frame.

Sampling unit. A defined area on which a measurement will be taken.

Sea state. A code combining information on wind, waves, and swell height to describe oceanic conditions; numbered from 0 to 9 . The most useful in marine debris surveys are sea states 0 through 4 , with sea states of 5 or greater being used for severe conditions (i.e., gales). Sea states (SS) 0 through 4 are as follows:

SS 0 = sea like a mirror; winds $<1 \mathrm{nmi}$; average wave height is $0 \mathrm{~m}$.

SS 1 = a smooth sea; ripples, very light winds; average wave height $0-0.3 \mathrm{~m}$.

SS 2 = a slight sea; small wavelets; winds light to gentle; average wave height $0.3-0.6 \mathrm{~m}$.

SS 3 = a moderate sea; large wavelets, crests beginning to break; winds gentle to moderate; average wave height $0.6-1.2 \mathrm{~m}$.

SS 4 = a rough sea; moderate waves; whitecaps; winds moderate to strong breeze; average wave height $1.2-2.4 \mathrm{~m}$.

(from Duxbury and Duxbury 1984).

Secondary packaging. Packaging used to collate multiples of other containers, usually used while transporting goods.

Shore. The zone between the water's edge at normal low tide and the shoreward limit of effective wave action.

Shoreward limit of wave action. The landward limit of effective wave action that generally occurs on the upper foreshore and usually is identified by a pronounced concentration of debris.
Small debris. Solid waste of human origin or manufacture that is $<2.5 \mathrm{~cm}$.

Standing stock. Amount of material found in the sampling unit at a specified time.

Statistical hypothesis. A statement about a population parameter that a researcher is interested in testing; the most usual parameters of interest are population means or changes in population means.

Statistical power. The probability of rejecting a null hypothesis when that hypothesis is false. Used in trend assessment studies to determine the number of survey units to be used. Typically, a power of $75 \%$ or more is used in sample size calculations.

Stratification. The use of additional information to divide the sampling frame into non-overlapping groups and then selecting a simple random sample from each group. Use of stratification may produce a gain in precision in the parameter estimates.

Systematic survey. A survey design that follows a rule for choosing the sampling units. For example, after a random starting point is chosen, every $k$ th sampling unit is used. Often used with a grid to sample a large geographic area.

Target population. The difference between the population of interest and any restricted-access areas within the population of interest. If there are no restrictions, the target population and the population of interest are the same.

Transect. The linear sampling unit on a beach or in the open water of known length. Width may or may not be defined. For strip transects, width is fixed; for line transects, width is not fixed.

Trawl/seine web. Twisted or braided fishing net (Cole et al. 1990).

Trawl survey. A survey made using a boat that pulls a net at set depths in the water column (e.g., surface, mid-water, bottom).

Very large debris. Solid waste of human origin or manufacture that is $>1 \mathrm{~m}$.

Vessels of opportunity. A ship dedicated to a purpose not related to studying debris but which allows researchers to conduct debris studies that do not conflict with the ship's primary purpose.

Vessel-source debris. Solid materials of human origin which were discarded at sea.

$<$ Less than.

$>$ Greater than.

$\leq$ Less than or equal to.

$\geq$ Greater than or equal to. 


\section{List of Acronyms}

$\begin{array}{ll}\text { EPA } & \text { Environmental Protection Agency } \\ \text { FAO } & \text { Food and Agricultural Organization (of the United Nations) } \\ \text { IOC } & \text { Intergovernmental Oceanographic Commission (of UNESCO) } \\ \text { GIPME } & \text { Global Investigation of Pollution in the Marine Environment } \\ \text { CMC } & \text { Center for Marine Conservation } \\ \text { MARPOL } & \text { International Convention for the Prevention of Pollution from Ships } \\ \text { NMML } & \text { National Marine Mammal Laboratory } \\ \text { IMO } & \text { International Maritime Organization } \\ \text { NOAA } & \text { National Oceanic and Atmospheric Administration } \\ \text { ROV } & \text { remote operating vehicle } \\ \text { CPUE } & \text { catch per unit effort }\end{array}$





\section{Citations}

Ainley, D. G., W. R. Fraser, and L. B. Spear.

1990a. The incidence of plastic in the diets of Antarctic seabirds. In Proceedings of the second international conference on marine debris, 2-7 April 1989, Honolulu, HI (R. S. Shomuta and M. L. Godfrey, eds.), p. 682-691. NOAA Tech. Memo. NMFS, NOAA-TM-NMFS-SWFSC-154.

Ainley, D. G., L. B. Spear, and C. A. Ribic.

1990b. The incidence of plastics in the diets of pelagic seabirds in the eastern equatorial Pacific region. In Proceedings of the second international conference on marine debris; 2-7 April 1989, Honolulu, HI (R. S. Shomura and M. L. Godfrey, eds.), p. 653-664. NOAA Tech. Memo. NMFS, NOAA-TM-NMFS-SWFSC-154.

Andersen, N.R., R. Dawson, and G. Kullenberg.

1986. The program of Global Investigation of Pollution in the Marine Environment (GIPME) of the Intergovernmental Oceanographic Commission (IOC). Mar. Tech. Soc. J. 20:21-28.

Andre, J. B., and R. Ittner.

1980. Hawaiian monk seal entangled in fishing net. 'Elepaio (J. Hawaiian Audubon Soc.) 41:51.

Anonymous

1981. Nylon thread pollution. Mar. Poll. Bull. 12:397.

Atwood, D. K., F. J. Burton, J. E. Corredor, G. R. Harvey, A. J. Mata-

Jimenez, A. Vasquez-Botello, and B. A. Wade.

1987a. Results of the CARIPOL petroleum pollution monitoring project in the wider Caribbean. Mar. Pollut. Bull. $18: 540-548$

Atwood, D. K., H. H. Cummings, W. J. Nodal, and R. C. Culbertson.

1987b. The CARIPOL petroleum pollution monitoring project and the CARIPOL petroleum pollution database. Caribbean Jour. Sci. 23:1-3.

Atwood, D. K, F. J. Burton, J. E. Corredor, G. R. Harvey, A. J. Mata-

Jimenez, A. Vasquez-Botello, and B. A. Wade.

1987c. Petroleum pollution in the Caribbean. Oceanus $30: 25-32$

Augerot, $\mathrm{X}$.

1988. Plastic in the ocean: what are we doing to clean it up? Washington Sea Grant Marine Advisory Services, Univ. Washington, Seattle, WA, 8 p.

Austin, H. M., and P. M. Stoop-Glas.

1977. The distribution of polystyrene spheres and nibs in Block Island Sound during 1972-1973. Chesapeake Sci. 18:89-92.

Azzarello, M. Y., and E. S. Van Vleet.

1987. Marine birds and plastic pollution. Mar. Ecol. Prog. Ser. 37:295-303.

Baba, N., K. Yoshida, M. Onoda, N. Nagai, and S. Toishi.

1988. Results of research on floating fishing gear and fish net fragments in the area southwest of the Pribilof Islands and off southern coasts of the Aleutian Islands, July-August 1985. In Proceedings of the North Pacific Rim fisherman's conference on marine debris; 13-16 October 1987, KailuaKona, HI (D. L. Alverson and J. A. June, eds.), p. 143164. Natural Resources Consultants, Seattle, WA.

Baba, N., M. Kiyota, and K. Yoshida.

1990. Distribution of marine debris and northern fur seals in the eastern Bering Sea. In Proceedings of the second international conference on marine debris; 2-7 April 1989, Honolulu, HI (R. S. Shomura and M. L. Godfrey eds.), p. 419-430. NOAA Tech. Memo. NMFS, NOAA-TM-NMFSSWFSC-154.
Bakkala, R. G., and K. Wakabayashi, eds.

1985. Results of the cooperative U.S.-Japan groundfish investigations in the Bering Sea during May-August 1979. Int. North Pacific Fisheries Comm., Vancouver, Canada, 249 p.

Balazs, G. $\mathrm{H}$.

1979. Synthetic debris observed on a Hawaiian monk seal. 'Elepaio (J. Hawaiian Audubon Soc.) 40:43-44.

1985. Impact of ocean debris on marine turtles: entanglement and ingestion. In Proceedings of the workshop on the fate and impact of marine debris; 27-29 November 1984, Honolulu, HI. NOAA Tech. Memo., NMFS, NOAA-TMNMFS-SWFC-54.

Baltz, D. M., and G. V. Morejohn.

1976. Evidence from seabirds of plastic particle pollution off central California. Western Birds 7:111-112.

Barnard, J., W. Myers, J. Pearce, F. Ramsey, M. Sissenwine, and

W. Smith.

1985. Surveys for monitoring changes and trends in renewable resources: forests and marine fisheries. The American Statistician 39:363-373.

Bayer, R. D., and R. E. Olson.

1988. Plastic particles in 3 Oregon fulmars. Oregon Birds $14: 155-156$

Bean, M. J.

1984. United States and international authorities applicable to entanglement of marine mammals and other organisms in lost or discarded fishing gear and other debris. Rep. to Mar. Mamm. Comm. Washington, D.C., 56 p.

1987. Legal strategies for reducing persistent plastics in the marine environment. Mar. Pollut. Bull. 18(6B): $357-360$.

Berger, J. D., and C. E. Armistead.

1987. Discarded net material in Alaskan waters, 1982-84. NOAA Tech, Memo., NMFS F/NWC-110.

Bigg, M. A.

1979. Incidence of adult northern fur seals entangled in debris on St. Paul Island, 1978. Background paper submitted to the 22nd Annual Meeting of the Standing Scientific Committee, North Pacific Fur Seal Commission, 9-13 April 1979, Washington, D.C., Pacific Biological Station, Nanaimo, British Columbia V9R SK6, Canada, 6 p.

1982. Sizes of scrap fishnet and plastic packing bands from western Vancouver Island during August-September 1982. Background paper submitted to the 26th Annual Meeting of the Standing Scientific Committee, North Pacific Fur Seal Commission, 28-29 March 1983, Washington D.C. Pacific Biological Station, Nanaimo, British Columbia V9R SK6, Canada, 4 p.

Bingel, F., D. Avsar, and M. Ünsal.

1987. A note on plastic materials in trawl catches in the north-eastern Mediterranean. Meeresforsch 31:227-233.

Bond, S. I.

1971. Red phalarope mortality in Southern California Calif. Birds 2:97.

Bonner, W. N., and T. S. McCann.

1982. Neck collars on fur seals, Arctocephalus gazella, at South Georgia. Br. Antarct. Surv. Bull. 57:73-77.

Bourne, W. R. P

1983. Reappraisal of the threats to seabirds. Mar. Pollut. Bull. 14:1-2.

1985. Turtles and pollution. Mar. Pollut. Bull. 16:177-178. 
Bourne, W. R. P. (chair).

1990. Report of the working group on entanglement of marine life. In Proceedings of the second international conference on marine debris; 2-7 April 1989, Honolulu, HI, (R. S. Shomura and M. L. Godfrey, eds.), p. 1207-1215. NOAA Tech. Memo. NMFS, NOAA-TM-NMFS-SWFSC- 154.

Bourne, W. R. P., and M. J. Imber.

1982. Plastic pellets collected by a prion on Gough Island, central South Atlantic Ocean. Mar. Pollut. Bull. 13:20-21.

Brockwell, P. J., and R. A. Davis.

1989. Time series: theory and methods. Springer-Verlag, New York. 519 p.

Burnham, K. P., and D. R. Anderson.

1984. The need for distance data in transect counts. J. Wildl. Manage. 48:1248-1254

Burnham, K. P., D. R. Anderson, and J. L. Laake.

1980. Estimation of density from line transect sampling of biological populations. Wildl. Monogr. 72.

1985. Efficiency and bias in strip and line transect sampling. J. Wildl. Manage. 49:1012-1018.

Butler, J. N., and B. F. Morris.

1974. Quantitative monitoring and variability of pelagic tar in the North Atlantic. In Marine pollution monitoring (petroleum), proceedings of a symposium and workshop held at NBS, 13-17 May 1974, Gaithersburg, Maryland. NBS Spec. publ. 409.

Caddy, J. R.

1976. Practical considerations for quantitative estimation of benthos from a submersible. In Underwater research (E.A. Drew, J. N. Lythgoe, and J. D. Woods, eds.), p. 285298. Academic Press Inc., NY.

Calkins, D. G.

1985. Stellar sea lion entanglement in marine debris. In Proceedings of the workshop on the fate and impact of marine debris; 27-29 November 1984, Honolulu, HI (R. S. Shomura and H. O. Yoshida, eds.), p. 308-314. NOAA Tech. Memo. NMFS, NOAA-TM-NMFS-SWFC-54.

Carpenter, E. J.

1976. Plastics, pelagic tar, and other litter. In Strategies for marine pollution monitoring (E.D. Goldberg, ed.) p. 7789. John Wiley and Sons. NY.

Carpenter, E. J., and K. L. Smith, Jr.

1972. Plastics on the Sargasso Sea surface. Science 175:1240-1241.

Carpenter, E. J., S. J. Anderson, G. R. Harvey, H. P. Miklas, and B. B. Peck.

1972. Polystyrene spherules in coastal waters. Science 178:749-750.

Carr, A.

1986. Rips, FADS, and little loggerheads. BioScience 36:92-100.

1987. Impact of non-degradable marine debris on the ecology and survival outlook of sea turtles. Mar. Pollut. Bull. 18(6B):352-356.

Carr, A. H., E. H. Amaral, A. W. Hulbert, and R. Cooper.

1985. Underwater survey of simulated lost demersal and lost commercial gill nețs off New England. In Proceedings of the workshop on the fate and impact of marine debris, 27-29 November 1984, Honolulu, HE (R.S. Shomura and H.O. Yoshida, eds.), p. 439-447. NOAA Tech. Memo. NMFS, NOAA-TM-NMFS-SWFC-54.

Caulton, E., and M. Mocogni.

1987. Preliminary studies of man-made litter in the Firth of Forth, Scotland. Mar. Pollut. Bull. 18(6B):446-450.
Cawthorn, M. W

1985. Entanglement in and ingestion of plastic litter by marine mammals, sharks, and turtles in New Zealand waters. In Proceedings of the workshop on the fate and impact of marine debris, 27-29 November 1984, Honolulu HI (R.S. Shomura and H.O. Yoshida, eds.), p. 336343. NOAA Tech Memo. NOAA-TM-NMFS-SWFS-54.

1989. Impacts of marine debris on wildlife in New Zealand coastal waters: Marine debris in New Zealand's coastal waters; proceedings of the national workshop on marine debris, Department of Conservation, 9 March 1989, Wellington.

CEE (Center for Environmental Education).

1986. Marine wildlife entanglement in North America. Center for Environmental Education, Washington D.C. $219 \mathrm{pp}$.

1987a. Plastics in the ocean: more than a litter probIem. Center for Environmental Education, Washington D.C. $128 \mathrm{pp}$.

1987b. 1986 Texas coastal cleanup report. Center for Environmental Education, Washington, D.C. 56 p.

1988. Texas coastal cleanup report. Center for Environmental Education, Washington, D.C. 105 pp.

CMC (Center for Marine Conservation).

1991. Cleaning North America's beaches, 1990 beach cleanup results. Center for Marine Conservation, Washington, D.C. $291 \mathrm{p}$.

Clark, R. B.

1986. Marine pollution. Clarendon Press, Oxford. 215 pp.

Coe, J. M.

1986. Derelict fishing gear: disaster or nuisance? M.A. thesis, Univ. of Wash., Seattle, WA. 79 p.

Cole, C. Andrew, John P. Kumer, David A. Manski, and Daniel V. Richards (eds).

1990. Annual report of National Park Marine Debris Monitoring Program: 1989 marine debris Survey. Tech. Report NPS/NRWV/NRTR-90/04.

Coleman, F. C., and D. H. S. Wehle.

1984. Plastic pollution: a world-wide problem. Parks 9:912.

Colton, J. B., Jr.

1974. Plastics in the ocean. Oceanus 18:61-64.

Colton, J. B., Jr., F. D. Knapp, and B. R. Burns.

1974. Plastic particles in surface waters of the northwestern Atlantic. Science 185:491-497.

Conant, $\mathrm{S}$.

1984. Man-made debris and marine wildlife in the Northwestern Hawaiian Islands. 'Elepaio 1 (J. Hawaiian Audubon Soc.) 44:87-88.

Connors, P. G., and K. G. Smith.

1982. Oceanic plastic particle pollution: suspected effect on fat deposition in red phalaropes. Mar. Pollut. Bull. 13: $18-20$.

Conover, W. J.

1980. Practical nonparametric statistics. John Wiley and Sons, NY, 493 p.

Corredor, J. E., D. K. Atwood, A. Mata, and A. Vasquez-Botello (eds.).

1987. Proceedings of the CARIPOL symposium on research and monitoring of petroleum pollution in the Caribbean Sea and Adjacent Regions convened in La Parguera, Puerto Rico, 2-6 December 1985. Caribbean Jour. Sci. 23(1).

Crittenden, R. N.

1989. Abundance estimation based on echo counts. Ph.D. dissertation, Univ. Washington, Seattle, 169 p. 
Croxall, J.

1990. Impact of incidental mortality on Antarctic marine vertebrates. Antarctic Science 2:1

Croxall, J. P., S. Rodwell, and X. L. Boyd.

1990. Entanglement in man-made debris of Antarctic fur seals at Bird Island, South Georgia. Marine Mammal Science 6:221-233.

Cundell, A. M.

1973. Plastic materials accumulating in Narragansett Bay. Mar. Pollut. Bull. 4:187-188.

Dahlberg, M. L., and R. H. Day.

1985. Observations of man-made objects on the surface of the North Pacific Ocean. In Proceedings of the workshop on the fate and impact of marine debris, 27-29 November 1984, Honolulu, HI, (R.S. Shomura and H.O. Yoshida, eds.) p. 198-212. NOAA Tech. Memo. NMFS, NOAA-TM-NMFSSWFC-54.

Dart, J. K. G., and P. S. Rainbow.

1976. Some underwater techniques for estimating echinoderm populations. In Underwater research (E. A. Drew, J. N. Lythgoe, and J. D. Woods, eds.), p. 302-312. Academic Press Inc., NY.

Day, R. H.

1980. The occurrence and characteristics of plastic pollution in Alaska's marine birds. M.S. thesis, Univ. Alaska, Fairbanks. $111 \mathrm{p}$.

Day, R. H., and D. G. Shaw.

1987. Patterns in the abundance of pelagic plastic and tar in the North Pacific Ocean, 1976-1985. Mar. Pollut. Bull. 18(6B):31 1-316

Day, R. H., D. G. Shaw, and S. E. Ignell.

1990a. The quantitative distribution and characteristics of marine debris in the North Pacific Ocean, 1984-88. In Proceedings of the second international conference on marine debris; 2-7 April 1989, Honolulu, HI (R. S. Shomura and M. L. Godfrey, eds.), p. 182-211. NOAA Tech. Memo. NMFS, NOAA-TM-NMFS-SWFSC-154.

1990b. The quantitative distribution and characteristics of neuston plastic in the North Pacific Ocean, 1984-88. In Proceedings of the second international conference on marine debris; 2-7 April 1989, Honolulu, HI (R. S. Shomura and M. L. Godfrey, eds.), p. 247-266. NOAA Tech. Memo. NMFS, NOAA-TM-NMFS-SWFSC-154.

Day, R. H., D. H. S. Wehle, and F. C. Coleman.

1985. Ingestion of plastic pollutants by marine birds. In Proceedings of the workshop on the fate and impact of marine debris; 27-29 November 1984, HI (R. S. Shomura and H. O. Yoshida, eds.), p. 344-386. NOAA Tech. memo. NMFS, NOAA-TM-NMFS-SWFC-54

Dean, $\mathrm{T}$.

1985. Plastic hazards to birds. Br. Birds. 78:661-662.

DeGange, A. R., and T. C. Newby.

1980. Mortality of seabirds and fish in a lost salmon driftnet. Mar. Pollut. Bull. 11:322-323.

Dickerman, R. W., and R. G. Goelet.

1987. Northern Gannet starvation after swallowing styrofoam. Mar. Pollut. Bull. 18:293.

Dixon, T. J., and T. R. Dixon.

1983. Marine litter distribution and composition in the North Sea. Mar. Pollut. Bull. 14:145-148.

Dixon, $\Upsilon$. R.

1981. Danger on the beach. Mar. Pollut. Bull. 12:3.

1987. More reports of dangerous packages and munitions. Mar. Pollut. Bull. 18:146.
Dixon, T. R., and A. J. Cooke.

1977. Discarded containers on a Kent beach. Mar. Pollut. Bull. 8:105-109.

Dixon, T. R., and A. J. Dixon.

1980. Marine litter surveillance at two sites on the western Cherbourg Peninsula and west Jutland shores of the English Channel and southern North Sea. Marine Litter Research Programme, Stage 2. The Tidy Britain Group, The Pier Wagen, Great Britain, $80 \mathrm{p}$

Dixon, T.R., and T.J. Dixon

1981a. Marine litter surveillance. Mar. Pollut. Bull. 12:289-295.

1981b. Aeolian Sky packaged chemicals pollution incident. Mar. Pollut. Bull. 12:53-56.

1983. Marine litter surveillance on the North Atlantic Ocean shores of Portugal and the Western Isles of Scotland. Marine Litter Research Programme, Stage 5. The Tidy Britain Group, the Pier Wagen, Great Britain, $70 \mathrm{p}$.

1986. Packaged dangerous goods washed on to beaches of England and Wales. The Environmentalist 6:209-218.

Dixon, T. R. and C. Hawksley.

1980. Litter on the beaches of the British Isles. Report of the First National Shoreline Litter Survey sponsored by The Sunday Times. Marine Litter Research Programme, Stage 3, The Tidy Britain Group, 70 p.

Doubleday, W. G. and D. Rivard (eds.).

1981. Bottom trawl surveys: proceedings of a workshop; 1214 November 1980, Ottawa, Canada. Can. Spec. Publ. Fish. Aquat. Sci. 58, 273 p.

Duerr, C.

1980. Plastic is forever: our nondegradable treasures. Oceans, November 1980:59-60.

Duronslet, M. J., D. B. Revera, and K. M. Stanley.

1991. Marine debris and sea turtle strandings on beaches of the upper Texas and southwestern Louisiana coasts, June 1987 through September 1989. NOAA Tech. Memo NMFS-SEFC.

Duxbury, A.C., and A. Duxbury.

1984. An introduction to the world's ocean. Addison Wesley Publ. Co., Menlo Park, CA; Reading, MA, 408 p.

FAO

1989. Report of the IOC/FAO/UNEP review meeting on the persistent synthetic materials pilot survey; 12-14 June 1989, Haifa, Israel, 46 p.

Feder, H. M., S. C. Jewett, and J. R. Hilsinger.

1978. Man-made debris on the Bering Sea fioor. Mar. Pollut. Bull. 9:52-53.

Fowler, C. W

1982. Entanglement as an explanation for the decline in northern fur seals of the Pribilof Islands. Background paper submitted to the 25th Annual Meeting of the Standing Scientific Committee of the North Pacific Fur Seal Commission, 9-13 April 1984, Moscow, U.S.S.R. NOAA, National Marine Mammal Lab., 7600 Sand Point Way N.E., Seattle, WA $98115,24 \mathrm{p}$.

1984. Entanglement in fishing debris as a contributing factor in the decline of northern fur seals on the Pribilof Islands. Background paper submitted to the 27th Annual Meeting of the Standing Scientific Committee of the North Pacific Fur Seal Commission, 9-13 April 1984, Moscow, U.S.S.R. NOAA, National Marine Mammal Lab., 7600 Sand Point Way N.E., Seattle, WA $98115,33 \mathrm{p}$.

1985. An evaluation of the role of entanglement in the population dynamics of northern fur seals on the Pribilof Islands. In Proceedings of the workshop on the fate and impact of marine debris; 27-29 November 1984, Honolulu, HI (R.S. Shomura and H. O. Yoshida, eds.), p. 291307. NOAA Tech. Memo. NMFS, NOAA-TM-NMFS-SWFC-54. 
1987. Marine debris and northern fur seals: a case study. Mar. Pollut. Bull. 18(6B):326-335.

1988. A review of seal and sea lion entanglement in marine fishing debris. In Proceedings of the North Pacific Rim fisherman's conference on marine debris; 13-16 October 1987, Kailua-Kona, HI (D. L. Alverson and J. A. June, eds.), p. 16-63. Natural Resources Consultants, Seattle, WA.

Fowler, C. W., and T. R. Merrell.

1986. Victims of plastic technology. Alaska Fish and Game 18:34-37

Fowler, C. W. and T. J. Ragen.

1990. Entanglement studies, St. Paul Island, 1989 juvenile male northern fur seals. NMFS, Northwest and Alaska Fisheries Centers NWAFC Processed Report 90-06.

Fowler, C. W., R. Merrick, and N. Baba.

1989. Entanglement studies, St. Paul Island, 1988 juvenile male roundups. NMFS, Northwest and Alaska Fisheries Centers NWAFC Processed Report 89.-01.

Fowler, C. W., R. Merrick, and J. D. Baker.

1990. Studies of the population level effects of entanglement on northern fur seals. In Proceedings of the second international conference on marine debris; 2-7 April 1989, Honolulu, HI (R.S. Shomura and H. O. Yoshida, eds.), p. 291307. NOAA Tech. Memo. NMFS, NOAA-TM-NMFS. SWFSC-154.

Fry, D. M., S. I. Fefer, and L. Sileo.

1987. Ingestion of plastic debris by Laysan albatrosses and wedge-tailed shearwaters in the Hawaiian Islands. Mar. Pollut. Bull. 18(6B):339-343.

Furness, B. L.

1983. Plastic particles in three Procellariiform seabirds from the Benguela Current, South Africa. Mar. Pollut. Bull. 14:307-308.

Furness, R. W.

1985a. Plastic particle pollution: accumulation by Procellariiform seabirds at Scottish colonies. Mar. Pollut. Bull. 16:103-106.

1985b. Ingestion of plastic particles by seabirds at Gough 1sland, South Aclantic Ocean. Environ. Poll. (Series A) $38: 261-272$

Garner, ].

1967. Modern deep sea trawling gear. Fishing News (Books) Lid., London.

Gerrodette, T.

1985. Toward a population dynamics of marine debris. In Proceedings of the workshop on the fate and impact of marine debris; 27-29 November 1984, Honolulu, HI (R. S. Shomura and H. O. Yoshida, eds.), p. 508-518. NOAA Tech. Memo. NMFS, NOAA-NMFS-SWFC-54.

Gilbert, R. O.

1987. Statistical methods for environmental pollution monitoring. Van Nostrand Reinhold Company. NY.

Golik, A.

1982. The distribution and behaviour of tar balls along the Israeli coast. Estuarine Coastal and Shelf Sci. 15:267-276.

Golik, A., and Y. Gertner.

1990. Solid waste on the Israeli coast - composition, sources, and management. In Proceedings of the second international conference on marine debris; 2-7 April 1989. Honolulu, HI (R.S. Shomura and M. L. Godfrey), p. 369378. NOAA Tech, Memo. NMFS, NOAA-TM-NMFSSWFSC-154.

Golik, A. and N. Rosenberg.

1987. Quantitative evaluation of beach stranded tar balls by means of air photographs. Mar. Pollut. Bull. 18:289-293.
Gosliner, $M$.

1985. Legal authorities pertinent to entanglement by marine debris. In Proceedings of the workshop on the fate and impact of marine debris; 27-29 November 1984, Honolulu, HI (R. S. Shomura and H. O. Yoshida), p. 15-33. NOAA Tech. Memo. NMFS, NOAA-NMFS-SWFC-54

Gould, P. J., and D. J. Forsell.

1989. Techniques for shipboard surveys of marine birds. U.S. Fish Wildl. Serv. Tech. Rep. 25. Washington, D.C., $22 \mathrm{p}$

Gramentz, D.

1988. Involvement of loggerhead turtle with the plastic, metal, and hydrocarbon pollution in the Central Mediterranean. Mar. Poll. Bull. 19:11-13.

Gregory, M. R.

1977. Plastic pellets on New Zealand beaches. Mar. Pollut. Bull. 8:82-84.

1978a. Accumulation and distribution of virgin plastic granules on New Zealand beaches. N.Z. J. of Marine and Freshwater Research 12:399-414.

1978b. Virgin plastic granules on southwest Pacific beaches and their possible environmental implications. Tenth Int. Congress on Sedimentology 1:270-271.

1983. Virgin plastic granules on some beaches of eastern Canada and Bermuda. Marine Environ. Res. 10:73-92.

1987. Plastics and other seaborne litter on the shores of New Zealand's subantarctic islands. New Zealand Antarctic Record 7:32-47.

1990. Plastics: accumulation, distribution, and environmental effects of meso-, macro-, and megalitter in surface waters and on shores of the southwest Pacific. In Proceedings of the second international conference on marine debris; 2-7 April 1989, Honolulu, HI (R. S. Shomura and M. L. Godfrey), p. 55-84. NOAA Tech. Memo. NMFS, NOAATM-N.MFS-SWFSC-154.

Gregory, M. R., R. M. Kirk, and M. C. G. Mabin.

1984. Pelagic tar, oil, plastics and other litter in the surface waters of the New Zealand Sector of the Southern Ocean, and on Ross Dependency shores. N.Z. J. Ant. Res. 6:12-28.

Harper, P. C., and J. A. Fowler.

1987. Plastic pellets in New Zealand storm-killed prions (Pachyptila spp.). Notornis 34:65-70.

Hays, H. and G. Cormons.

1974. Plastic particles found in tern pellets, on coastal beaches and at factory sites. Mar. Pollut. Bull. 5:44-46.

HMEPA (Hellenic Marine Environment Protection Association).

1991. Public awareness campaign to limit garbage pollution of the Greek seas and beaches. Final rep. MEDSPA-89-1/ GR/008/GR/S, Mediterrean Special Action Programme for the Environment of the European Communities.

Henderson, J. R.

1984. Encounters of Hawaiian monk seals with fishing gear at Lisianski Island, 1982. Mar. Fish. Rev. 46:59-61.

1985. A review of Hawaiian monk seal entanglements in marine debris. In Proceedings of the workshop on the fate and impact of marine debris; 27-29 November 1984, Honolulu, HI (R. S. Shomura and H. O. Yoshida, eds.), p. 326335. NOAA Tech Memo. NOAA-TM-NMFS-SWFS-54.

1988. Marine debris in Hawaii. In Proceedings of the North Pacific Rim fisherman's conference on marine debris; 13-16 October 1987, Kailua-Kona, HI. Natural Resources Consultants, Seatlle, WA.

1990. Recent entanglements of Hawaiian monk seals in marine debris. In Proceedings of the second international conference on marine debris; 2-7 April 1989, Honolulu, HI, p. 540-553. NOAA Tech. Memo. NMFS, NOAA-TM-NMFSSWFSC-154. 
Henderson, J. R., and M. B. Pillos.

1985. Accumulation of net fragments and other marine debris in the Northwestern Hawaiian Islands (Abstract only). In Proceedings of the workshop on the fate and impact of marine debris; 27-29 November 1984, Honolulu, HI (R. S. Shomura and H. O. Yoshida, eds.), p. 326-335. NOAA Tech Memo. NOAA-TM-NMFS-SWFS-54.

Henderson, J. R., S. L. Austin, and M. B. Pillos.

1987. Summary of webbing and net fragments found on northwestern Hawaiian Islands beaches, 1982-1986. NOAA, NMFS, SWFC Admin. Rep. H-87-1 1, 15 p.

Heneman, B., and the Center for Environmental Education.

1988. Persistent marine debris in the North Sea, northwest Atlantic ocean, wider Caribbean area, and the west coast of Baja California. Unpubl. rep. to the Marine Mammal Commission and National Ocean Pollution Program Office, NOAA, USDC, Contr. Rep. MM3309598-5.

Heyerdabl, $T$.

1971. Atlantic Ocean pollution and biota observed by the 'Ra' Expeditions. Biol. Conservation 3:164-167.

High, W. L.

1985. Some consequences of lost fishing gear. In Proceedings of the workshop on the fate and impact of marine debris: 27-29 November 1984, Honolulu, HI (R. S. Shomura and H. O. Yoshida, eds.), p. 430-437. NOAA Tech Memo. NOAA-TM-NMFS-SWFS-54.

Hirsch, R. M., and J. R. Slack.

1984. A nonparametric trend test for seasonal data with serial dependence. Water Resources Research 20:727-732.

Hirsch, R. M., J. R. Slack, and R. A. Smith.

1982. Techniques of trend analysis for monthly water quality data. Water Resources Research 18:107-121.

Hiscock, $\mathrm{K}$.

1987. Subtidal rock and shallow sediments using diving. In Biological surveys of estuaries and coasts (J. M. Baker and W. J. Wolfe, eds.), p. 198-237. Cambridge United Publishing, Cambridge.

1989. Development of methods for surveys and monitoring using diving. Progress in Underwater Science 13:57-64.

Hjelmeland, K., B. H. Pedersen, and E. M. Nilssen.

1988. Trypsin content in intestines of herring larvae, Clupea harengus, ingesting inert polystyrene spheres or live crustacea prey. Mar. Bio. 98:331-335.

Holmstrōm, A.

1975. Plastic films on the bottom of the Skagerack. Nature (London) 255:622-623.

Horsman, P. V.

1982. The amount of garbage pollution from merchant ships. Mar. Pollut. Bull. 13:167-169.

1985. Garbage kills. BBC Wildlife, August, 391-393.

Hoss, D. E., and L. R. Settle.

1990. Ingestion of plastics by teleost fishes. In Proceedings of the second international conference on marine debris, 2-7 April 1989, Honolulu, HI (R. S. Shomura and M. L. Godfrey), p. 693-709. NOAA Tech. Memo. NMFS, NOAATM-NMFS-SWFSC-154.

Ignell, S. E.

1985. Results of the 1985 research on the highseas squid driftnet fisheries of the North Pacific Ocean. Document submitted to by the International North Pacific Fisheries Commission, Tokyo, Japan, November 1985. Northwest and Alaska Fisheries Center, NMFS, NOAA, Auke Bay Laboratory, Auke Bay, Alaska.

Ignell, S. E., and M. L. Dahlberg.

1986. Results of cooperative research on the distribution of marine debris in the North Pacific Ocean. Document sub- mitted to the International North Pacific Fisheries Commission, Anchorage, AK, November 1986, NWAFC, NMFS, NOAA, Auke Bay Lab., P. O. Box 210155, Auke Bay, AK. $99821,15 \mathrm{p}$.

IOC (Intergovernmental Oceanographic Commission)

1984. Manual for monitoring oil and dissolved/dispersed petroleum hydrocarbons in marine waters and on beaches; Procedures for the petroleum component of the IOC Marine Pollution Monitoring System (MARPOLMON - P). UNESCO Manuals and Guides No. 13, 35 p.

Isaaks, E. H., and R. M. Srivastava.

1989. An introduction to applied geostatistics. Oxford Univ, Press. NY.

Jewett, S. C.

1976. Pollutants of the Northeast Gulf of Alaska. Mar. Pollut. Bull. 7:169.

Johnson, S. W.

1988. Deposition of entanglement debris on Alaskan beaches. In Proceedings of the North Pacific Rim fisherman's conference on marine debris, 13-16 October 1987, Kailua-Kona, HI (D. L. Averson and J. A. June, eds.), p. 207-231. Natural Resources Consultants, Seatule, WA.

1989. Deposition, fate, and characteristics of derelict trawl web on an Alaskan beach. Mar. Pollut. Bull. 20:164-168.

1990a. Distribution, abundance, and source of entanglement debris and other plastics on Alaskan beaches, 1982-88. In Proceedings of the second international conference on marine debris, 2-7 April 1989, Honolulu, HI (R. S. Shomura and M. L. Godfrey, eds.), p. 331-348. NOAA Tech. Memo. NMFS, NOAA-TM-NMFS-SWFSC-154.

1990b. Entanglement debris on Alaskan beaches, 1989. NWAFC Processed Report 90-10. 16 p.

Johnson, S. W., and T. R. Merrell.

1988. Entanglement debris on Alaskan beaches, 1986. NOAA Tech. Memo., NMFS, F/NWC-126. 26 p.

Jones, L. L., and R. C. Ferrero.

1985. Observations of net debris and associated entanglements in the North Pacific Ocean and Bering Sea, 197884. In Proceedings of the workshop on the fate and impact of marine debris; 27-29 November 1984, Honolulu, HI (R. S. Shomura and M. L. Godfrey, eds.), p. 183196. NOAA Tech Memo. NOAA-TM-NMFS-SWFS-54.

June, J. A.

1990. Type, source, and abundance of trawl-caught marine debris off Oregon, in the eastern Bering Sea, and in Norton Sound in 1988. In Proceedings of the second international conference on marine debris, 2-7 April 1989, Honolulu, HI (R. S. Shomura and H. O. Yoshida, eds.), p. 279301. NOAA Tech. Memo. NMFS, NOAA-TM-NMFS-SWFSC154.

Kartar, S., R. A. Milne, and M. Sainsbury.

1973. Polystyrene waste in the Severn estuary. Mar. Pollut. Bull, 4:144.

Kartar, S., F. Abou-Seedo, and M. Sainsbury.

1976. Polystyrene spherules in the Severn estuary-A progress report. Mar. Pollut. Bull. 7:52.

Keller, G. H.

1977. The submersible-a unique tool for marine geology. In Submersibles and their use in oceanography and ocean engineering, Elsevier Scientific Publ. Co., Amsterdam, Netherlands.

Kenyon, K. W., and E. Kridler.

1969. Laysan albatrosses swallow indigestible matter. Auk $86: 339-343$ 
Keppel, G.

1982. Design and analysis, a researcher's handbook, 2nd edition. Prentice-Hall, Inc. Englewood Cliffs, NJ.

Klemm, B., and D. Wendt.

1990. Beach confetti. Sea Frontiers 36:28-29.

Kubota, T.

1990. Synthetic materials found in the stomachs of longnose lancetfish collected from Suruga Bay, central Japan. In Proceedings of the second international conference on marine debris, 2-7 April 1989, Honolulu, HI (R. S. Shomura and M. L. Godfrey, eds.), p. 710-717. NOAA Tech. Memo. NMFS, NOAA-TM-NMFS-SWFSC-154.

Kullenberg, G.

1986. The IOC programme on marine pollution. Mar. Pollut. Bull. 17:341-352.

Laist, D. W.

1987. Overview of the biological effects of lost and discarded plastic debris in the marine environment. Mar. Pollut. Bull, 18(6B):319-326.

Lenihan, H. S., J. S. Oliver, J. M. Oakden, and M. D. Stephenson. 1990. Intense and localized benthic marine pollution around McMurdo Sound, Antarctica. Mar. Pol. Bull. 21:422-430.

Lentz, S. A.

1987. Plastics in the marine environment: legal approaches for international action. Mar. Pollut. Bull. 18(6B):361365 .

Lettenmaier, D. P.

1978. Design considerations for ambient stream quality monitoring. Water Resources Bulletin 14:884-902.

Lettenmaier, D. P., L. L. Conquest, and J. P. Hughes.

1982. Routine streams and rivers water quality trend monitoring review. C. W. Harris Hydraulics Laboratory. Dept. of Civil Engineering, Univ. of Washington, Seattle, WA, Technical Report No. 75.

Lindstedt, D. M., and J. C. Holmes.

1989. Debris is not a cheese: litter in coastal Louisiana. proceedings of the sixth symposium on coastal and ocean management, p. 1297-1310.

Lutz, P. L.

1990. Studies on the ingestion of plastic and latex by sea turtles. In Proceedings of the second international conference on marine debris, 2-7 April 1989, Honolulu, HI (R. S. Shomura and M. L. Godfrey, eds.), p. 719 735. NOAA Tech. Memo. NMFS, NOAA-TM-NMFSSWFSC-154.

Manski, D. A., W. P. Gregg, C. A. Cole, and D. V. Richards.

1991. Annual report of the national park marine debris monitoring program, 1990 marine debris surveys. USDI NPS Technical Report NPS/NRWV/NRTR-91. In press.

Manville, II, A. M.

1990. A survey of plastics on western Aleutian Island beaches and related wildlife entanglement. In Proceedings of the second international conference on marine debris; 2-7 April 1989, Honolulu, HI (R. S. Shomura and M. L. Godfrey), p. 349-363. NOAA Tech. Memo. NMFS, NOAATM-NMFS-SWFSC- 154.

MMC (Marine Mammal Commission).

1987. Annual report of the Marine Mammal Commission calendar year 1986. Rep. to Congress. NTIS PB98-154092, $193 \mathrm{p}$.

1991. Annual report of the Marine Mammal Commission calendar year 1990 . Rep. to Congress. NTIS. 270 p.
MPDTF (Marine Plastic Debris Task Force).

1988. Marine plastic debris action plan for Washington State. Washington State Dept. of Natural Resources. 45 pp.

Marquez, J. A., and I. Zandi.

1985. Litter management-measurement aspects. J. Res. Manage. Tech. 14:67-75.

McConnell, K. E. (chair).

1990. Report of the working group on economic aspects of marine debris. In Proceedings of the second international conference on marine debris; 2-7 April 1989, Honolulu, HI (R. S. Shomura and M. L. Godfrey, eds.), p. 12351239. NOAA Tech. Memo. NMFS, NOAA-TM-NMFSSWFSC-154.

McCoy, F. W.

1988. Floating megalitter in the eastern Mediterranean. Mar. Pollut. Bull. 19:25-28.

Meade, N. F., K. M. Drazek, and V. R. Leeworthy.

1990. An economic perspective on the problem of marine debris. In Proceedings of the second international conference on marine debris, 2-7 April 1989, Honolulu, HI (R. S. Shomura and M. L. Godfrey, eds.), p. 777-791. NOAA Tech. Memo. NMFS, NOAA-TM-NMFS-SWFSC-154.

Merrell, T. R.

1980. Accumulation of plastic litter on beaches of Amchitka Island, Alaska. Mar. Environ. Res. 3:171-184.

1984. A decade of change in nets and plastic litter from fisheries off Alaska. Mar. Pollut. Bull. 15 :378-384.

1985. Fishnets and other plastic litter on Alaska beaches. In Proceedings of the workshop on the fate and impact of marine debris; 27-29 November 1984, Honolulu, HI (R. S. Shomura and H. O. Yoshida, eds.), p. 160-182. Memo. NOAA-TM-NMFS-SWFS- 54.

Merrell, T. R., and S. W. Johnson.

1987. Surveys of plastic litter on Alaskan beaches, 1985. NOAA Tech. Memo. NMFS F/NWG-116. 21 p.

Mio, S., and S. Takehama.

1988. Estimation of distribution of marine debris based on the 1986 sighting survey. In Proceedings of the North Pacific Rim fisherman's conference on marine debris; 13-16 October 1987, Kailua-Kona, HI (D. L. Alverson and J. A. June, eds.), p. 64-94. Natural Resources Consultants, Seattle, WA.

Mio, S., S. Takehama, and S. Matsumura.

1990. Distribution and density of fioating objects in the North Pacific based on 1987 sighting survey. In Proceedings of the second international conference on marine de: bris; 2-7 April 1989, Honolulu, HI (R. S. Shomura and M. L. Godfrey, eds.), p. 212-246. NOAA Tech. Memo. NMFS, NOAA-TM-NMFS-SWFSC-154.

Morris, A. W., and E. I. Hamilton.

1974. Polystyrene spherules in the Bristol Channel. Mar. Pollut. Bull. 5:26-27.

Morris, R. J

1980a. Floating plastic debris in the Mediterranean. Mar. Pollut. Bull. 11:125.

1980b. Plastic debris in the surface waters of the South Atlantic. Mar. Pollut. Bull. 11:164-166.

Nasu, K., and K. Hiramatsu.

1990. Distribution and density of marine debris in the North Pacific based on sighting surveys in 1989. Document submitted to the Annual Meeting of the International North Pacific Fisheries Commission, Vancouver, Canada, 1990. October. Fisheries Agency of Japan, National Research Insti- 
tute of Far Seas Fisheries, 7-1 Orido 5 chome, Shimizu, Shizuoka, Japan 424. 28 p.

NAS (National Academy of Sciences).

1975. Marine litter. In Assessing potential ocean pollutants. A report of the study panel on assessing potential ocean pollutants to the Ocean Affairs Board, Commission on Natural Resources, National Research Council, National Academy of Sciences, Washington, D.C.

Neilson, J.

1985. The Oregon experience. In Proceedings of the workshop on the fate and impact of marine debris; 27-29 November 1984, Honolulu, $\mathrm{HI}$ (R. S. Shomura and H. O. Yoshida, eds.), p. 154-159. NOAA Tech Memo. NOAA-TMNMFS-SWFS-54.

Ogi, $\mathrm{H}$.

1990. Ingestion of plastic particles by sooty and short-tailed shearwaters in the North Pacific. In Proceedings of the second international conference on marine debris, 2-7 April 1989, Honolulu, HI (R. S. Shomura and M. L. Godfrey, eds.), p. 635-652. NOAA Tech. Memo. NMFS, NOAA-TM-NMFS-SWFSC-154.

O'Hara, K. J.

1989. Trash on America's beaches: a national assessment. Center for Marine Conservation, Washington D.C.

1990. National marine debris data base: findings on beach debris reported by citizens. In Proceedings of the second international conference on marine debris; 2-7 April 1989, Honolulu, HI (R. S. Shomura and M. L. Godfrey, eds.), p. 379-391. NOAA Tech. Memo. NMFS, NOAA-TM-NMFSSWFSC-154.

O'Hara, K. J., and P. Debenham.

1989. Cleaning America's beaches: 1988 national beach cleanup results. Center for Marine Conservation, Washington, D.C. 202 p.

O'Hara, K. J., and L. K. Younger.

1990. Cleaning North America's beaches, 1989 beach cleanup results. Center for Marine Conservation, Washington, D.C. $310 \mathrm{p}$.

O'Hara, K. J., S. ludicello, and R. Bierce.

1988. A citizens guide to plastic in the ocean: more than a litter problem. Center for Environmental Education, Washington, D.C. $131 \mathrm{p}$

Palmer, H. D.

1977. The use of manned submersibles in the study of ocean waste disposal. In Submersibles and their use in oceanography and ocean engineering (R. A. Geyer, ed.), p. 317-334. Elsevier Scientific Publ. Co., Amsterdam, Netherlands.

Parker, P. A.

1990. Clearing the oceans of plastic. Sea Frontiers 36:1827.

Parslow, J. L. F., and D. J. Jefferies.

1972. Elastic thread pollution in puffins. Mar. Pollut. Bull. $3: 43-45$.

Pettit, T. N., G. S. Grant, and G. C. Whittow.

1981. Ingestion of plastics by Laysan albatross. Auk 98:839 841.

Plotkin, P., and A. F. Amos.

1990. Effects of anthropogenic debris on sea turtles in the northwestern Gulf of Mexico. In Proceedings of the second international conference on marine debris; 2-7 April 1989, Honolulu, HI (R. S. Shomura and M. L. Godfrey, eds.), p. 736-743. NOAA Tech. Memo. NMFS, NOAA-TMNMFS-SWFSC-154.
Pritzlaff, J. A. (ed.).

1979. International safety standard guidelines for the operation of undersea vehicles. Marine Technology Society, Washington, D.C.

Pruter, A. T.

1987a. Sources, quantities and distribution of persistent plastics in the marine environment. Mar. Pollut. Bull. 18(6B):305-310.

1987b. Plastics in the marine environment. Fisheries 12:16-17.

Randall, B. M., R. M. Randall, and G. J. Rossouw.

1983. Plastic particle pollution in great Shearwater (Puffinius gravis) from Gough Island. South African Journal of Antarctic Research 13:49-50.

Ribic, C. A. (chair).

1990. Report of the working group on methods to assess the amount and types of marine debris. In Proceedings of the second international conference on marine debris; $2-7$ April 1989, Honolulu, HI (R. S. Shomura and M. L. Godfrey, eds.), p. 1201-1206. NOAA Tech. Memo. NMFS, NOAA-TM-NMFS-SWFSC- 154.

1991. Design of shoreline surveys for aquatic litter pollution. Final report to U.S. EPA Office of Marine and Estuarine Protection. EPA/600/3-91/026. NTIS PB 91179051/AS.

Ribic, C. A., and L. J. Bledsoe.

1986. Design of surveys for density of surface marine debris in the North Pacific. NOAA, NMFS, NWAFC Processed Rept. No. 267. $69 \mathrm{p}$.

1990. Estimating the density of floating marine debris: Design considerations. In Proceedings of the second international conference on marine debris; 2-7 April 1989, Honolulu, HI (R. S. Shomura and M. L. Godfrey, eds.), p. 302-308. NOAA Tech. Memo. NMFS, NOAA-TM-NMFSSWFSC-154.

Ribic, C. A., and S. W. Johnson.

1990. Guidelines for the design of beach debris surveys. In Proceedings of the second international conference on marine debris; 2-7 April 1989, Honolulu, HI (R. S. Shomura and M. L. Godfrey, eds.), p. 392-402. NOAA Tech. Memo. NMFS, NOAA-TM-NMFS-SWFSC-154.

Rice, W. D., and A. A. Wolman.

1982. Whale census in the Gulf of Alaska, June to August 1980. Rep. to the Int. Whaling Comm. 32:491-497.

Risebrough, R.W.

1969. The sea: should we write it off as the future garbage pit? From background book supplement, 13th National Conference, U.S. National Comm. for UNESCO, San Francisco, 23-25 November. $23 \mathrm{p}$

Rothstein, S. I.

1973. Plastic particle pollution of the surface of the Atlantic Ocean: evidence from a seabird. Condor 75 : 344-345.

Ryan, P. G.

1985. Plastic pollution at sea and in seabirds off southern Africa (Abstract only), In Proceedings of the workshop on the fate and impact of marine debris; 27-29 November 1984, Honolulu, HI (R. S. Shomura and H. O. Yoshida, eds.), p. 523. NOAA Tech. Memo. NMFS, NOAA-NMFSSWFC-5 4

1986. The incidence and effects of ingested plastic in seabirds. Ms.C. thesis, Univ. Cape Town, South Africa.

1987a. The effects of ingested plastic on seabirds: correlations between plastic load and body condition. Environ. Pollut. 46:119-125. 
1987b. The incidence and characteristics of plastic particles ingested by seabirds. Mar. Environ. Res. 23:175-206.

1988a. Effects of ingested plastic on seabird feeding: evidence from chickens. Mar. Pollut. Bull. 19:125-128.

1988b. The characteristics and distribution of plastic particles at the sea-surface off the Southwestern Cape Province, South Africa. Mar. Environ. Res. 25:249-273.

1988c. Intraspecific variation in plastic ingestion by seabirds and the fiux of plastic through seabird popula(ions. Condor 90:446-452.

1990a. The effects of ingested plastic and other marine debris on seabirds. In Proceedings of the second international conference on marine debris; 2-7 April 1989, Honolulu, HI (R. S. Shomura and M. L. Godfrey, eds.), p. 623-634. NOAA Tech. Memo. NMFS, NOAA-TM-NMFSSWFSC-154.

1990b. The marine plastic debris problem off southern Africa: types of debris, their environmental effects, and control measures. In Proceedings of the second international conference on marine debris, 2-7 April 1989, Honolulu, HI (R. S. Shomura and M. L. Godfrey, eds.), p. 85102. NOAA Tech. Memo. NMFS, NOAA-TM-NMFSSWFSC-154.

Ryan, P. G., and S. Jackson.

1987. The life span of ingested plastic particles in seabirds and their effect on digestive efficiency. Mar. Pollut. Bull. 18:217-219.

Ryan, P. G., A. D. Connell, and B. D. Gardner.

1988. Plastic ingestion and PCBs in seabirds: is there a relationship? Mar. Pollut. Bull. 19:174-176.

Sadove, S. S., and S. J. Morreale.

1990. Marine mammal and sea turtle encounters with marine debris in the New York Bight and the northeast Atlantic. In Proceedings of the second international conference on marine debris; 2-7 April 1989, Honolulu, HI (R. S. Shomura and M. L. Godfrey, eds.), p. 560-570. NOAA Tech. Memo. NMFS, NOAA-TM-NMFS-SWFSC-154.

Sameoto, D. D., and L. O. Jaroszynski.

1969. Otter surface sampler: A new neuston net. J. Fish. Res. Bd. Canada 26:2240-2244.

Sanger, G. A.

1974. On the effect of fish net scraps and other oceanic debris in northern fur seals. Background paper submitted to the 17th Annual Meeting of the Standing Scientific Committee of the North Pacific Fur Seal Commission, 11-25 March 1974, Ottawa, Canada, National Marine Mammal Lab., 7600 Sand Point Way N.E., Seattle, WA 98115.9 p.

Scheffer, V.B.

1950. Experiments in the marking of seals and sea lions. U.S. Fish. Wildl. Serv., Spec. Sci. Rep. Wildl. 4. 33 p.

Schrey, E., and G. J. M. Vauk.

1987. Records of entangled Gannets (Sula bassana) at Helgoland, German Bight. Mar. Pollut. Bull. 18(6B):350-352.

Scordino, J.

1985. Studies on fur seal entanglement, 1981-84, St. Paul Island, Alaska. In Proceedings of the workshop on the fate and impact of marine debris; $27-29$ November 1984, Honolulu, HI (R. S. Shomura and H. O. Yoshida, eds.), p. 278290. NOAA Tech Memo. NOAA-TM-NMFS-SWFS-54.

Scordino, J., and R. Fisher.

1983. Investigations on fur seal entanglement in net fragments, plastic bands and other debris in 1981 and 1982, St. Paul Island, Alaska. Background paper submitted to the 26th Annual Meeting of the Standing Scientific Committee the North Pacific Fur Seal Commission, 28 March-8 April 1983, Washington, D.C., NOAA, National Marine Mammal Lab., 7600 Sand PointWay NE, Seattle, WA 98115.90 p.

Scordino, J., G. Beekman, H. Kajimura, K. Yoshida, Y. Fujimaka, and $\mathrm{M}$. Tomita.

1984. Investigations on fur seal entanglement in 1983 and comparisons with 198I and 1982 entanglement data, St. Paul Island, Alaska. Document submitted to the 27th Annual meeting of the Standing Scientific Committee, North Pacific Fur Seal Commission, 29 March-6 April 1984, Moscow. NOAA, National Marine Mammal Lab., 7600 Sand Point Way NE, Seattle, WA 98115. 26 p.

Scordino, J., H. Kajimura, N. Baba, and A. Furuta.

1988. Fur seal entanglement studies in 1984, St. Paul Island, Alaska. In Fur seal investigations, 1985 (P. Kozloff and H. Kajimura, eds.). p. 70-78. NOAA Tech. Memo., NMFS F/NWC-146.

Scolt, G.

1972. Plastics packaging and coastal pollution. Int. Journal of Env. Studies 3:35-36.

1975. The growth of plastic packaging litter. Int. Journal of Env. Studies 7:131-132.

Seber, G. A. F.

1982. The estimation of animal abundance and related parameters. Charles Griffin and Company Lid., London, 654 p.

Shaughnessy, P. D.

1980. Entanglement of Cape fur seals with man made objects. Mar. Pollut. Bull. 11:332-336.

Shaw, D. G.

1977. Pelagic tar and plastic in the Gulf of Alaska and Bering Sea 1975. Sci. Total Environ. 8:13-20.

Shaw, D. G., and G. A. Mapes.

1979. Surface circulation and the distribution of pelagic tar and plastic. Mar. Pollut. Bull. 10:160-162.

Shaw, W.

1990. Summary of marine debris sightings during Canadian high seas research surveys, 1989-1990. Document presented at the Annual Meeting of the International North Pacific Fisheries Commission, Vancouver, British Columbia, Canada, November 1990. Department of Fisheries and Oceans, Biological Sciences Branch, Pacific Biological Station, Nanaimo, B.C., Canada V9R 5K6.

Shiber, J. G.

1979. Plastic pellets on the coast of Lebanon. Mar. Pollut. Bull. 10:28-30.

1982. Plastic pellets on Spain's 'Costa del Sol' beaches. Mar. Pollut. Bull. 13:409-412.

Shomura, R. S., and H. O. Yoshida, eds.

1985. Proceedings of the workshop on the fate and impact of marine debris; 27-19 March 1984, Honolulu, HI. NOAA Tech. Memo, NMFS NOAA-YM-NMFS-SWFC-54.

Sileo, L. (chair).

1990. Report of the working group on ingestion. In Proceedings of the second international conference on marine debris, 2-7 April 1989, Honolulu, HI (R. S. Shomura and M. L. Godfrey, eds.), p. 1226-1234. NOAA Tech. Memo. NMFS, NOAA-TM-NMFS-SWFSC-154.

Sileo, L., P. R. Sievert, M. D. Samuel, and S. I. Fefer.

1990. Prevalence and characteristics of plastic ingested by Hawaiian seabirds. In Proceedings of the second international conference on marine debris, 2-7 April 1989, Honolulu, HI (R. S. Shomura and M. L. Godfrey, eds.), p. 665681. NOAA Tech. Memo. NMFS, NOAA-TM-NMFSSWFSC-154. 
Slip, D. J., and H. R. Burton.

1990. The composition and origin of marine debris stranded on the shores of subantarctic Macquarie Island. In Proceedings of the Second International Conference on Marine Debris, 2-7 April 1989, Honolulu, HI (R. S. Shomura and M. L. Godfrey, eds.), p. 403-416. NOAA Tech. Memo. NMFS, NOAA-TM-NMFS-SWFSC-154.

Slip, D. J., K. Green, and E. J. Woehler.

1990. Ingestion of anthropogenic articles by seabirds at Macquarie Island. Marine Ornithology 18:74-77.

Sokal, R. R., and F. J. Rohlf.

1981. Biometry, 2nd edition. W. H. Freeman and Co., San Francisco.

Stewart, B. S., and P. K. Yochem

1985. Entanglement of pinnipeds in net and line fragments and other debris in the Southern California Bight. In Proceedings of the workshop on the fate and impact of marine debris, 27-29 November 1984, Honolulu, HI (R. S. Shomura and H. O. Yoshida, eds.), p. 315-325. NOAA Tech. Memo. NMFS, NOAA-TM-NMFS-SWFC-54.

1987. Entanglement of pinnipeds in synthetic debris and fishing net and fishing line fragments at San Nicolas and San Miguel Islands, California, 1978-1986. Mar. Pollut. Bull. 18(6B):336-339.

1990. Pinniped entanglement in synthetic materials in the Southern California Bight. In Proceedings of the second international conference on marine debris; 2-7 April 1989, Honolulu, HI (R. S. Shomura and M. L. Godfrey, eds.), p. 792-809. NOAA Tech. Memo. NMFS, NOAA-TM-NMFSSWFSC-154

Takehama, $\mathrm{S}$.

1990. Estimation of damages to fishing vessels caused by marine debris, based on insurance statistics. In Proceedings of the second international conference on marine debris; 2-7 April 1989, Honolulu, HI (R. S. Shomura and M. L. Godfrey, eds.), p. 792-809. NOAA Tech. Memo. NMFS, NOAA-TM-NMFS-SWFSC-154.

Trulli, W. R., H. K. Trulli, and D. P. Redford.

1990. Characterization of marine debris in selected harbors of the United States. In Proceedings of the second international conference on marine debris; 2-7 April 1989, Honolulu, HI (R. S. Shomura and M. L. Godfrey, eds.), p. 304324. NOAA Tech. Memo. NMFS, NOAA-TM-NMFSSWFSC-154.

U.S. EPA (U.S. Environmental Protection Agency).

1987. Standard operating procedures for the collection and at-sea processing of neuston samples. SOP No. 4-35, Revision No. 01, U.S. EPA Office of Marine and Estuarine Protection, Incineration-at-Sea Program.

1990a. Methods to manage and control plastic wastes, report to Congress. Office of Solid Waste/Office of Marine and Estuarine Protection, EPA/530-SW-89-051. Washington, D.C.

1990b. Final data report for the study of floatables in U.S. waters (Harbor Studies Program) November 1988 through February 1989. Office of Marine and Estuarine Protection, EPA 503/490-003. Washington, D.C. 139 pp. + Appendices.

van Dolah, R. F., V. G. Burrell, Jr., and S. B. West.

1980. The distribution of pelagic tar and plastics in the South Atlantic Bight. Mar. Pollut. Bull. 11:352-356.

van Franeker, J. A.

1983. Plastics-een bedreiging voor zeevogels (with English summary). Nbr. NSO 4:41-61.
1985. Plastic ingestion in the North Atlantic fulmar. Mar. Pollut. Bull. 16:367-369.

van Franeker, J. A. and P. J. Bell.

1988. Plastic ingestion by petrels breeding in Antarctica. Mar. Poll. Bull, 19:672-674.

Vauk, G. J. M., and E. Schrey.

1987. Litter pollution from ships in the German Bight. Mar. Pollut. Bull. 18(6B):316-318

Venrick, E. L., T. W. Backman, W. C. Bartram, C. J. Platt, M. S. Thornhill, and R. E. Yates.

1973. Man-made objects on the surface of the North Pacific Ocean. Nature 241:271.

Verner, S. S.

1990. Handbook for preparing quality assurance project plans for environmental measurements. Technical Resources, Inc., Rockville, MD.

Wagner, K. D.

1990. Medical wastes and the beach washups of 1988: Issues and impacts. In Proceedings of the second international conference on marine debris; 2-7 Aprịl 1989, Honolulu, HI (R. S. Shomura and M. L. Godfrey, eds.), p. 81l824. NOAA Tech. Memo. NMFS, NOAA-TM-NMFSSWFSC-154.

Walker, W. A., and J. M. Coe.

1990. Survey of marine debris ingestion by odontocete cetaceans. In Proceedings of the second international conference on marine debris; 2-7 April 1989, Honolulu, HI (R. S. Shomura and M. L. Godfrey, eds.), p. 747774. NOAA Tech. Memo. NMFS, NOAA-TM-NMFSSWFSC- 154

Wallace, $\mathrm{N}$

1985. Debris entanglement in the marine environment: a review. In Proceedings of the workshop on the fate and impact of marine Debris; 27-29 November 1984 Honolulu, HI (R. S. Shomura and H. O. Yoshida, eds.), p. 259-277. NOAA Tech Memo. NOAA-TM-NMFS-SWFS54

Wehle, D. H. S., and F. C. Coleman.

1983. Plastics at sea. Nat. Hist. (Feb.) :20-26.

Wilber, R. J.

1987. Plastics in the north Atlantic. Oceanus 30:61-68.

Willoughby, N. G.

1986. Man-made litter on the shores of the Thousand Island Archipelago, Java. Mar. Pollut. BuIl. 17:224-228.

Wolfe, D. A.

1987. Persistent plastics and debris in the ocean: an international problem of ocean disposal. Mar. Pollut. Bull. $18(6 \mathrm{~B}): 303-305$

Wong, C. S., D. R. Green, and W. J. Cretney.

1974. Quantitative tar and plastic waste distributions in the Pacific Ocean. Nature 247:30-32.

Wong, C. S., D. MacDonald, and W. J. Cretney.

1976. Distribution of tar and other particulate pollutants along the Beaufort Sea coast. Beaufort Sea Project, Victoria, British Columbia, Canada. Beaufort Sea Technical Report No. 13.

Yagi, N., and M. Nomura.

1988. Sighting survey on marine debris in the mid-western Pacific from 1977 through 1986. In Proceedings of the North Pacific Rim fisherman's conference on marine debris; 13-16 October 1987, Kailua-Kona, HI (D. L. Alverson and J. A. June, eds.), p. 130-142. Natural Resources Consultants, Seattle, WA. 
Yoshida, K., and N. Baba.

1985a. A survey of drifting stray fishing net fragments in the northern Sea of Japan (Western Pacific Ocean). Document submitted to the 28th Meeting of the Standing Scientific Committee of the North Pacific Fur Seal Commission, Tokyo, 4-12 April 1985, 13 pp.

1985b. Results of a survey on drifting fishing gear or fish net pieces in the Bering Sea. Document submitted to the $28 \mathrm{th}$ Meeting of the Standing Scientific Committee of the North Pacific Fur Seal Commission, 4-12 April 1985, Tokyo, 13 pp. Yukinawa, M., and S. Mio.

1990. Preliminary report on the distribution of small-sized marine debris in Suruga Bay. In Proceedings of the second international conference on marine debris; 2-7 April 1989, Honolulu, HI (R. S. Shomura and M. L. Godfrey, eds.), p. 325-330. NOAA Tech. Memo. NMFS, NOAA-TM-NMFSSWFSC-154.

Zonfrillo, B

1985. Petrels eating contraceptives, polythene and plastic beads. Br. Birds 78:360-351.

Zsolnay, A

1987. Spatial and temporal variation of pelagic tar in the Mediterranean Sea. Chemosphere 16:399-404. 